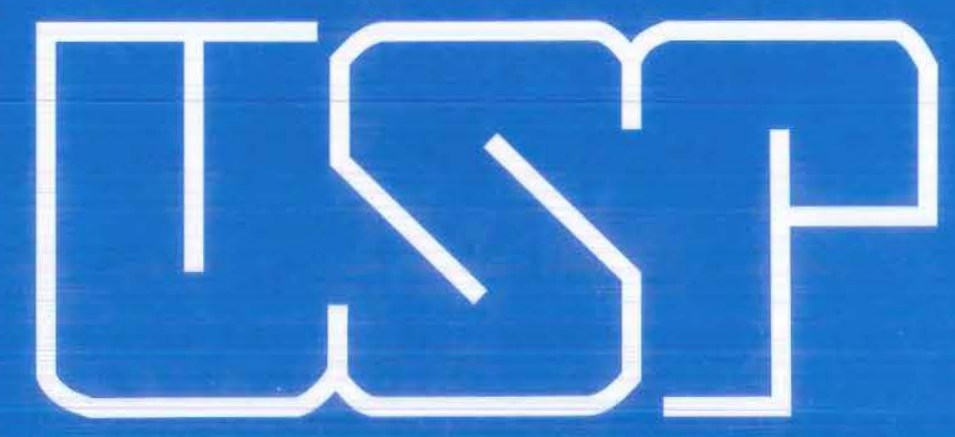

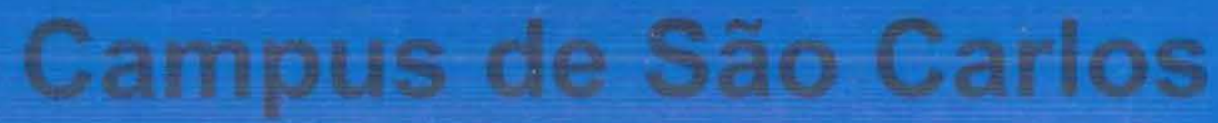

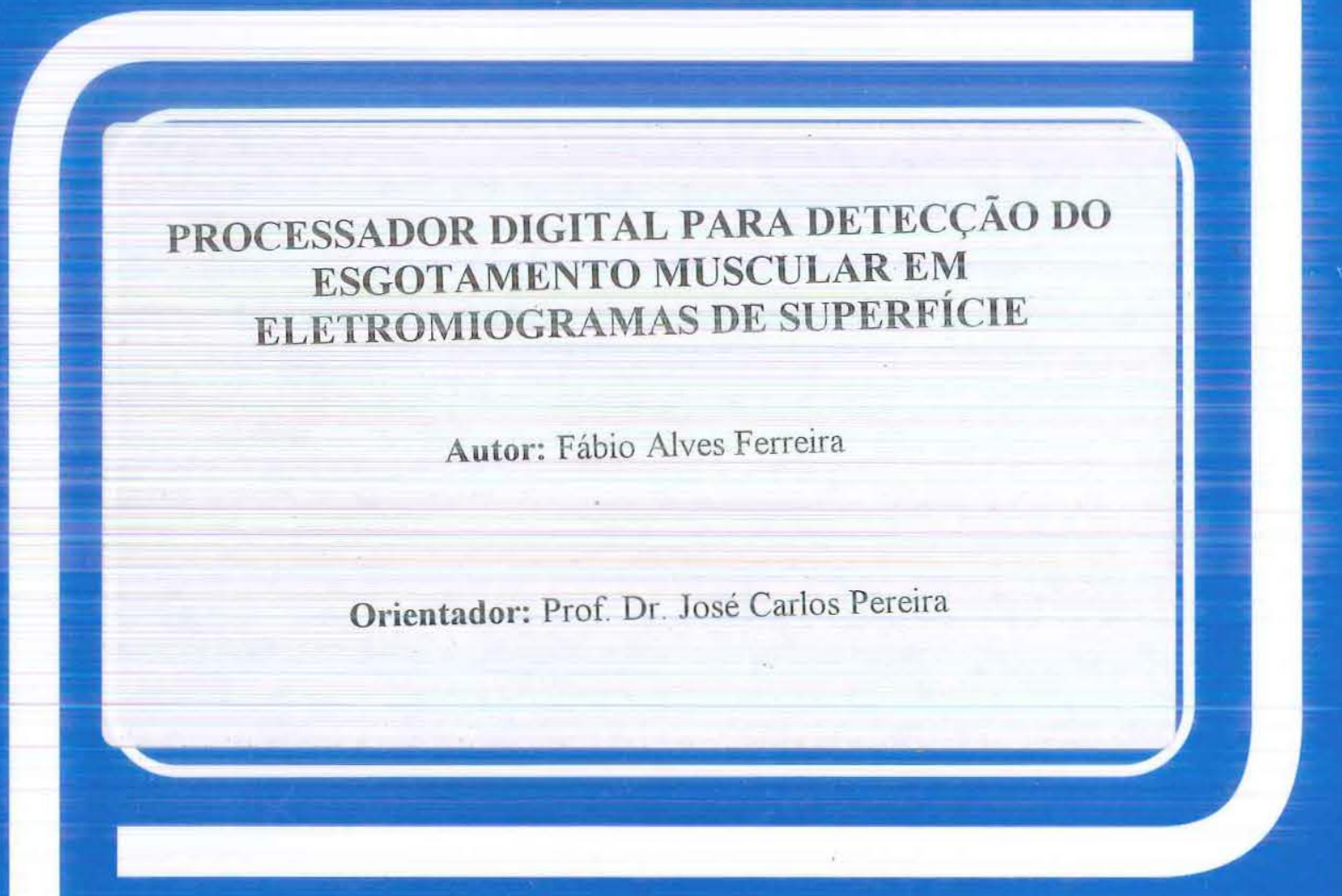

UNIVERSIDADE DE SÃO PAULO

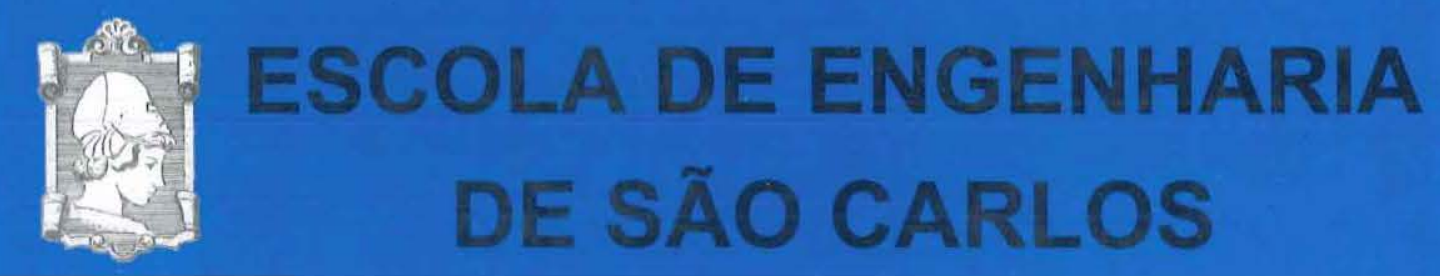




\section{PROCESSADOR DIGITAL PARA DETECÇÃO DO ESGOTAMENTO MUSCULAR EM ELETROMIOGRAMAS DE SUPERFÍCIE}

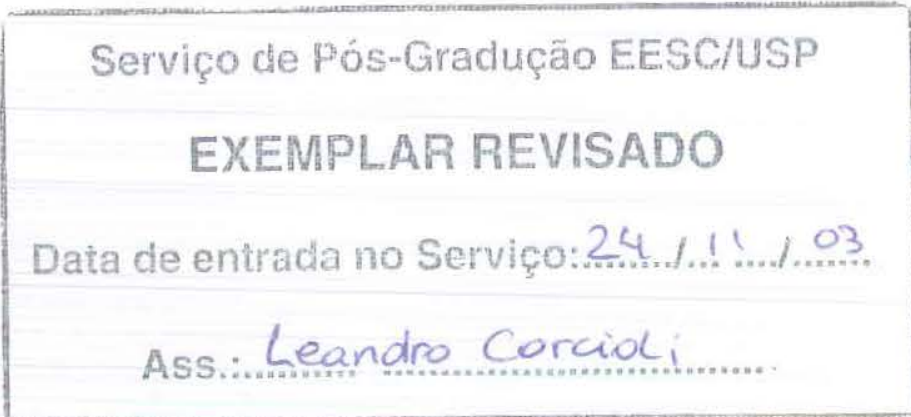

\section{Fábio Alves Ferreira}
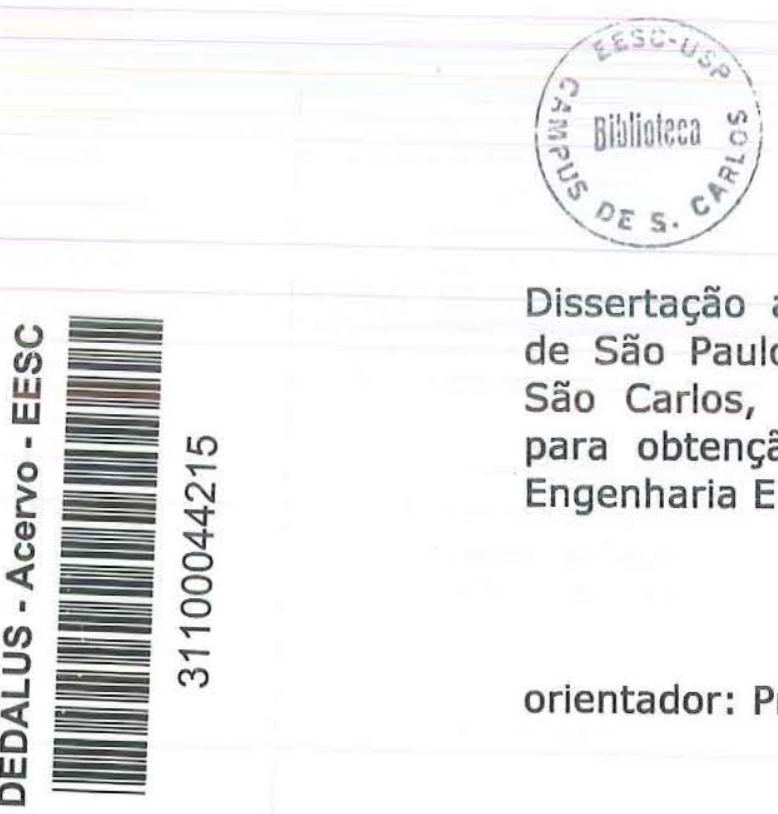

Dissertação apresentada à Universidade de São Paulo, Escola de Engenharia de São Carlos, como parte dos requisitos para obtenção do título de Mestre em Engenharia Elétrica

orientador: Prof. Dr. José Carlos Pereira 


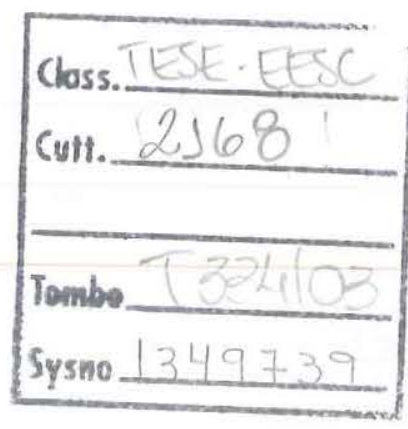

Ficha catalográfica preparada pela Seção de Tratamento da Informação do Serviço de Biblioteca - EESC/USP

1. VHDL. 2. Eletromiograma. 3. Fadiga muscular. 4. Esgotamento muscular. 5. Instrumentação. 6. EMG. I. Título. 
FOLHA DE JULGAMENTO

Candidato: Engenheiro FABIO ALVES FERRIEIRA

Dissertação defendida éjulgada em 17-09-2003 perante a Comissão Julgadora:

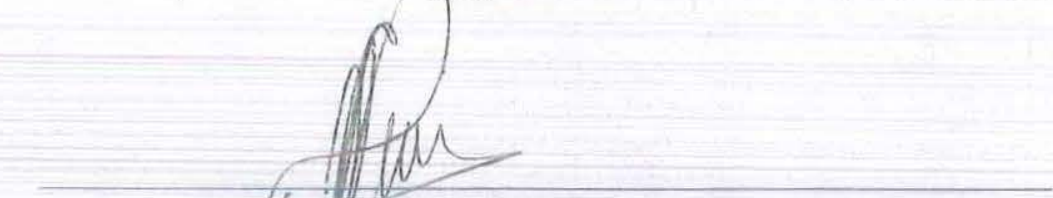

Prof. Tit. JOSÉ QAARLOS PEREIRA (Orientador)

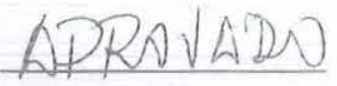

(Escola de Ergenparia de São Carlos/USP)

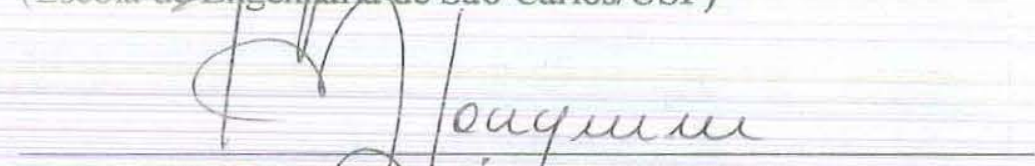

Prof. Dr. MARCELO BASÍLIO JOAQUIM

(Escola de Engenharia de São Carlos/USP)

\section{Aleibuatac}

Profa. Dra. APARECHA MARIA CATAI

(Universidade Federal de São Carlos/UFSCar)
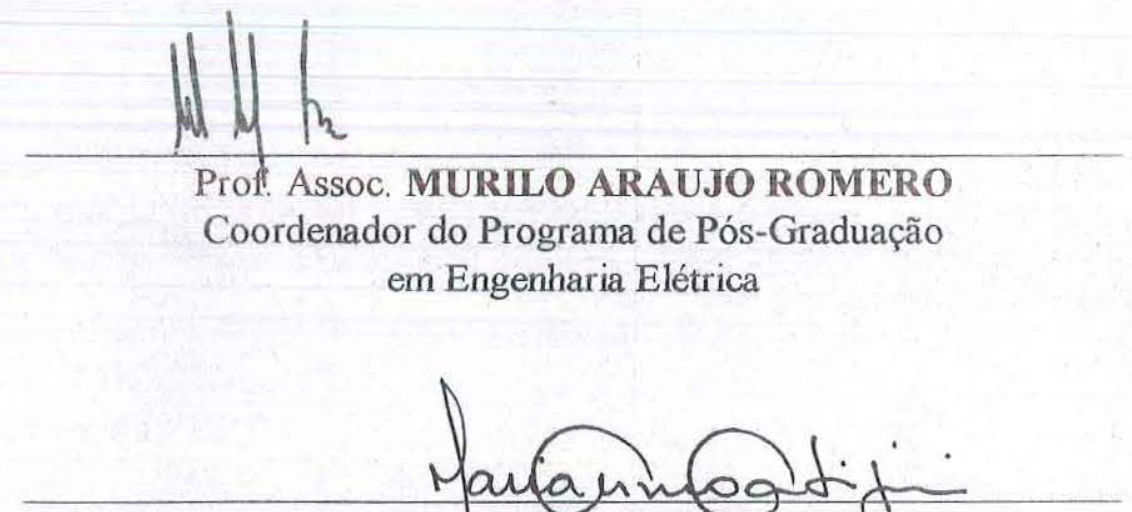

Profa. Assoc. MARIA Do CARMO CAIDURI

Presidente da Comissão de Pós-Graduação 


\section{AGRADECIMUENTOOS}

ao professor Dr. José Carlos Pereira (Departamento de Engenharia Elétrica, USP/EESC/SEL) pela orientação em Processamento Digital de Sinais e Microeletrônica, pela paciência e pelos exemplos de seriedade e conduta;

ao professor Dr. Alberto Cliquet Júnior (USP/EESC/SEL) pelas idéias e incentivos para o desenvolvimento de trabalhos em Bioengenharia junto ao Hospital das Clínicas da Universidade Estadual de Campinas;

ao professor Dr. Marcelo Basílio Joaquim (USP/EESC/SEL) pelas valiosas discussões sobre Processamento Digital de Sinais que contribuíram para um melhor entendimento dos resultados;

às professoras Dra. Ester da Silva e Dra. Aparecida Maria Catai (Departamento de Fisioterapia, Universidade Federal de São Carlos) pelas contribuições na obtenção de materiais utilizados na pesquisa e nas revisões desta dissertação.

ao professor Dr. Orivaldo Lopes da Silva (Departamento de Engenharia de Materiais, USP/EESC), pelos esclarecimentos sobre os termos e mecanismos relacionados físiologia, anatomia e dinâmica do corpo humano;

ao professor Dr. Roberto Merletti (Dipartimento di Elettronica, Politecnico di Torino, Italy) e Dra. Madeleine Lowery (Department of Electronic and Electrical Engineering, National University of Ireland, Dublin) pelas opiniões práticas nas etapas iniciais deste trabalho;

aos professores José Carlos Sartori e Paulo Roberto Veronese (USP/EESC/SEL), pelas sólidas contribuições em minha formação;

aos profissionais do SPS/BSTC (Semiconductor Products Sector, Brazil Semiconductor Technology Center), Motorola Industrial, pelo apoio no projeto e simulações do Bloco de Processamento Digital; 
aos amigos do Laboratório de Biocibernética e Engenharia de Reabilitação: François, Fransérgio, Juracy e Rodrigo, cujas participações viabilizaram a utilização de dados muito mais apurados;

aos amigos do Laboratório de Instrumentação e Microeletrônica: Marcelo, Mori e Yoghi, pelas valiosas discussões sobre teoria e prática da eletrônica e computação;

aos amigos Cristiano Benevento, Leonardo Mitsuyuki, Marcus Gil Gomes, Sílvio Nogueira e Ana Carolina, Márcia Onofre e Zilda Silveira pela presença nos melhores momentos;

aos meus grandes amigos Hélio Kikuchi, Rafael Vieira e Valdinei Belini que compartilharam longas noites sobre livros, pranchetas, simuladores e tantas outras aventuras;

aos meus irmãos Iane e Marcelo.

à Raquel.

Agradeço ainda ao $\mathrm{CNPq}$, Capes e Fapesp por viabilizarem as pesquisas de Iniciação Científica e Mestrado;

ao IEEE (Institute of Electric and Electronic Engineers) e SB $\mu$ (Sociedade Brasileira de Microeletrônica) pela disponibilização de informações do Estado da Arte em Microeletrônica, Processamento Digital de Sinais e Bioengenharia;

e a Motorola Industrial pelo treinamento em ferramentas EDA/CAD, técnicas e processos de Microeletrônica, e por permitir a utilização de sua infraestrutura computacional para o desenvolvimento desta pesquisa. 
Resumo

\section{Capítulo 1}

1.1. Introdução

\section{Capítulo 2}

2.1. Estimulação Elétrica Neuromuscular (EENM)

2.1.1. Eletrodo Estimulador de Superfície: Ponto de aplicação do estímulo 07

2.2. Esgotamento Muscular para Excitação Constante 07

2.2.1. Eletromiograma de Superfície (EMG - Surface Electromyogram) 08

2.2.2. Eletrodo de Eletromiografia Bipolar de Superfície: posicionamento 09

2.3. Índice de Esgotamento Muscular (IF) 11

2.3.1. Velocidade de Condução (CV - Conduction Velocity) 13

2.3.2. Valor Eficaz (RMS: Root Mean Square) 13

2.3.3. Valor Retificado Médio (ARV - Average Rectified Value) 14

2.3.4. Frequência Mediana do Espectro de Potências

(MDF - Median Frequency) 14

2.3.5. Frequência Média do Espectro de Potências

$\begin{array}{ll}\text { (MNF - Mean Frequency) } & 15 \\ \text { 2.3.6. Comparação entre índices } & 16\end{array}$

2.3.7. Intervalo de Cálculo dos ICMs: condição quasi-estacionária 16

\section{Capítulo 3}

3.1. Amostragem do EMG de músculo paralisado $\quad 19$

3.1.1. Aplicação do Estímulo 20

3.1.2. Frequência de Amostragem 21

3.1.3. Captura do Sinal de EMG 22

3.2. Resultados Parciais 23

3.2.1. Filtragem Linear 24

3.2.2. Índices RMS e ARV 27

3.2.3. Índices MDF e MNF 29

3.2.4. Comparação entre Índices de Fadiga 34

3.2.5. Escolha do ICM para o Sistema de Controle da EENM 35 


\section{Capítulo 4}

4.1. Sistema de Controle da Estimulação Elétrica Neuromuscular (EENM) 38

4.2. Descrição Geral do Sistema de Controle da EENM 40

4.3. O Bloco de Processamento Digital (BPD) 42

4.3.1. Sinais de Entrada $\quad 42$

4.3.2. Sinais de Saída 42

4.4. Processamento Digital do Sinal Eletromiográfico 44

\section{Capítulo 5}

5.1. Captura do Sinal de EMG (voluntário sem lesão medular) 48

5.2. Análise do EMG normal $\quad 50$

5.3. Os mbientesde Simulação

5.4. O Filtro Recursivo 54

5.4.1. Cálculo dos Coeficientes do Filtro IIR 55

5.4.2. Filtro Rejeita-Faixa $\quad 56$

5.4.3. Filtro Passa-Faixa 57

5.5. Tranformação de Domínio (FFT) 59

5.5.1. Comparação entre processamentos VHDL e Matlab para o FFT 60

5.6. Somador Cumulativo 62

5.6.1. Comparação entre processamentos VHDL e Matlab para o Somador
Cumulativo

5.7. Somador Retificador 63

5.8.Comparador Digital 63

5.9.Simulação Digital utilizando EMG de músculo paralisado 65

\section{Capítulo 6}

6.1. Conclusões

Referências Bibliográficas

\section{Anexos}

Anexo A: Scripts Matlab

Anexo B: Códigos VHDL

Anexo C Siglas e Símbolos 


\section{RESUMO}

Este trabalho visa desenvolver instrumentação de apoio para tratamentos de reabilitação de lesados medulares. Trata de propor um sistema de controle, seus componentes e operações para monitorar o avanço do esgotamento muscular, com o intuito de evitar a fatigamento total da estrutura muscular principalmente se sob efeitos de Estimulação Elétrica Neuro-Muscular (EENM).

Foi desenvolvida pesquisa inicial sobre a atividade elétrica de grupos musculares clinicamente normais $\mathrm{cm}$ contração voluntária e de grupos musculares paralisados sob efeito de eletro-estimulação. Em ambos casos, eletromiogramas de superfície (EMG) foram processados para verificar a manifestação mioelétrica da fadiga. Índices de Contração Muscular foram selecionados para utilização no Sistema de Controle da EENM.

Serão apresentados os cálculos e rotinas computacionais utilizadas no projeto e simulação do Bloco de Processamento Digital (BPD), dedicado a monitorar os sinais do Sistema de Controle da EENM para avaliar o progresso do esgotamento muscular sobre os sinais de EMG, e quantificar o decréscimo da energia muscular em função do tempo em que a estrutura estiver sendo exercitada, contribuindo para monitorar a performance física tanto de indivíduos normais quanto de lesados medulares. 


\section{ABSTRACT}

This work aims to develop support instrumentation to be used on Rehabilitation Treatments of medullar injured individuals. It proposes a control system, its components and operations to monitor muscular exhaustion, with the objective to avoid the total muscle structure fatigue mainly under effects of Neural-Muscular Electrical Stimulation (EENM).

It was carried out an initial research into the electric activity of clinically normal muscle groups under voluntary contraction and of paralyzed muscles groups under clectrical stimulation effects. In both cases, the surface electromyogram signals (EMG) have been processed to verify the myoelectric manifestation of fatigue. Muscular Contraction Indexes were selected to be used in the EENM Control System.

It will be presented the calculus and computational routines used in the design and simulation of the Digital Processing Block (BPD), dedicated to monitor the signals of the EENM Control System to evaluate the progress of the muscular exhaustion in EMG signals, and quantify the muscular energy decrease as a function of the time when the structure is exercised, contributing to monitor the physical performance of normal and medullar injured individuals. 


\section{CAPÍtULO 1}

\subsection{Introdução}

Um dos campos de pesquisa que mais vem se destacando nas últimas décadas relaciona duas áreas do conhecimento científico: a Engenharia e a Medicina. Grupos de pesquisadores de ambas áreas vêm trabalhando em conjunto para desenvolver dispositivos que auxiliem na identificação de problemas do sistema neuro-motor humano. Alguns destes dispositivos estão relacionados com a identificação de doenças (prevenção ou prédiagnóstico), e outros com o tratamento de reabilitação.

Diversos núcleos de pesquisa desenvolvem estudos sobre o sistema neuromuscular com o intuito de obter seu modelo mais preciso. Os testes são feitos desde as menores unidades motoras em animais, até a mais complexa rede de músculos humanos.

Um sistema neuromuscular sadio é capaz de avaliar a quantidade de energia metabólica para gerar movimento de forma finamente controlada. Esse controle só é possível devido à habilidade do cérebro de requisitar unidades motoras sob distribuição espaço-temporal multiplexada. Entenda-se por unidade motora o menor conjunto de fibras musculares, capaz de contrair ou distender-se segundo estímulos neuro-motores.

A informação advinda das várias regiões do cérebro, que atuam como processadores paralelos, é multiplexada para que possa ser propagada em um único canal: a medula espinhal. Essa informação, composta por um conjunto de impulsos elétricos, ao atingir a região onde deverá atuar, inicia a distribuição de acionamentos para as unidades motoras. 
$\mathrm{O}$ acionamento de uma unidade motora é feito segundo uma taxa (firing rate) que varia de acordo com o valor da força que se deseja gerar em um grupo muscular. Um trem de impulsos de acionamento pode ter seu período diminuído para gerar maiores níveis de força média. Esse sinal é aplicado de diferentes formas para as demais unidades motoras do conjunto. Quanto maior a força que se deseja, maior será a freqüência de acionamento e maior será a quantidade de unidades motoras requisitadas. Com isso teremos uma requisição de acionamento espaço-temporal, que irá contribuir para que se atinja os mais altos níveis de força média por períodos relativamente longos.

Quando se perde a capacidade de utilizar o processamento do cérebro para acionar grupos musculares, devido a traumas na medula espinhal, pode-se utilizar estímulos elétricos aplicados por dispositivos eletrônicos. Essa técnica, aplicada com o intuito de reabilitar os movimentos dos membros paralisados, vem trazendo significativa melhora à qualidade de vida de lesados medulares, por contribuir com a reeducação muscular, prevenção contra osteoporose e atrofia, redução temporária de espasticidade, contraturas e edemas, aumento da circulação sanguínea, força e resistência muscular, melhoria da capacidade cardio-pulmonar, e muitos outros aspectos clínicos ([Sel85]).

Tais dispositivos, que utilizam técnicas de Estimulação Elétrica Neuromuscular (EENM), permitem acionar os músculos superficiais responsáveis pelo movimento. Vários trabalhos relacionados a eletro-estimulação, utilizam eletrodos implantados, que vão desde aplicação por micro-agulhas até implantes cirúrgicos permanentes. Essa técnica pode trazer complicações para a estrutura muscular pois está submetida a níveis de rejeição ao material que compõe o eletrodo. Estimuladores superficiais não estão sujeitos a rejeição como no caso anterior.

Em qualquer que seja o método de aplicação do estímulo elétrico (superficial ou implantado), teremos uma requisição muscular muito abrangente, o que vem a ser um problema pois não há como controlar até o momento, a distribuição espaço-temporal de acionamento das unidades motoras de forma tão fina quanto a que o cérebro realiza. Surge então o problema da fadiga muscular. 
Qualquer estrutura muscular está sujeita a fadiga quando submetida a grandes esforços dinâmicos ou estáticos. Acompanhando o tratamento de reabilitação de lesados medulares, observa-se que ao longo dos exercícios o grupo muscular deixa de responder a um determinado nível do estímulo elétrico. Normalmente o que se faz é aumentar a amplitude do estímulo elétrico para prolongar os períodos de exercício nas sessões de reabilitação. Podemos então especificar um termo para identificar a primeira ocorrência da fadiga muscular para uma excitação constante, ao qual nos referiremos como "Esgotamento Muscular".

A fadiga muscular acontece quando a musculatura não responde a nenhum nível de estímulo elétrico. Já o esgotamento muscular se refere a um nível constante de estimulação; a estrutura deixa de responder para aquele nível específico.

Um indivíduo clinicamente normal, cujo determinado grupo muscular é submetido a condições de máximo estresse, irá perceber o decaimento de sua energia muscular devido principalmente ao aumento de sensibilidade (dor). Já o lesado medular na maioria dos casos, não possui sensibilidade na região estimulada e portanto não percebe o decaimento da energia muscular durante os exercícios com eletro-estimulação. Sua musculatura pode deixar de responder ao estímulo elétrico, o que no caso de exercícios de locomoção bipedal, poderia levar o usuário à queda.

Baseado neste problema elaborou-se a linha de pesquisa abordada neste mestrado. A proposta é desenvolver estudos sobre os componentes envolvidos na mecânica deste esgotamento muscular para utilizá-los em um sistema mais amplo, capaz de monitorar os efeitos do sinal de estímulo sobre o grupo de músculos. Será abordado justamente o problema da instrumentação necessária para estabelecer o monitoramento e controle da EENM para evitar que a estrutura entre em fadiga.

Muitos métodos têm sido empregados para controlar os sistemas de EENM, utilizando malha aberta [Chi92], [Cob94], [Yam90], [Pop99], ou malha fechada [Fra95], [Kha89-1], [Kha89-2], [Pop99]. Os modelos utilizados, geralmente não são precisos pois limitam o número de graus de liberdade (segmentos do corpo tratados como corpos rígidos, juntas como simples dobradiças, etc) [Win90]. No entanto, esta aproximação se faz necessária para atingir um objetivo primordial: produzir movimento. 
Dessa forma, este trabalho de Mestrado em Engenharia Elétrica está basicamente dividido em duas atividades de pesquisa:

Proposta de um sistema para controlar a estimulação elétrica de músculos paralisados de modo a evitar o fatigamento máximo da estrutura muscular, contribuindo para desenvolver instrumentação de apoio no tratamento de traumas fisiológicos, ou para monitoramento de performance física.

Projeto e Simulações de um Bloco de Processamento Digital (BPD), baseado em descrição de hardware (VHDL), ferramentas EDA/CAD Mentor Graphics $\AA^{\circledR}$, dedicado ao processamento de sinais oriundos de sensores de eletromiograma de superfície, para ser aplicado no Sistema de Controle da EENM.

O Processador Digital BPD servirá para monitorar o avanço do esgotamento muscular em eletromiogramas de superfície extraído de músculos sob efeitos de eletroestimulação. Veremos ainda que o BPD também poderá ser utilizado para monitorar a performance física de indivíduos clinicamente normais, uma vez que o processamento matemático sobre o sinal de EMG pode ser aplicado igualmente em ambos casos. 


\section{CAPÍTULO 2}

$\mathrm{O}$ indivíduo que perde a capacidade de acionar voluntariamente as unidades motoras dos músculos de seus membros pode fazer uso de dispositivos eletrônicos que transfiram o impulso elétrico ao grupo muscular que se quer acionar. Técnicas para aplicação de estímulos externos estão descritas em publicações de vários núcleos de pesquisa neuromuscular ([Sen97], [Owe89], [Mer88], [Eht98], [Hea00], [Kna88]).

Basicamente temos que um sinal elétrico impulsivo com freqüência e amplitude devidamente configuradas, pode induzir o músculo à contração por um período que depende das características físicas do indivíduo. Como já mencionado no capítulo anterior, o monitoramento desse período de contração com o intuito de acompanhar o decaimento da energia muscular, representa o foco do presente trabalho.

\subsection{Estimulação Elétrica Neuromuscular (EENM)}

O tratamento que vem sendo utilizado como uma forma eficaz para manter as capacidades físicas de lesados medulares, baseia-se na aplicação do sinal de estímulo elétrico, forma de onda da Figura 2.1, diretamente sobre a zona de inervação do músculo paralisado.

De acordo com vários artigos sobre estimulação elétrica, pode-se verificar diferentes valores para os parâmetros do sinal de estímulo. De uma forma geral, existem sugestões de que a freqüência do sinal de estímulo (f) deve estar entre 16 e $40 \mathrm{~Hz}$ e o período de aplicação $(\mathrm{t})$ entre 100 e $600 \mu$ s, podendo ser contínuo ou intermitente, como mostra a Figura 2.1. 


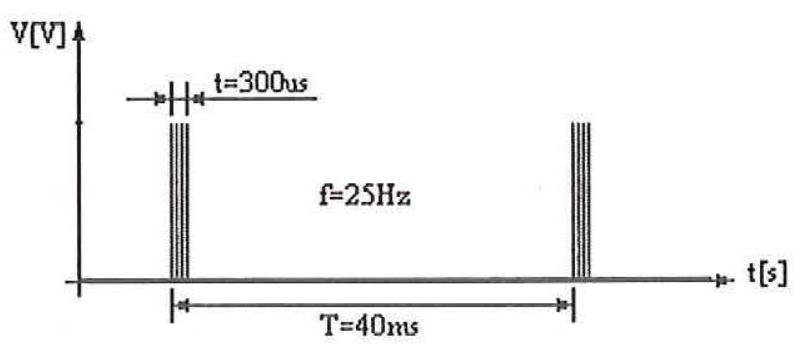

Figura 2.1: Forma de Onda do Estímulo Elétrico Intermitente

Estes parâmetros podem ser ajustados de acordo com o organismo do indivíduo. Normalmente o que se faz é utilizar um valor fixo para a freqüência do sinal e para o período de aplicação do estímulo, uma vez que estes pouco influenciam no resultado final da estimulação, e configurar a amplitude de pico do sinal de acordo com a sensibilidade da estrutura muscular. Esta amplitude, que em média tem valor igual à $200 \mathrm{~V}$ e vai determinar a força muscular obtida com o estímulo elétrico, deve ser ajustada mediante testes prévios com o usuário.

Apesar de a diferença de potencial a que o músculo fica submetido ser relativamente alta, amplitude na ordem de $200 \mathrm{~V}$, o período de aplicação é curto, o que implica um nível eficaz relativamente baixo. O resultado é o surgimento de uma corrente elétrica que conduz as unidade motoras superficiais do grupo muscular eletro-estimulado à total contração.

Muitos trabalhos analisam a forma de onda do sinal de estímulo superficial em função do efeito que pode causar nas musculaturas paralisadas em tratamento de reabilitação. Chen [Che97] discute os efeitos da aplicação de um sinal intermitente contra a aplicação de um sinal contínuo. Observando os seus gráficos experimentais de torque do músculo estimulado em função do tempo, temos que a estimulação contínua apresenta uma distribuição muito mais uniforme, com uma menor variabilidade mas com um decaimento mais acentuado em relação aos gráficos da estimulação intermitente.

Para implementar o Sistema de Controle da EENM, descrito no Capítulo 4, deveríamos dispor de um sinal de realimentação o mais estável possível, que seria melhor alcançado utilizando a estimulação contínua. No entanto, temos que o sinal intermitente 
prolonga o tempo de resposta do músculo, sendo portanto mais conveniente para a aplicação a que se destina este trabalho. Optou-se então por adotar o estímulo intermitente e acompanhar as variações do sinal de realimentação através de filtragem analógica e digital.

\subsubsection{Eletrodo Estimulador de Superfície: Ponto de aplicação do estímulo}

A aplicação do sinal de estimulação é feita diretamente sobre a epiderme do indivíduo, submetida à tricotomia e limpeza com álcool para reduzir o valor da impedância epiderme-eletrodo. Importante que também esteja seca para proteger contra eventuais queimaduras.

Normalmente as experiências de EENM são realizadas sobre a musculatura superficial de membros inferiores de voluntários paraplégicos, utilizando-se dois eletrodos separados por uma distância dependente da extensão do grupo muscular.

O eletrodo estimulador de superfície deve ser posicionado aproximadamente sobre o ponto de maior concentração do grupo de músculos: zona de inervação. Tais eletrodos variam de forma e tamanho. Os mais comuns são eletrodos circulares de $(\phi=3 \mathrm{~cm})$ e retangulares de $(8 \times 12 \mathrm{~cm})$. Daí a necessidade do acompanhamento de um profissional com formação especializada em anatomia, antropometria e fisiologia do corpo humano, para que se possa identificar o ponto ótimo de aplicação do sinal de estímulo.

Identificado o ponto de aplicação, podemos passar a avaliar o fenômeno do esgotamento muscular.

\subsection{Esgotamento Muscular para Excitação Constante}

No passado o esgotamento era observado através do ponto de falha da força muscular, ou seja, um instante no qual o indivíduo não pudesse sustentar uma força prédeterminada. É bem conhecido que o esgotamento é um fenômeno contínuo que surge desde o início da contração. Se ainda hoje esse conceito de falha da força fosse usado, ficaríamos restringidos a observar o esgotamento somente a partir do ponto de falha. Não seria possível estudar a evolução logo na primeira fase da contração. 
Recentemente foi proposto avaliar a manifestação mioelétrica do esgotamento muscular observando os aspectos mecânicos, elétricos e até eletromagnéticos. Os aspectos mecânicos só conseguem detectar o esgotamento no momento em que este se encontra muito avançado, sendo menos sensível para as manifestações desde o início e ao longo da contração.

Aspectos eletromagnéticos ainda precisam de investigações mais detalhadas, até que se possa determinar com segurança a correlação entre o sinal de EMG, obtido por exemplo com um sensor de efeito Hall (sensor que obtém uma amostra elétrica do campo eletromagnético resultante incidente), e a manifestação do esgotamento muscular, uma vez que o campo eletromagnético resultante na epiderme tem um valor muito baixo e com forte influência de ruídos externos.

Já do ponto de vista elétrico, temos que a manifestação do esgotamento pode ser melhor acompanhada ao longo do tempo, uma vez que o sinal elétrico advindo do músculo, após um processamento matemático específico, fornece informações muito mais precisas, altamente correlacionadas às manifestações do esgotamento muscular.

No princípio esta análise era feita baseada em sinais de eletrodos implantados, sujeitos à rejeição do organismo. Hoje, pode-se contar com novos materiais de contato, mais sensíveis, e equipamentos mais sofisticados, capazes de capturar o sinal eletromiográfico e conformá-lo para níveis convenientes de modo que se possa investigar as manifestações do esgotamento muscular de forma não-invasiva.

\subsubsection{Eletromiograma de Superfície (EMG)}

O monitoramento do esgotamento muscular para prevenção da fadiga é provavelmente a mais promissora aplicação clínica do EMG. Na década passada muitos trabalhos relataram métodos para avaliar as manifestações elétricas do esgotamento muscular durante contrações de força constante. Baseado nos Índices de Contração Muscular (ICM) que foram descobertos através de processamento digital de sinais de 
EMG, observamos que seria possível utilizá-lo como realimentação para o Sistema de Controle da EENM.

A Eletromiografia é a forma mais utilizada para amostrar o somatório de contribuições das unidades motoras. Relativamente simples de se obter (amostragem e armazenamento), mede o potencial gerado no volume condutor envolvendo as fibras de cada unidade motora, fornecendo informações relacionadas à anatomia e fisiologia dos grupos musculares: comprimento, profundidade, orientação das fibras musculares e largura das zonas de inervação [Mer99-2].

Durante uma contração voluntária os potenciais das unidades motoras são assíncronos enquanto numa contração eletricamente estimulada eles são sincronizados com os impulsos de estimulação, o que será de grande valor para avaliar o comportamento da fadiga ao longo do período de estimulação elétrica.

\subsubsection{Eletrodo de Eletromiografia Bipolar de Supenfície: posicionamento}

Um conjunto de junções neuromusculares é referido como zona de inervação. A maioria dos músculos possui 2 ou 3 zonas de inervação. Ponto motor é a posição sobre a epiderme que oferece o menor limiar (threshold) que separa a região de repouso da região ativa, não coincide necessariamente com a zona de inervação. Entenda-se por região de repouso, a região em que foi anotado o EMG para o músculo relaxado, e região ativa, para o músculo em contração voluntária ou eletro-estimulada.

O EMG monopolar realiza a medida dos componentes elétricos gerados nas zonas de inervação das fibras musculares com bastante precisão, mas não é utilizada com freqüência em configurações experimentais devido à dificuldade de eliminar as interferências da rede de alimentação $(60 \mathrm{~Hz})$. Já o EMG bipolar reduz este problema, apesar de ainda conter componentes residuais desta interferência da alimentação [Mer991].

É sabido que a forma de posicionar os eletrodos ao longo do comprimento da unidade motora tem efeitos consideráveis na morfologia do sinal mioelétrico e nas 
estimativas de suas variáveis. Algumas pesquisas mostram que próximo à zona de inervação de tendões, as estimativas dos Índices de Contração Muscular (ICM) adquirem baixa confiabilidade devido à presença de freqüências harmônicas de ordem superior. Para eletrodos posicionados entre as zonas de inervação e terminação da unidade motora, o sinal bipolar fica menos sensível aos efeitos de altas freqüências.

A distância entre os eletrodos influencia diretamente as estimativas de variáveis espectrais, pois pode alterar valores como o da Impedância Biológica que influi diretamente sobre a amplitude, polaridade e fase do sinal de EMG; quanto maior a distância, maior o volume de deteç̧ão e conseqüentemente maior a influência de componentes gerados nas inervações.

$\mathrm{O}$ alinhamento entre eletrodos também é outra fonte de erro muito freqüente devido à dificuldade de detectar a direção das fibras no músculo. O ângulo entre a linha que interliga os eletrodos e a linha de direção das fibras pode causar alterações na forma do sinal, resultando em estimativas que podem tornar o EMG insensível a parâmetros importantes.

Alguns trabalhos defendem o posicionamento dos eletrodos de EMG na direção paralela à linha das fibras musculares ([Mer99-1], [Pea00]), outros utilizam posicionamento perpendicular ([Sen97], [McG88]), ou ainda diagonal, [Low00]. O ponto motor do grupo muscular, definido como o local onde o EMG apresenta o menor threshold, pode servir para auxiliar no posicionamento dos eletrodos de realimentação. Nesse caso estamos tomando como modelo um indivíduo clinicamente normal, cujas posições de pontos motores podem servir de referência para localizar os pontos motores de lesados medulares.

Realizando teste em voluntários, pôde-se identificar em alguns casos a existência de mais de um ponto motor, dos quais foi escolhido o dominante, ou seja, o que aparentemente produzia o menor limiar de região ativa. Para este caso, o ponto motor dominante, encontra-se na direção perpendicular a linha de aplicação do estímulo, sobre a linha média. 
Por fim, o eletrodo de referência (terra), deve ser posicionado na epiderme de numa das extremidades da estrutura óssea que sustenta o grupo muscular. Esse terminal é necessário pois a captura sinal de EMG analógico baseia-se em técnicas diferenciais (amplificadores diferenciais). De preferência, o eletrodo de referência (Terra) do EMG deve ser posicionado próximo ao terminal negativo do estimulador elétrico, como mostra a Figura 2.2.

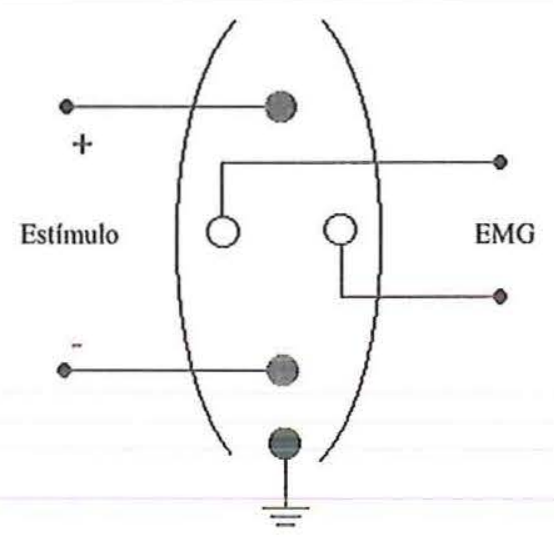

Figura 2.2: Exemplo de Posicionamento dos Eletrodos de Estimulação e de EMG

Em posse dos melhores pontos para posicionamento dos eletrodos de realimentação, podemos passar agora a identificar de que maneira pode-se extrair parâmetros do EMG de tal forma que se possa monitorar o progresso do esgotamento muscular desde o início da contração. Estes parâmetros serão utilizados posteriormente no Sistema de Controle da EENM (Capítulo 4).

\section{3. Índices de Contração Muscular (ICM)}

De uma forma geral, os Índices de Contração Muscular para exercícios estáticos de força constante se comportam como no gráfico da Figura 2.3. O decaimento do valor absoluto do ICM com o passar do tempo será tão mais precoce quanto maior for a freqüência da requisição à contração, tanto para contração voluntária quanto para a estimulada eletricamente. 


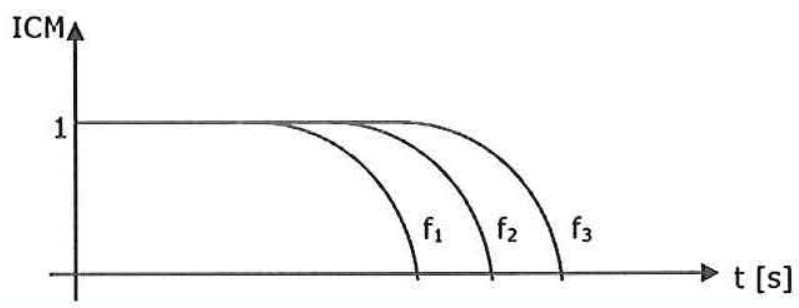

Figura 2.3: Ilustração de um ICM genérico em função do tempo

f1 > f2 > f3; onde fi é freqüência do estímulo elétrico

Quanto maior for a taxa de requisição à contração, ou seja, quanto maior a freqüência de estímulo elétrico, mais rapidamente o grupo muscular entrará em fadiga. Esse decréscimo dos valores dos ICMs pode ser avaliados de forma a identificar uma região crítica, dentro da qual o grupo muscular pode-se considerar fatigado.

Importante lembrar que em exercício de locomoção bipedal para paraplégicos, o esgotamento de músculos como o quadríceps, pode levar o paciente à queda e tornar o grupo muscular insensível aos estímulos por um longo período, prejudicando assim as sessões de reabilitação. O monitoramento do ICM em tempo real poderia a priori prevenir tais acidentes.

Podemos então analisar cinco dos ICMs mais comuns nos meios de pesquisa: velocidade de condução, valor eficaz, valor retificado médio, freqüência mediana e freqüência média do espectro de potências. 


\subsubsection{Velocidade de Condução (CV - Conduction Velocity)}

A Velocidade de Condução é um parâmetro fisiológico bem conhecido por estar relacionada ao tipo e diâmetro da fibra muscular, concentração iônica, potencial hidrogeniônico $(\mathrm{pH})$ e à taxa de acionamento (firing rate) da unidade motora [Far00]. Mede basicamente a velocidade que o sinal de EMG demanda para percorrer uma distância pré-estabelecida.

Essa medida é feita utilizando normalmente dois ou mais pares de eletrodos dispostos numa mesma direção separados por uma distância anotada. Técnicas de correlação cruzada no domínio da freqüência são normalmente utilizadas para determinar os índices de CV [Mer99-1].

O decaimento progressivo da CV na fibra muscular é um componente muito freqüentemente associado à manifestação mioelétrica do esgotamento muscular. Existem poucas pesquisas disponíveis sobre o cálculo da CV utilizando apenas um canal de aquisição, como a descrita por Spinelli et al [Spi98]. Porém, seu método baseia-se no cálculo de autocorrelação, o que dificultaria o processamento em tempo real.

\subsubsection{Valor Eficaz (RMS: Root Mean Square)}

O Valor Eficaz do EMG é um parâmetro muito utilizado para monitoramento do esgotamento muscular devido a sua simplicidade de cálculo via software. A Equação 2.1 apresenta a fórmula de cálculo do valor eficaz de um sinal $\mathrm{s}(\mathrm{t})$ no intervalo [0;T]s.

$$
R M S=\sqrt{\frac{1}{T} \int_{0}^{T} s(t)^{2} d t}
$$


Da Equação 2.1, após calcular o quadrado do sinal de entrada, pode-se partir para o cálculo da integral do sinal resultante (área abaixo da curva). O cálculo da raiz quadrada poderia representar um problema para desenvolver o hardware de monitoramento, devido à característica não-linear.

\subsubsection{Valor Retificado Médio (ARV - Average Rectified Value)}

Outra forma mais simples que a anterior de monitorar fadiga seria através do Valor Retificado Médio. Este índice eliminaria o problema de cálculo da raiz quadrada observado no caso do valor eficaz.

$$
A R V=\frac{1}{N} a b s(s(t))
$$

(Equação 2.2)

Por ser um índice muito mais simples, temos por conseqüência menos informação a respeito do comportamento do grupo muscular e do fenômeno da fadiga ao longo do tempo. Este índice ainda é muito popular por viabilizar circuitos integrados de pequena área e alta velocidade de processamento.

\subsubsection{Frequiência Mediana do Espectro de Potências (MDF - Median Frequency)}

A Freqüência Mediana do Espectro de Potências é um parâmetro que vem sendo largamente estudado nos meios de processamento do sinal de EMG. Trata-se de uma variável espectral e é definida como sendo a freqüência $f_{c}$ que divide o espectro de potências do sinal em duas áreas iguais. Pode ser representada pela equação 2.3.

$$
\int_{0}^{M D F} S(f) d f=\int_{M D F}^{\infty} S(f) d f
$$

É fato bem conhecido que o Espectro de Potências do sinal de EMG caminha em direção a freqüências mais baixas durante uma contração sustentada de força constante, bem antes de qualquer manifestação de fadiga ser evidente. Daí a grande quantidade de pesquisas sobre tal variável. 
Dessa forma, quando o sinal de EMG é gravado durante contrações voluntárias ou eletro-estimuladas, o que se observa ao longo do tempo é o fenômeno da Compressão Espectral. Essa compressão se deve principalmente a redução da velocidade de condução da fibra muscular, associado ao decremento progressivo do $\mathrm{pH}$ do fluido intersticial causado pela acumulação de catabólitos produzidos durante a contração [Stu81].

Erfanian [Erf96] mostra que a freqüência mediana tende a diminuir durante a eletro-estimulação, e novamente volta a aumentar durante um estado denominado de Máxima Fadiga. Este resultado tem significado fundamental na deteç̧ão da zona crítica de esgotamento muscular.

Podemos adotar a Freqüência Mediana como uma medida para monitorar a compressão espectral, e verificar de que maneira este parâmetro se relaciona com o avanço do esgotamento muscular.

\subsubsection{Freqüência Média do Espectro de Potências (MNF - Mean Frequency)}

A Freqüência Média do Espectro de Potências é definida como sendo a média ao longo do tempo da Freqüência Mediana. Representada pela Equação 2.4, a MNF representa uma medida menos suscetível a grandes variações.

$$
\operatorname{MNF}(n)=\frac{1}{n} \sum_{i=1}^{n} \operatorname{MDF}(i)
$$

Diferentemente do índice MDF, o MNF é um parâmetro que carrega componentes desde o início da contração, pois identifica a média de todos os pontos de MDF ao longo do tempo. A MDF não traz informação do sinal desde o início da contração pois é calculado em um curto intervalo (vide item 2.3.7) do sinal de EMG que está sendo monitorado. 


\subsubsection{Comparação entre Índices}

Merletti et al [Mer99-1] propôs uma comparação entre os diferentes índices de detecção da fadiga. De acordo com os seus resultados, temos que os três índices que mais se aproximam entre si são a Velocidade de Condução (CV), a freqüência Mediana (MDF) e a freqüência Média (MNF) do Espectro de Potências. O valor eficaz (RMS) e o retificado médio (ARV) também se mantêm próximos entre si, porém distantes do mais exato de todos, a Velocidade de Condução.

A Velocidade de Condução exige que se utilizem no mínimo dois pares de eletrodos - no mesmo trabalho, Merletti propõe um sistema tripolar - o que caracteriza uma desvantagem mecânica, além da já comentada dificuldade para determinação dos atrasos do sinal no cálculo de tal parâmetro (Correlação Cruzada).

No Capítulo 3 faremos uma comparação efetiva entre os ICMs aqui apresentados, com exceção da Velocidade de Condução, utilizando sinal de EMG amostrado a partir de um grupo muscular paralisado sob efeito de eletro-estimulação de um voluntário com lesão medular. No Capítulo 5, onde estaremos fazendo as simulações com o Bloco de Processamento Digital, utilizaremos o sinal de EMG de um voluntário clinicamente normal, além de realizar as simulações também para o sinal do voluntário com lesão medular.

\subsubsection{Intervalo de Cáiculo dos ICM: condição quasi-estacionária}

É comum utilizar intervalos de $1 \mathrm{~s}$ a 2 s do sinal de EMG para calcular o respectivo Índice de Contração Muscular, uma vez que este é o intervalo para o qual o sinal é considerado estacionário. Mais recentemente vários grupos de pesquisa vêm se utilizando do intervalo de $500 \mathrm{~ms}$, para o qual o sinal é considerado quasi-estacionário. Veremos no Capítulo 3, que o cálculo dos índices para intervalos próximos de $500 \mathrm{~ms}$ apresenta resultados muito convenientes para monitorar o decaimento da energia muscular ao longo do tempo de exercício. 
Considerando que o sinal de EMG analisado em janelas de 500ms durante uma contração isométrica de força constante seja um processo estocástico quasi-estacionário de banda limitada com média zero e distribuição gaussiana [Bas85], podemos adotar o referido intervalo como base de tempo para tomada de decisões.

O sistema de monitoramento do esgotamento muscular, proposto no Capítulo 4, deverá então ir armazenando em tempo real todos os pontos amostrados do sinal de EMG, e a cada intervalo de $500 \mathrm{~ms}$, realizar uma avaliação para identificar a energia muscular atual em relação à gerada no início do exercício. Passemos então ao estudo dos ICMs de um caso real. 


\section{CAPÍTULO 3}

Do ponto de vista cinesiológico, há muitas diferenças entre contrações musculares de movimentos estáticos e movimentos dinâmicos. Grande parte dos estudos sobre fadiga em músculos paralisados foram realizados principalmente sobre contração estática com estimulação elétrica contínua. Como ainda são poucos os dados disponíveis sobre a contração dinâmica, vamos utilizar neste trabalho o EMG amostrado de uma contração isométrica, estática de força constante.

A contração estática é a forma mais normalmente investigada devido a maior facilidade em organizar e controlar os experimentos. O objetivo é verificar o comportamento dos ICMs apresentados no Capítulo 2 de um EMG real, para que se possa identificar qual ou quais será mais convenientes para monitorar o progresso do esgotamento muscular e conseqüentemente prevenção da fadiga.

Neste Capítulo será apresentada a análise feita sobre o sinal de EMG capturado a partir de grupo muscular paralisado sob efeito de estimulação elétrica. O objetivo é identificar qual seria o ICM mais conveniente para implementar um sistema de controle para a EENM. No Capítulo 5, com o intuito de testar o BPD em ambos casos, o processamento será aplicado também sobre o sinal de EMG extraído de indivíduo clinicamente normal em contração voluntária. 


\subsection{Amostragem do EMG de músculo paralisado}

A amostragem do sinal de EMG foi realizada no Departamento de Ortopedia do Hospital das Clínicas de Campinas (Unicamp), sob monitoria de pesquisadores familiarizados com os métodos de eletro-estimulação.

O músculo que foi utilizado neste experimento é o quadríceps direito. Um voluntário do sexo masculino, 31 anos, $80 \mathrm{Kg}$, paraplégico desde 1988, lesão T11, baixa espasticidade, sem medicamentos, foi posicionado em uma cadeira de rodas travada, com o calcanhar direito tocando o chão. Nesta posição, o ângulo formado entre tíbia e fêmur é de aproximadamente $95^{\circ}$; veja modelo de segmentos articulados na Figura 3.1.

A temperatura ambiente de $28^{\circ} \mathrm{C}$ e a temperatura epidérmica de $36^{\circ} \mathrm{C}$ mantiveram-se constantes ao longo da amostragem do EMG. O voluntário foi requisitado a manter-se relaxado e não reagir voluntariamente ao sinal de estimulação.

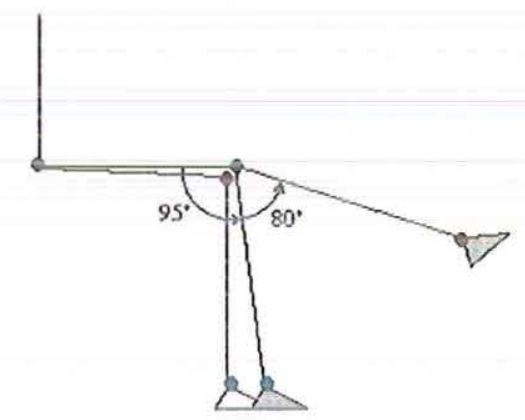

Figura 3.1: Modelo de Segmentos Articulados - posicionamento do membro inferior direito

O pico do sinal de estimulação foi ajustado mecanicamente. Com o músculo relaxado, a amplitude foi sendo incrementada até obter contração um ângulo de aproximadamente $175^{\circ}$ entre tíbia e fêmur.

Logo no início do experimento, com a estrutura músculo-esquelética nesta configuração $\left(175^{\circ}\right)$, pode-se anotar o valor de referência para os índices de fadiga. Os pontos 
seguintes, anotados ao longo do tempo, serão avaliados como valores percentuais desta referência inicial.

A amostragem do sinal de EMG foi feita até o ponto em que o músculo entrou na região de máximo esgotamento, ou seja, o grupo muscular tende a enfraquecer e o ângulo entre tíbia e fêmur tende a diminuir até que o calcâneo atinja posição considerada de mínima energia, $95^{\circ}$ iniciais, quando então o estímulo foi descontinuado.

\subsubsection{Aplicação do Estímulo}

O estimulador utilizado neste experimento foi desenvolvido pelos próprios pesquisadores neuromusculares do Hospital das Clínicas de Campinas (UNICAMP). Trata-se de um sistema eletrônico que gera uma tensão monopolar intermitente de amplitude constante, com freqüência de $25 \mathrm{~Hz}$ e período de estímulo igual a $300 \mu$ s, como apresentado na Figura 2.1. A faixa dinâmica (mínimo e máximo valor) do sinal de saída é de 0-220V. A amplitude do estímulo elétrico foi ajustada manualmente de acordo com a resposta muscular do voluntário.

A grande vantagem em se utilizar estimuladores de tensão constante reside no fato de a densidade de corrente ser constante (Equação 3.1). Uma eventual diminuição da área de contato, causada por deslocamento do eletrodo estimulador durante a sessão de eletroestimulação, implica uma diminuição da corrente de estímulo, o que vem a proteger o paciente contra eventuais lesões (queimaduras) causadas por elevada densidade de corrente.

$$
\partial_{I}=\frac{I}{A}=c t e
$$

Foram utilizados eletrodos estimuladores $3 \mathrm{M}$ de área retangular $(8 \times 12 \mathrm{~cm})$, que são equipados com um gel condutor aderente que contribui para reduzir a impedância de contato. 
Os eletrodos foram posicionados sobre a região próxima às zonas de inervação do músculo quadríceps, ficando separados por uma distância de $25 \mathrm{~cm}$.

A região da epiderme onde seriam posicionados os eletrodos de eletro-estimulação foi submetida à tricotomia e limpeza com álcool. Depois de averiguar se a região estava devidamente seca, os eletrodos foram fixados como mostra a Figura 2.2.

\subsubsection{Freqüência de Amostragem}

O EMG possui componentes espectrais significativos até a freqüência de $500 \mathrm{~Hz}$. Por isso a grande maioria das publicações adota a freqüência de $1 \mathrm{KHz}$ para a amostragem do sinal, evitando o aliasing no espectro de potências segundo teorema de Nyquist.

Assumindo margem 3 para a freqüência de Nyquist, obtemos uma freqüência de amostragem de $3 \mathrm{KHz}$. Em $40 \mathrm{~ms}$ de sinal (25Hz), teremos anotado:

$$
3000^{\text {pontos }} / \mathrm{s} \times 40 \mathrm{~ms}=120 \text { pontos }
$$

Arredondando para o próximo número que pode ser representado por uma potência de 2, o que vem a facilitar os cálculos de transformação de domínio [Opp87], vem:

$$
\frac{128 \text { pontos }}{40 \mathrm{~ms}}=3200^{\text {pontos }} / \mathrm{s}=3 \mathrm{~K} 2 \mathrm{~Hz}
$$

Logo o sistema que irá realizar a captura, descrito a seguir, foi ajustado para capturar o sinal de EMG a uma taxa de 3200 amostras por segundo (3.2KHz).

Observação: a freqüência de $3 \mathrm{~K} 2 \mathrm{~Hz}$ seria utilizada para gerar o pulso de estímulo internamente ao Bloco de Processamento Digital. No entanto, em estudos posteriores observou-se que a grande maioria dos equipamentos de eletromiografia utiliza a freqüência de 
amostragem de $1 \mathrm{KHz}$, sendo essa a freqüência mais recomendada. Dessa forma, nesse capítulo utilizaremos o EMG de músculo paralisado amostrado a uma taxa de $3.2 \mathrm{KHz}$. No Capítulo 5 utilizaremos o EMG de músculo normal amostrado a $1 \mathrm{KHz}$.

\subsubsection{Captura do Sinal de EMG}

Para realizar a captura do sinal de EMG, foi utilizado equipamento LINX ${ }^{\circledR}$. O condicionamento do sinal foi feito através de placa condicionadora MCS 1000, que possui ganho 50 para seus oito canais. A amostragem foi feita por uma interface de aquisição de dados CAD 1256, com precisão de 12 bits, que responde a freqüências na faixa de $0-5 \mathrm{KHz}$, para sinais bipolares dentro da faixa dinâmica $\pm 15 \mathrm{~V}$, a uma taxa da $3200 \mathrm{~Hz}$. Sua interface com computador permitiu visualização do sinal em tempo real.

Foram utilizados eletrodos ativos de superfície LINX ${ }^{\circledR}$, modelo PA602, que possuem amplificador diferencial integrado ao mesmo substrato. São formados por 2 barras de Prata e Cloreto de Prata $(\mathrm{Ag}-\mathrm{AgCl})$ de $1 \mathrm{~cm}$ por $1 \mathrm{~mm}$ dispostas paralelamente e distantes $1 \mathrm{~cm}$ entre si. Estes eletrodos ativos têm um ganho de 20 vezes. Somando-se a amplificação do eletrodo ativo com a da placa condicionadora, totaliza-se um ganho de 1000 vezes.

Os eletrodos ativos foram posicionados como descrito na Figura 2.2, separados por uma distância de $15 \mathrm{~cm}$, distância esta específica para o atual voluntário, pois é extremamente dependente da formação da estrutura ósteo-músculo-ligamentar. Daí a necessidade do acompanhamento de um especialista em fisiologia humana para a correta identificação do ponto motor dominante descrito no item 2.2.2. O terminal de Terra (eletrodo de referência), foi posicionado na extremidade distal do fêmur. Desta forma, pôde-se iniciar a amostragem dos sinais de contração do músculo quadríceps direito.

O sinal de EMG foi capturado completamente, incluindo os pulsos de estimulação. Veremos que se faz necessário um circuito para suprimir do EMG os pulsos de estímulo (Artefatos) e os efeitos imediatamente posteriores aos mesmos (Ondas M), descritos a partir 
do tem 3.2.1. Veremos ainda que essa supressão é necessária para aumentar a precisão do sistema, porém não é fundamental para o monitoramento dos ICMs.

\subsection{Resultados Parciais}

O EMG capturado foi armazenado em um arquivo do tipo texto composto basicamente por duas colunas: tempo e amplitude. Utilizando software Matlab 5.3.0.10183 (R11), pôde-se realizar o processamento para obtenção dos ICMs.

Os gráficos da Figura 3.2 apresentam o sinal bruto normalizado ao longo do período de estimulação. No início da estimulação, percebe-se por inspeção no gráfico 3.2.a, que a musculatura tende a responder com um nível crescente de energia, ou seja, a contração vai se tornando mais forte até atingir um nível de força constante, estabilizando para o resto do exercício. O final do exercício é determinado pelo ponto em que o calcâneo toca o chão, quando então a estimulação é desligada. Em 3.2.b pode-se notar o decaimento da resposta muscular mediante o mesmo estímulo inicial.

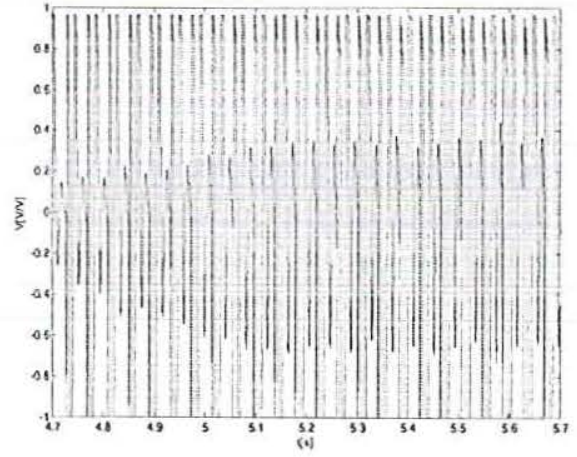

(a) início do exercício

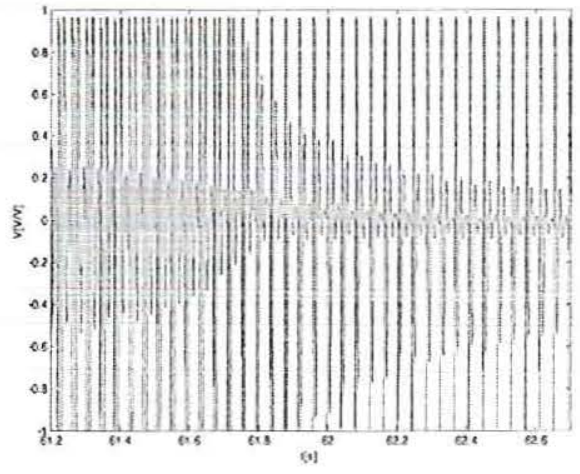

(b) fim do exercício

Figura 3.2: EMG Bruto de Músculo Paralisado sob efeito de Eletroestimulação

Pode-se então verificar qualitativamente a manifestação mioelétrica do esgotamento muscular no EMG. Resta agora determinar uma forma de quantificar esse esgotamento como uma função do tempo. 
Nos itens seguintes vamos tratar de calcular os ICM que serão extraídos do sinal de EMG bruto em intervalos de 500ms. Para calcular os parâmetros RMS, ARV, MDF e MNF, descritos nos itens de 2.3.2 a 2.3.5, precisaremos antes filtrar o sinal de EMG para remover as componentes de freqüência que interferem no resultado final, como será descrito no item 3.2.1. Para os índices MDF e MNF, por se tratarem de parâmetros espectrais, deveremos calcular a transformação do domínio do tempo para o domínio da freqüência através de Transformada de Fourier, como descrito nos itens 2.3.4, 2.3.5 e 3.2.3.

\subsubsection{Filtro Linear}

Picos de estimulação elétrica geram dois tipos de componentes no EMG que pouca interferem no processamento matemático para estimação dos ICM: os Artefatos e Ondas-M, ([Sen97], [Kna88]).

Os artefatos são os próprios pulsos de estímulo agora observados no EMG. No momento da estimulação, o sinal dos eletrodos estimuladores supera fortemente o sinal de resposta do músculo. Estes efeitos devem ser previstos e suprimidos no momento da amostragem. Um circuito CMOS de simples chaveamento poderia ser de grande utilidade contra os artefatos. No momento em que o estímulo estiver sendo aplicado, o sinal gerado pelos eletrodos de estimulação não deve ser lido pelos eletrodos de EMG. Com isso obteríamos uma maior precisão sobre os parâmetros de contração muscular extraídos do EMG.

A Onda-M, também conhecida por Potencial Eletricamente Evocado, é a resposta muscular imediatamente posterior à ativação simultânea de muitas unidades motoras pelo estímulo elétrico. $\mathrm{O}$ impulso elétrico faz uma requisição muito ampla de unidades motoras. $\mathrm{O}$ resultado é uma resposta abrupta que se prolonga por um intervalo de tempo que pode perdurar até o próximo impulso. É um elemento de baixa freqüência, normalmente abaixo de $25 \mathrm{~Hz}$, que interfere na exatidão dos ICMs. 
As Ondas-M poderiam ser eliminadas por filtros analógicos ou um certo processamento digital. Sennels et al [Sen97] propõe um processamento adaptativo para eliminação das ondas-M. Já Knaflitz e Merletti [Kna88] sugerem um tempo de chaveamento CMOS conveniente capaz de reduzir seus efeitos.

Como até o momento da amostragem do sinal de EMG que aqui será utilizado, não se dispunha de instrumentação que realizasse esse processamento de supressão de artefatos e ondas-M, então foram utilizados métodos clássicos de processamento digital para realizar uma filtragem linear no sinal de EMG bruto.

O filtro digital utilizado neste experimento foi projetado de modo a eliminar componentes espectrais inferiores a freqüência do sinal de estimulação (filtro passa-alta, Chebyshev Tipo 1 , com freqüência de corte igual a $25 \mathrm{~Hz}$ ) e superiores à máxima freqüência do EMG (filtro passa-baixa, Chebyshev Tipo 1, com freqüência de corte igual a $500 \mathrm{~Hz}$ ). Obtemos então as características de um filtro digital passa-faixa.

O sinal de EMG foi ainda submetido a um filtro rejeita-faixa para eliminar a interferência da rede elétrica $(60 \mathrm{~Hz})$. O diagrama de Bode da Figura 3.3 apresenta a resposta em freqüência dos filtros e a respectiva localização de pólos e zeros em relação ao círculo unitário. O modelamento matemático de ambos filtros IIR será detalhado no Capítulo 5. 

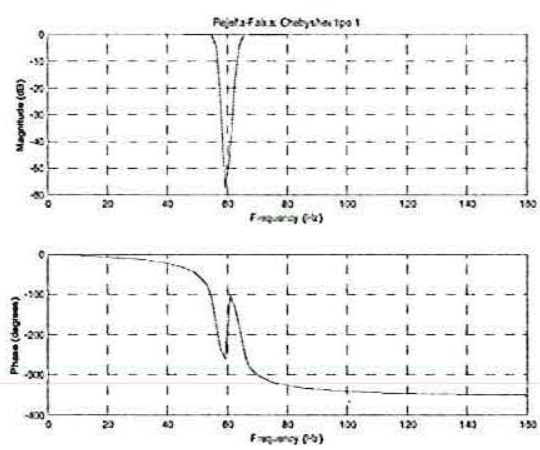

(a) Rejeita Faixa: Diagrama de Bode

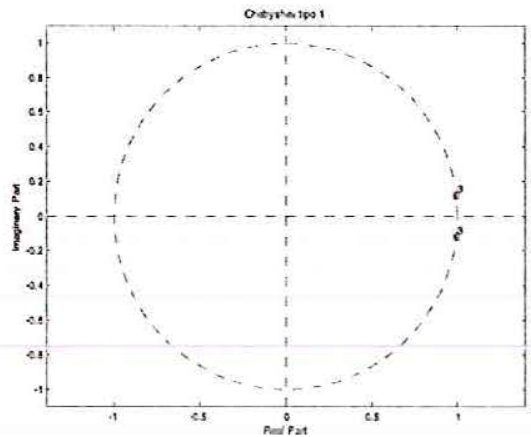

(b) Rejeita Faixa: Pólos e Zeros
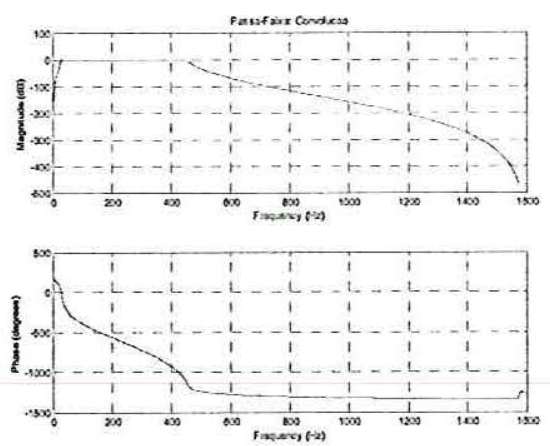

(c) Passa Faixa: Diagrama de Bode

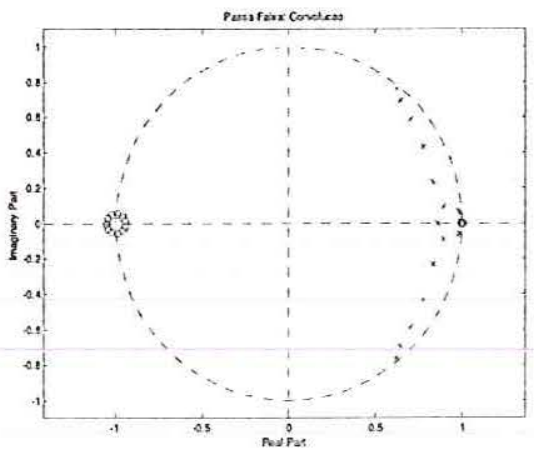

(d) Passa-Faixa: Pólos e Zeros

Figura 3.3: Resposta em Freqüência, Pólos e Zeros dos filtros utilizados neste processamento $\left(f_{0}=3 \mathrm{~K} 2 \mathrm{~Hz}\right)$

A Figura 3.3(a) apresenta do gráfico original do Matlab, apenas o trecho nas redondezas da frequência de rejeição $60 \mathrm{~Hz}$, uma vez que este se extende igualmente até a frequência de $1600 \mathrm{~Hz}$.

Pelo diagrama de Bode da Figura 3.3(a) e 3.3(b) temos que o filtro irá eliminar do sinal de EMG as componentes espectrais indesejadas conforme descrito no parágrafo anterior. A localização dos pólos dentro do círculo unitário é condição necessária e suficiente para garantir a estabilidade do filtro IIR.

Após submeter o sinal bruto de EMG aos filtros lineares passa-faixa e rejeita-faixa obtivemos um sinal com uma considerável redução das interferências dos Artefatos e das Ondas-M. 


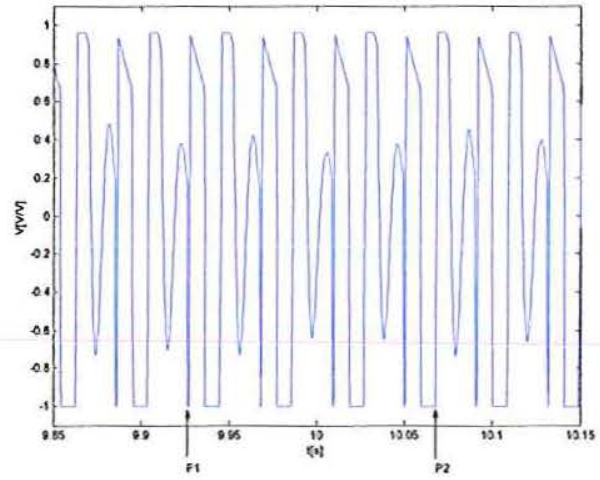

(a) $\odot$ EMG Bruto

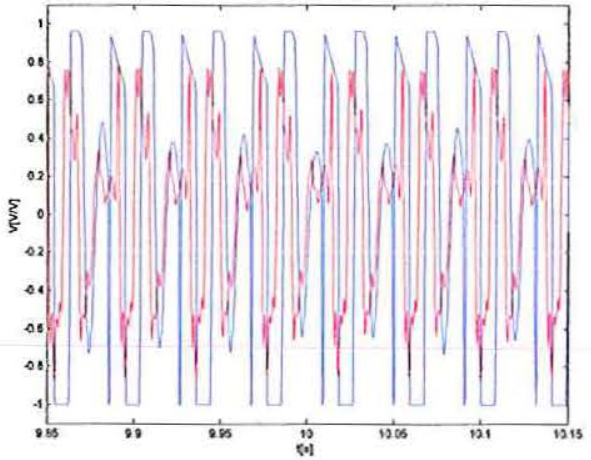

(b) EMG Filtrado

Figura 3.4: Comparação entre EMG antes e após o filtro linear P1; Artefato - pico do estímulo elétrico captado pelo sensor de EMG

P2: Onda-M - ampla resposta muscular imediatamente após o estímulo elétrico

Em posse do EMG filtrado, podemos partir para o processamento de estimação dos Índices de Contração Muscular.

\subsubsection{Indices RMS e ARV}

O tempo de duração do exercício foi de aproximadamente um minuto, desde o início da contração até o esgotamento total para amplitude de estímulo constante. Como estamos considerando que o sinal tenha característica quasi-estacionária para intervalos de $500 \mathrm{~ms}$, vamos adotar este intervalo como sendo o intervalo de cálculo dos parâmetros RMS e ARV.

Os gráficos da Figura 3.5 (a) e (b) foram obtidos através das Equações 2.1 e 2.2, respectivamente. O valor apresentado foi normalizado em relação ao valor no início da contração (referência). 


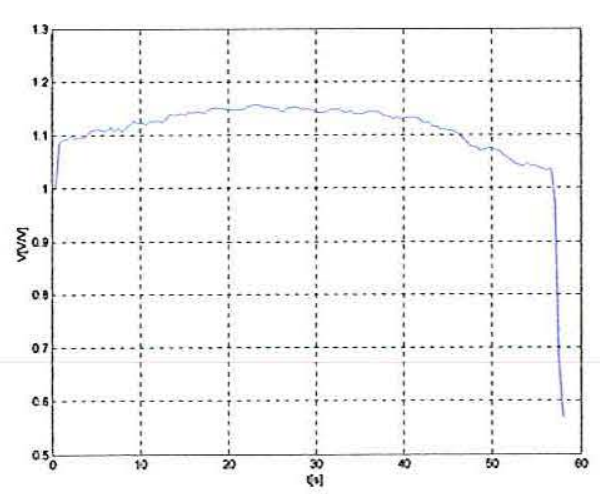

(a) indice RMS

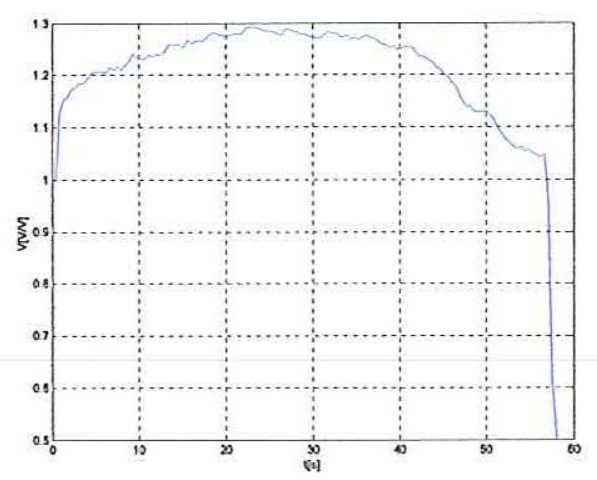

(b) índice ARV

Figura 3.5: Índices de Contração Muscular RMS e ARV

Ambos gráficos apresentam característica decrescente conforme o grupo muscular caminha para o estado de esgotamento máximo. Para o índice ARV a variação é da ordem de $15 \%$ entre o ponto de máximo e o ponto imediatamente anterior à descontinuidade próximo à marca de tempo $t=55 \mathrm{~s}$.

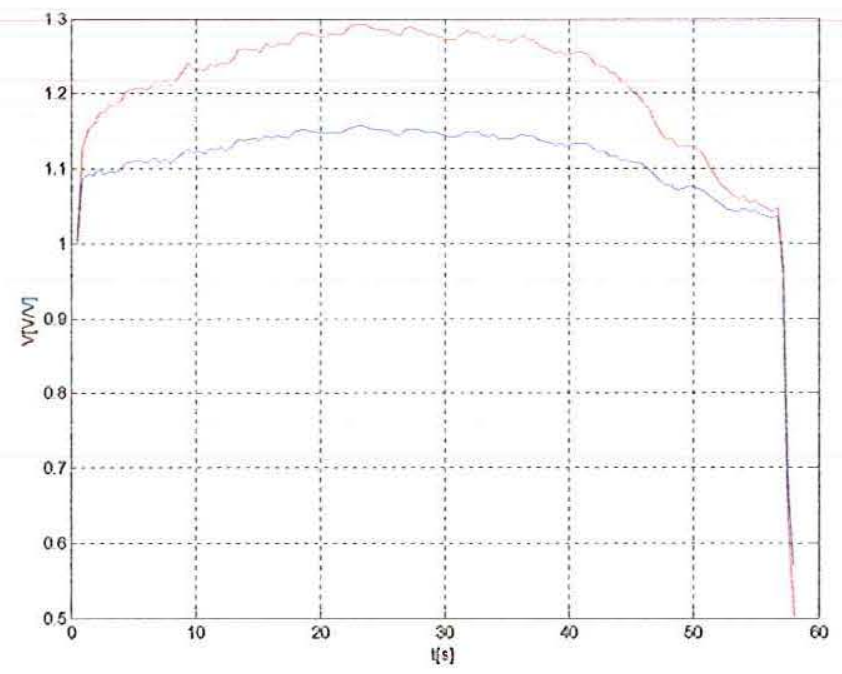

Figura 3.6: Comparação entre RMS e ARV

$$
\diamond: \text { ARV } \quad \text { : RMS }
$$


Por inspeção do gráfico da Figura 3.6, temos que o índice ARV apresenta uma variação mais acentuada que o RMS, o que vem a ser conveniente para realizar o monitoramento do decréscimo de energia muscular ao longo do tempo.

Uma primeira proposição seria desenvolver um sistema que informe o usuário através de um sinal binário os níveis de decréscimo de ARV em relação ao seu valor máximo. Por exemplo, a cada $1 \%$ de decréscimo de ARV em relação ao seu valor máximo, o sistema geraria um pulso para informar o usuário sobre o progresso de seu esgotamento muscular.

$\mathrm{O}$ ponto de descontinuidade $\mathrm{t}=55 \mathrm{~s}$ poderia servir para identificar uma Região Crítica de Esgotamento, onde o grupo muscular vai efetivamente deixar de responder ao estímulo e elétrico. No entanto, conforme observado durante a amostragem com o usuário lesado medular, este ponto de descontinuidade aconteceu quando o calcâneo tocou o solo, ou seja, em um momento muito posterior ao que se deseja para informar o usuário que o exercício deve ser descontinuado.

Logo, através dos índices ARV e RMS nada podemos afirmar sobre o máximo esgotamento da estrutura muscular. Apenas podemos monitorar o seu progresso, mas não há um limiar evidente onde possamos identificar o ponto tal que o exercício deva ser descontinuado.

\subsection{3. Índices MDF a MNF}

Merletti e Knaflitz [Mer89] verificaram que o janelamento retangular é aceitável e mesmo preferido para estimação da Freqüência Mediana, de trechos entre $250 \mathrm{~ms}$ e dois segundos. Como assumimos que vamos trabalhar com trechos de $500 \mathrm{~ms}$, onde o sinal assume característica quasi-estacionária, temos que a janela retangular é mais conveniente para o presente. 


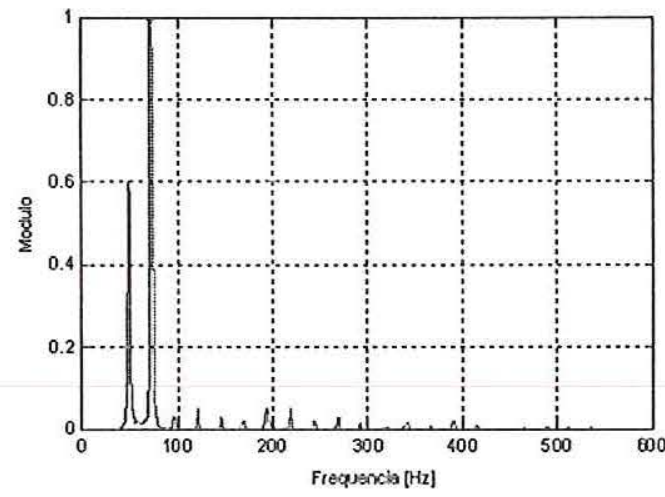

(a) Início do Exercício

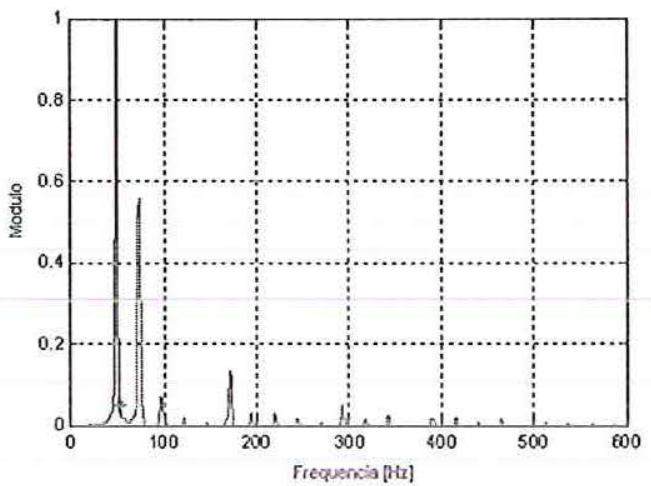

(c) Durante Exercício

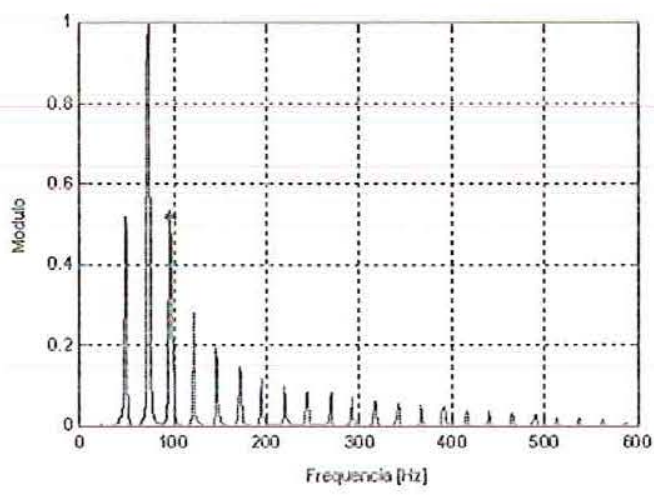

(a) Final do Exercício: Máximo Esgotamento

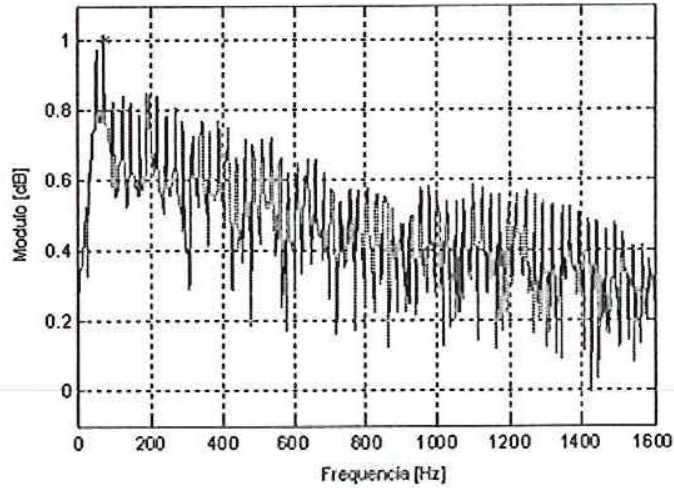

(b) Início do Exercício

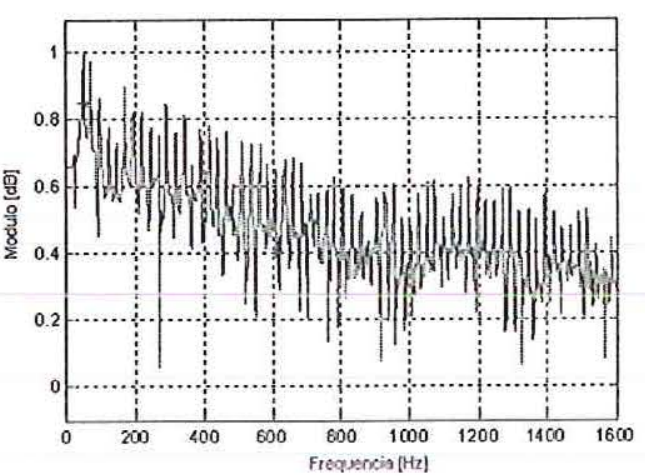

(b) Durante Exercício

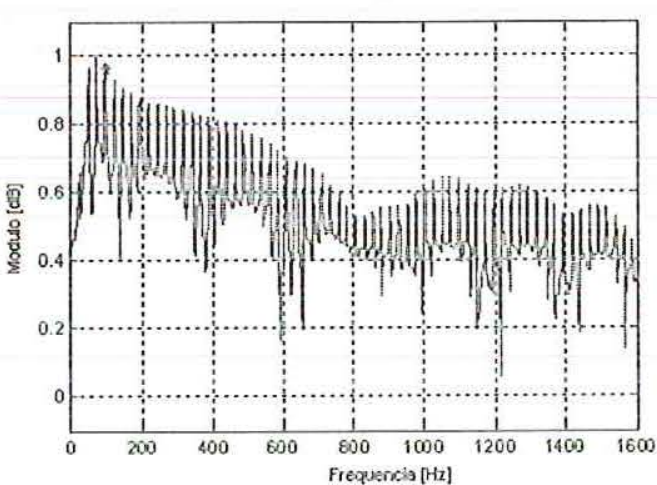

(f) Final do Exercício: Máximo Esgotamento

Figura 3.7: Espectro de Potências $(a, c, e)$ e Densidade Espectral de Potências $(b, d, f)$ para 3 momentos do exercício * : ponto que identifica a MDF do Espectro de Potências 
Baseado na Equação 2.3 e 2.4, temos que o cálculo da freqüência mediana e média envolve transformação do domínio do tempo para o domínio da freqüência. Foi então utilizada Transformada Rápida de Fourier para obter o espectro de potências (quadrado do módulo) e a densidade espectral de potências (valor em $\mathrm{dB}$ do espectro de potências). A Figura 3.7 mostra o espectro de potências de 3 trechos de 500ms do sinal de EMG: primeiro trecho anotado no início do exercício, segundo trecho anotado no meio e terceiro trecho no final do exercício.

Já é possível notar o efeito da compressão espectral comparando os Espectros de Potência da Figura 3.7 (a) e (c). Vamos quantificar essa compressão através dos índices MDF e MNF a seguir. Para obter tais índices devemos calcular a integral da curva do Espectro de Potências do trecho de 500ms do sinal de EMG.

Uma forma rápida de calcular o valor da integral do espectro de potências é através de soma cumulativa (área sob a curva).

$$
y(n)=\sum_{k=0}^{N-1} x(n-k) \quad n=0,1,2, \ldots, N-1
$$

Observação: o fator período de amostragem $\mathrm{t}_{\mathrm{a}}$ (inverso da frequência de amostragem) foi desconsiderado no cálculo da área sob a curva do Espectro de Potências pois não influencia no cálculo da Freqüência Mediana.

Na Equação 3.2, cada ponto $y(n)$ possui a soma de todos valores anteriores de $x(n)$. Assim $\mathrm{x}$ pode ser um vetor contendo o espectro de potência de um trecho de $500 \mathrm{~ms}$ do sinal de EMG, e y será o vetor contendo a respectiva soma cumulativa.

Dessa forma obtemos o valor da área abaixo da curva, numericamente igual à integral do espectro. Se o vetor y for normalizado, temos que a freqüência mediana pode ser calculada como sendo o ponto correspondente ao ponto 0.5 de y, ou seja, seu quinqüagésimo percentil. A Figura 3.8 apresenta o gráfico normalizado para a soma cumulativa dos espectros de potência para o início do exercício e para a região de máximo esgotamento. 


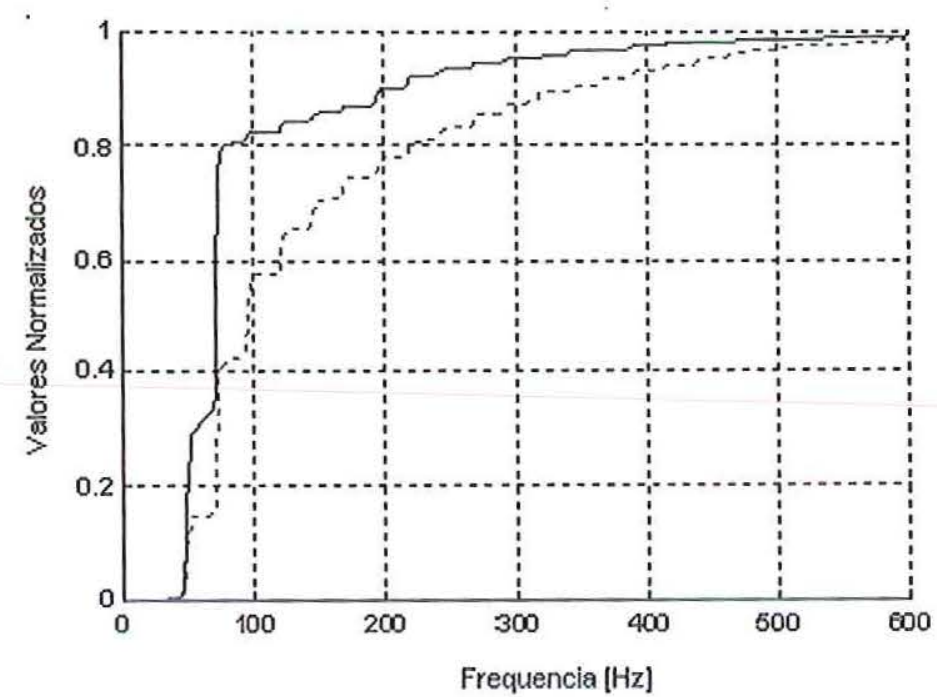

Figura 3.8: Comparação entre Somas Cumulativas no início e fim do exercício —. : Início do Exercício

Calculando a soma cumulativa do espectro de potências a cada trecho de $500 \mathrm{~ms}$ de EMG e em seguida a respectiva MDF, obtemos o gráfico da Figura 3.9 (a). Calculando a média de MDFs desde o início do exercício, obtemos o gráfico de MNF da Figura 3.9 (b). Como no item anterior, os gráficos foram normalizados em relação ao valor no início da contração.

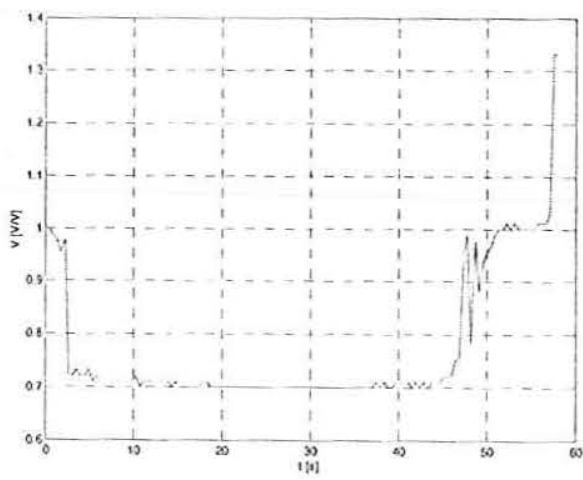

(a) MDF

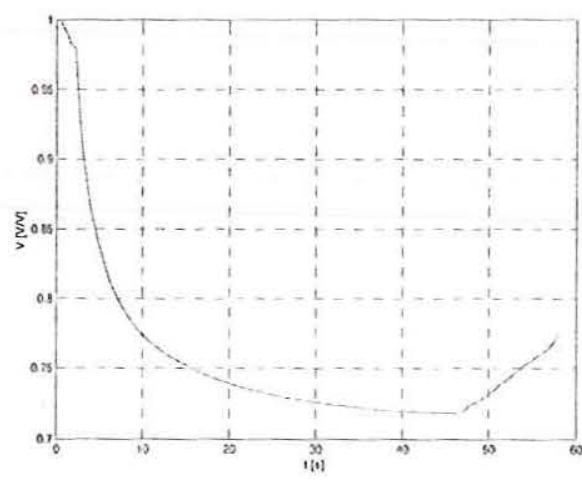

(b) MNF

Figura 3.9: Gráficos de MDF e MNF ao longo do exercício 
Comparando ambos índices (Figura 3.10), obtemos o resultado que vem sendo motivo de muitas publicações de pesquisadores neuro-musculares.

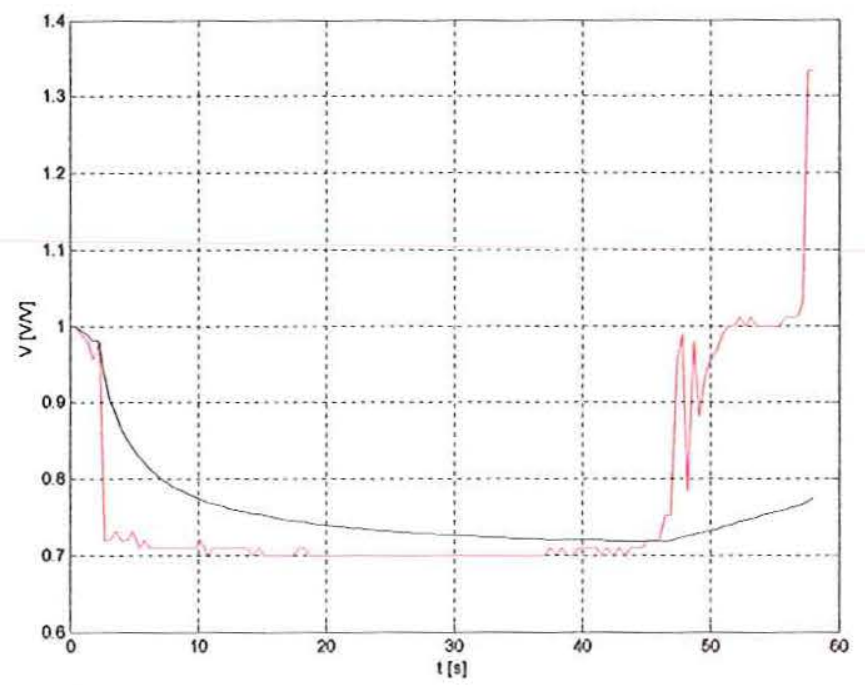

Figura 3.10: Comparação entre gráficos de MDF e MNF

Como já mencionado, variáveis espectrais como as freqüências mediana e média, são conhecidas por apresentar de forma mais evidente as manifestações de fadiga bem antes de qualquer outro índice. Especificamente para este caso de EMG de músculo paralisado, temos que ambos parâmetros espectrais MDF e MNF apresentam pontos de inflexão que delimitam mais precisamente o ponto de falha da força muscular.

Verifica-se aqui a proposição de Erfanian [Erf96] sobre o Máximo Esgotamento, onde a frequiência mediana decai com o progresso do esgotamento, e volta a aumentar quando se dirige ao ponto de Máximo Esgotamento. A freqüência Média acompanha essa premissa de forma menos sensível.

O resultado aqui apresentado tem grande utilidade para um sistema de monitoramento da fadiga muscular, pois a variação entre os níveis de MDF, por exemplo, anotada no início da contração até o ponto de Máximo Esgotamento, atinge ordens de $30 \%$. 


\subsubsection{Comparação entre Índices de Fadiga}

Inserindo todos os dados normalizados dos índices de fadiga num mesmo gráfico (Figura 3.11), obtemos uma comparação efetiva que colabora para definir qual será utilizado no Sistema de Controle da Estimulação Elétrica Neuro-Muscular.

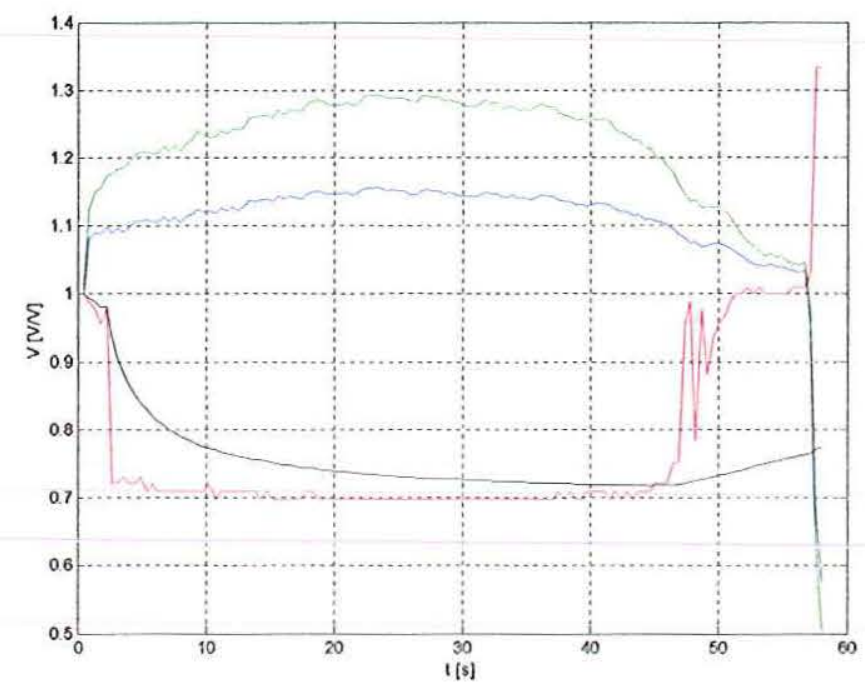

Figura 3.12: Comparação entre Índices de Contração Muscular

- : MNF (Mean Frequency)

$\checkmark:$ MDF (Median Frequency)

$\checkmark:$ RMS (Root Mean Square)

$\because:$ ARV (Average Rectified Value)

Este resultado é absolutamente compatível com os apresentados em várias publicações, que inclusive utilizam circuitos para supressão de Artefatos e Ondas-M, ([Mer99-1], [Mer99-2], [Kna88], [Sen97], [Erf96]).

Da Figura 3.11 podemos extrair que o índice MNF apresenta características mais apropriadas em relação aos demais ICMs para realizar o monitoramento do avanço do esgotamento muscular uma vez que, além de trazer informação desde o início da contração, fato não observado em nenhum dos demais ICMs, ainda possui em sua morfologia uma característica muito conveniente, que seria o ponto de inversão na taxa de decaimento nos momentos que precedem o Máximo Esgotamento [Erf96]. 
Observando o gráfico da Figura 3.11 e baseado em experiências com o EMG de músculos clinicamente normais, os quais serão apresentados no Capítulo 5, devemos fazer algumas considerações antes de escolher qual o índice, ou quais os índices mais apropriados para realizar o monitoramento do decréscimo da energia muscular ao longo do tempo.

\subsubsection{Escolha do ICM para o Sistema de Controle da EENM}

Estamos então interessados no índice, ou nos índices, que melhor sirva para monitorar o avanço do esgotamento muscular, de modo que seja possível manter o usuário informado sobre o decréscimo de sua energia muscular ao longo do tempo de exercício. Para definir o melhor índice devemos fazer algumas considerações.

\section{Consideração 1: Índices MDF e MNF versus ARV e RMS}

Da Figura 3.11 vem que os índices espectrais MNF e MDF apresentam em sua morfologia uma característica interessante em relação aos índices ARV e RMS, que seria a mudança na taxa de variação nos momentos que antecedem o máximo esgotamento. O sistema poderia monitorar essa inversão na taxa de decaimento para informar o usuário sobre sua condição de máximo esgotamento.

\section{Consideração 2: Índice MDF versus MNF}

Na Figura 3.11, o índice MDF possui pontos de inflexão muito mais acentuados que o MNF, o que seria de grande valor para detectar o limiar de esgotamento máximo. No entanto, observando os parâmetros espectrais de um sinal de EMG de músculo normal (Figura 5.3b), temos que o seu MDF ao longo do tempo apresenta grande variância, e nenhum ponto de inflexão que evidencie o momento que a musculatura entra em esgotamento. 
Para ambos casos, EMG de músculo normal e paralisado, observa-se que a MNF ao longo do tempo apresenta característica monotônica decrescente até o ponto de máximo esgotamento, o que vem a ser mais conveniente para o sistema de monitoramento.

\section{Consideração 3: Baixa variação de MNF imediatamente antes do Esgotamento Máximo}

No gráfico de MNF da Figura 3.11 (músculo paralisado) temos que, para os momentos imediatamente anteriores ao máximo esgotamento, este índice apresenta uma variação muito pequena, o que poderia ser considerado para o sistema de monitoramento como uma condição estável, sem alteração ou oscilação e, portanto, com pouca informação para avaliar o decréscimo da energia muscular ao longo do tempo. Podemos então considerar um dos índices ARV ou RMS para acompanhar o progresso do esgotamento muscular nos instantes imediatamente anteriores ao máximo esgotamento.

\section{Conclusão: Monitoramento baseado em MNF e ARV}

Devido à sua menor complexidade de cálculo em relação ao valor efícaz, e por apresentar maior faixa dinâmica, principalmente nos momentos que precedem o máximo esgotamento (inversão na taxa de decaimento de MNF), o índice ARV será utilizado em conjunto com o MNF para realizar o monitoramento no decréscimo de energia ao longo do tempo em EMGs obtidos a partir de músculos paralisados.

Adiantando o que será observado no Capítulo 5, o índice ARV não deverá ser utilizado para monitorar sinais de EMG de músculo normal, devido a sua característica oscilatória e de grande variância (vide Figura 5.3a) em tal sinal. Para tanto, deveremos elaborar uma forma de configurar o sistema de monitoramento de modo que se possa informá-lo que o sinal a ser monitorado advém de músculo normal ou de músculo paralisado.

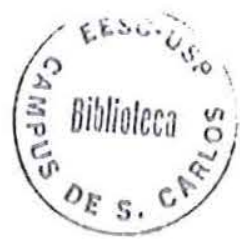




\section{CAPÍTULO 4}

A locomoção bipedal é um movimento dinâmico difícil de se controlar. Trata-se de um sistema mecânico complexo, multiatuador, redundante, que envolve a habilidade do cérebro de requisitar unidades motoras numa distribuição espaço-temporal multiplexada. No caso de lesados medulares o problema se agrava.

Sob o ponto de vista fisiológico, é recomendado que os exercícios de reabilitação devam persistir pelo maior tempo possível, até que se atinja o limiar anaeróbico. Esse limiar vai variar de pessoa a pessoa, pois dependerá do treinamento a que a estrutura muscular foi submetida antes da lesão medular. Grupos musculares pouco treinados possuem baixa resistência à fadiga.

Uma das limitações do uso da EENM nos tratamentos de reabilitação de movimentos em lesados musculares é justamente a falta de eficiência no controle do processo. Uma possível solução para o problema da fadiga muscular seria monitorar as variações dos índices Freqüência Média do Espectro de Potências (MNF) e Valor Retificado Médio (ARV) ao longo do tempo em que o músculo estiver sendo exercitado, como visto no capítulo anterior.

O sistema que será proposto tem o objetivo final de auxiliar nos tratamentos de eletro-neuro-estimulação de lesados medulares. Porém é perfeitamente utilizável para monitorar o esgotamento muscular de indivíduos clinicamente normais, uma vez que o Bloco de Processamento Digital que será descrito, apenas atua informando o usuário sobre o progresso do esgotamento de seu grupo muscular, não interferindo na forma de excitação (natural ou elétrica) a que o grupo muscular foi submetido. No Capítulo 5 será apresentado o processamento do sistema sobre o sinal de EMG extraído de um músculo normal. 


\subsection{Sistema de Controle da Estimulação Elétrica Neuromuscular (EENM)}

Estamos então interessados em elaborar um sistema que monitore ao longo do tempo as variáveis MNF e ARV e forneça ao usuário uma medida que lhe permita avaliar sua energia muscular ao longo do tempo de exercício.

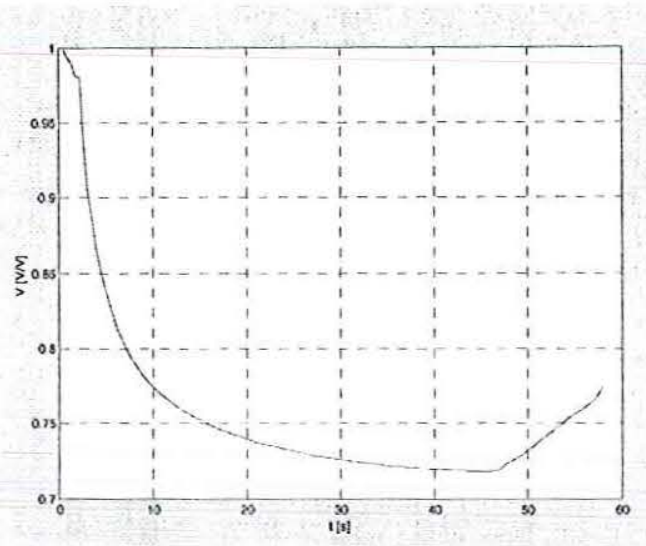

(a) Freqüência Média (MNF)

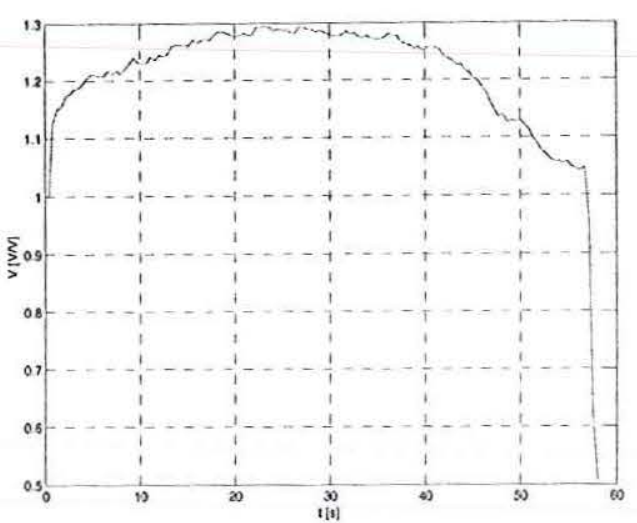

(b) Valor Retificado Médio (ARV)

Figura 4.1: MNF e ARV para EMG de músculo paralisado

Da Figura 4.1 que se trata de um caso específico de EMG de músculo paralisado, temos que os valores de MNF tendem a decrescer monotonicamente com o progresso do esgotamento muscular. Já o de ARV tende a decrescer a partir de um momento específico do exercício. Pode-se então monitorar o decaimento de ambos índices e emitir um sinal ao usuário a cada decréscimo de valor percentual constante.

Observando os níveis de variação para ambos casos ARV e MNF, podemos adotar um processamento que identifique, por exemplo, decréscimos de $1 \%$ em relação ao máximo valor atingido pelo respectivo índice. Essa seria uma boa medida para manter o usuário de EENM informado a respeito de quão rápido sua estrutura muscular entra em fadiga. 
Também se observa no gráfico da Figura 4.1 que no ponto de máximo esgotamento, temos um incremento na freqüência média. Podemos utilizar essa característica para que o sistema emita um sinal quando detectado $1 \%$ de acréscimo no valor da MNF, alertando o usuário que o grupo muscular está entrando na Região Máximo Esgotamento. Neste ponto, no caso de usuários com lesão medular, o estímulo elétrico deve ser descontinuado, uma vez que a força muscular obtida com tal estímulo começa a enfraquecer rapidamente.

Um dos objetivos deste sistema seria realizar o controle da estimulação dos grupos musculares de membros inferiores. Importante salientar que a aplicação do estímulo deve ser feita de modo que a flexão seja conduzida segundo movimentos suaves. Pode-se para isso atuar sobre a amplitude ou sobre a freqüência do sinal de estímulo.

Baseado na descrição acima, obtivemos a proposta geral de operação para o Sistema de Controle da EENM, representado pelo diagrama em blocos da Figura 4.2.

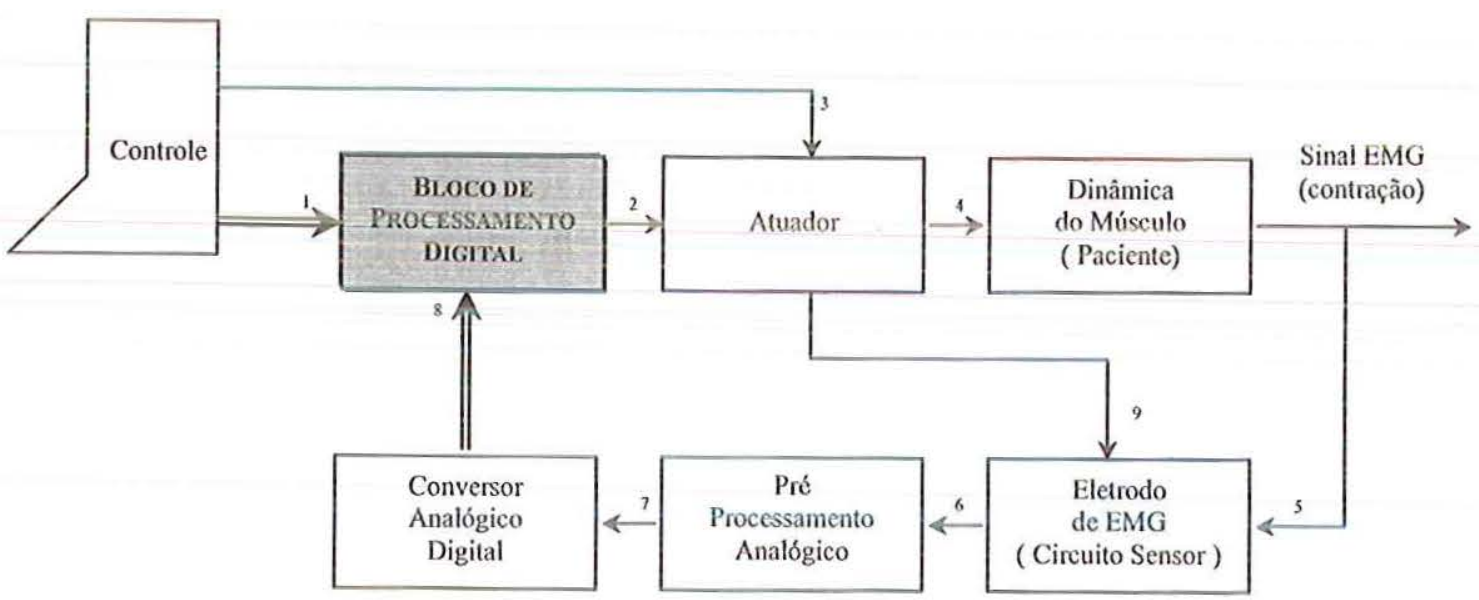

Figura 4.2: Diagrama em Blocos para o Sistema de Controle de EENM 


\section{Legenda:}

1: Sinais de Controle advindo de circuitos externos e/ou do próprio usuário: um desses sinais, mais especificamente o sinal "injured", informará o sistema sobre a natureza do sinal de EMG (músculo normal ou paralisado).

2: Sinal de "fad" e "maxfad" de saída do BPD utilizado pelo Atuador para controlar o estímulo elétrico - no caso de usuário lesado medular.

3: Sinal para ajuste da amplitude do estímulo, determinado a partir de testes prévios com o usuário.

4: Sinal analógico de EENM já amplificado para ser aplicado ao músculo.

5: Contração: Sinal de EMG.

6: Amostra analógica do sinal de EMG

7: Sinal filtrado e conformado para o conversor A/D.

8: Realimentação: amostra digitalizada de sinal EMG (12 bits).

9: Sinal de controle do Atuador para o Circuito Sensor.

\subsection{Descrição Geral do Sistema de Controle da EENM}

Bloco de Processamento Digital (BPD): monitora o sinal de EMG calculando o índice MNF e ARV em intervalos de $500 \mathrm{~ms}$, informando o usuário sobre o progresso do esgotamento muscular durante o exercício, através de dois sinais de saída: "fad" e "maxfad". Inclui circuitos: para Transformação de Domínio (FFT); Filtros Lineares (IIR); Somador Cumulativo; Comparador Digital e circuito para cálculo do Valor Retificado Médio (ARV) e da Freqüência Média do Espectro de Potências (MNF).

Atuador: sistema analógico com a principal função de conformar a tensão de pico do estímulo elétrico de acordo com a resposta da estrutura muscular do paciente. Depende de testes prévios. Realiza a aplicação do estímulo no músculo de forma gradual. Possui ainda sistema de proteção para garantir que o usuário não seja submetido a descargas elétricas. Emite um sinal para o Circuito Sensor exatamente no momento que precede a aplicação do estímulo elétrico. 
Circuito Sensor de EMG: possui um sistema de chaveamento que abre o malha no momento em que o estímulo elétrico está sendo aplicado. Dessa forma, o sinal do eletrodo estimulador não é lido pelo sistema, uma vez que este não traz informação relevante para o processamento de identificação da fadiga, e pode causar saturações. Com isso temos uma atenuação dos efeitos de Artefatos gerados no EMG pelos pulsos de estímulo elétrico. O sinal que informa o circuito de chaveamento para não ler o sinal de EMG no momento da estimulação elétrica, será recebido do circuito Atuador.

Conversor Analógico/Digital (12bits): a conversão A/D-12b poderá ser feita a priori utilizando-se circuitos integrados disponíveis comercialmente. Pode-se encaminhar uma pesquisa para a implementação de todo o ramo de realimentação em pastilha monolítica de silício. A precisão de 12 bits é normalmente sugerida por algumas publicações, baseado na variação de faixa dinâmica do sinal de EMG em função do tempo e das características morfológicas do EMG de determinados grupos musculares.

Pré-Processamento Analógico: inclui filtros analógicos e conformação da faixa dinâmica do sinal de saída para o estágio seguinte (conversor A/D).

O sistema completo exigiria o trabalho de uma equipe para implementá-lo integralmente no intervalo regular de Mestrado. Logo a proposta deste trabalho concentrase no desenvolvimento de uma parte do sistema supramencionado: o Bloco de Processamento Digital (BPD).

A seguir faremos uma descrição detalhada do funcionamento esperado para o BPD e a metodologia que se pretende utilizar para implementá-lo. 


\subsection{O Bloco de Processamento Digital (BPD)}

Basicamente trata-se de um sistema que recebe sinais digitais de controle para realizar um certo processamento matemático sobre o sinal de EMG, e avaliar o decaimento da energia da referida musculatura em relação aos valores máximos anotados durante o período de contração.

A ilustração da Figura 4.3 apresenta os sinais de entrada e saída do circuito integrado, que serão detalhados na seqüência.

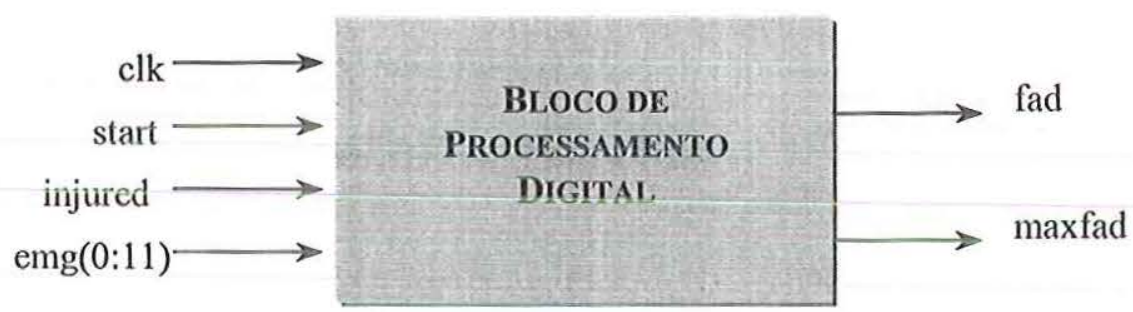

Figura 4.3: Sinais de Entrada e Saída para o BPD

\subsubsection{Sinais de Entrada}

clock: sinal binário com freqüência de $1000 \mathrm{~Hz}$.

start: comando para iniciar o monitoramento do esgotamento. Informa o sistema que um novo valor de referência para o índice de contração muscular (MNF,ARV) deve ser armazenado. Para a aplicação a que se destina, o mais conveniente seria fazer o monitoramento tomando como referência o maior valor do respectivo ICM observado durante o período de contração e calcular suas variações percentuais.

injured: comando que permite ao usuário configurar o sistema para calcular o sinal de saída "fad" considerando apenas o índice MNF (EMG de músculo normal), ou considerando além do MNF também o ARV (EMG de músculo paralisado). 
- injured =0: EMG anotado a partir de músculo clinicamente normal em contração voluntária. Para o monitoramento será considerado apenas o índice MNF.

- $\quad$ injured =1: EMG anotado a partir de músculo paralisado sob efeito de EENM. Para o monitoramento serão considerados os índices ARV e MNF.

emg(0:11): sinal de doze bits advindo do sensor de EMG, já devidamente amostrado e conformado por estágios anteriores como mostra o diagrama da Figura 4.2.

\subsubsection{Sinais de Saída}

fad: sinal de fadiga

- $f a d=0$ : Contração Normal e progresso do esgotamento muscular.

- $f a d=1: \quad$ Contração Normal $\rightarrow$ identifica decréscimo de $1 \%$ nos valores máximos

de MNF ou MNF e ARV, de acordo com o valor de injured.

Quando injured está em nível lógico baixo, o BPD aplicará um pulso no sinal fad toda vez que identificar um decréscimo de $1 \%$ em relação ao valor máximo do índice MNF. Para injured em nível lógico alto, o BPD aplicará o pulso em fad quando identificar um decréscimo de $1 \%$ em relação aos valores máximos dos índices MNF e ARV. O pulso terá a duração de 10 ciclos de clock.

maxfad: sinal de fadiga máxima

- $\max f a d=0$ : Contração Normal e progresso do esgotamento muscular.

- $\max f a d=1: \quad$ Máxima Fadiga $\rightarrow$ identifica um acréscimo de $1 \%$ sobre o mínimo valor atingido pela Freqüência Média. 


\subsection{Processamento Digital do Sinal Eletromiográfico}

Considerando que o sinal de EMG analisado em janelas de meio a dois segundos durante uma contração isométrica de força constante seja um processo estocástico quasiestacionário de banda limitada com média zero e distribuição gaussiana [Bas85], podemos partir para o monitoramento da Freqüência Média do Espectro de Potências.

O gráfico da Figura 4.3 apresenta os sinais de entrada e saída do BPD. Descendo um nível na hierarquia do BPD, podemos representar o sistema de acordo com o diagrama da Figura 4.4. Nesse diagrama, temos que todo o processamento será controlado pela Unidade Central de Processamento (CPU), que se encarregará de distribuir os sinais externos para as demais unidades.

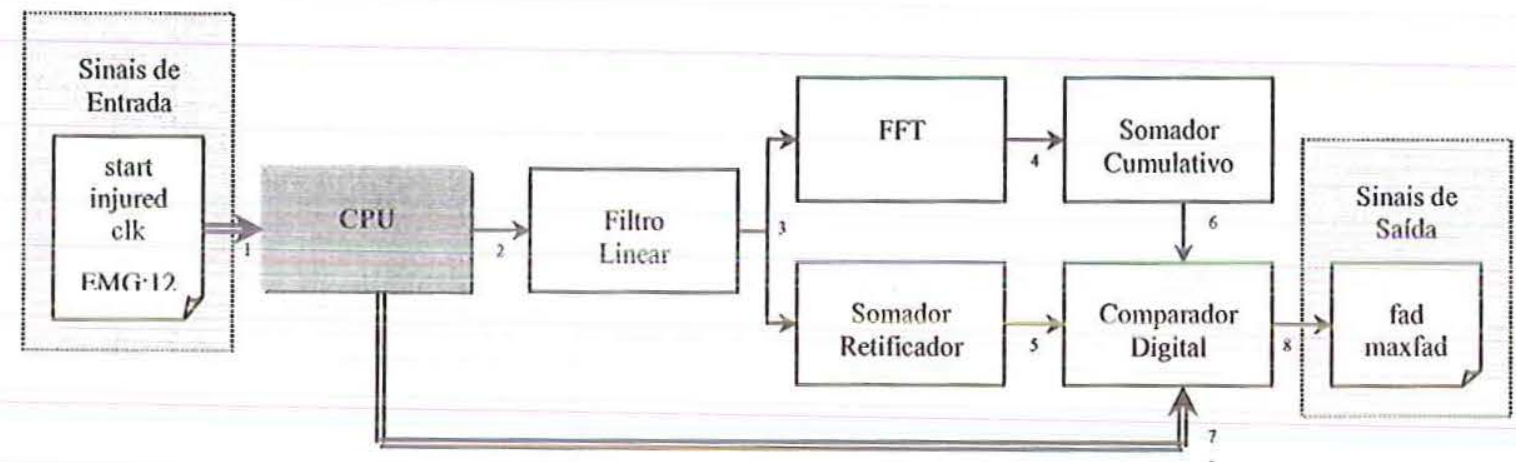

Figura 4.4: Diagrama Interno do BPD 


\section{Legenda:}

1: Sinais de Controle advindo de circuitos externos e do usuário: vide item 4.3.1.

2: Sinal de EMG sincronizado com o sinal de clock: a CPU transmite trechos de 500ms de sinal de EMG armazenados ao filtro linear.

3: Sinal de EMG filtrado: os 500ms são enviados ao Somador Retificador (para cálculo do ARV) e ao cálculo da FFT (transformação de domínio).

4: Espectro de Potências dos 500ms do sinal de EMG: transmitidos ao Cálculo da Freqüência Média.

5: Índice ARV do trecho de 500ms transmitido para comparação.

6: Índice MNF do trecho de 500ms transmitido para comparação.

7: Sinais "start" e "injured" transmitidos ao Comparador Digital para configurá-lo respectivamente a armazenar um novo valor de referência para os ICMs e informar o sistema se se trata de usuário clinicamente normal ou lesado medular.

8: Sinais de saída "fad" e "maxfad".

O filtro linear terá características previamente descritas (item 3.2.1): filtro passafaixa (composição entre filtro Chebyshev passa-alta com freqüência de corte igual a $25 \mathrm{~Hz}$ e filtro Chebyshev passa-baixa com freqüência de corte igual a $600 \mathrm{~Hz}$ ) seguido por filtro rejeita-faixa para eliminar a interferência da rede elétrica $(60 \mathrm{~Hz})$, conforme Diagrama de Bode da Figura 3.3.

Para obter a representação do trecho de 500ms do sinal de EMG no domínio da freqüência, o circuito utilizará Transformada Rápida de Fourier (FFT), considerando como saída o seu módulo ao quadrado (Espectro de Potências).

Para obter o valor da Freqüência Mediana, o circuito Somador Cumulativo calculará a área abaixo do gráfico do Espectro de Potências e o armazenará num vetor - o vetor da soma cumulativa - após normalização. Em seguida, varrerá o vetor de soma cumulativa para identificar a freqüência que possui como correspondente a metade do valor da área total do Espectro de Potências, ou seja, o seu $50^{\circ}$ percentil. Esta será então eleita MDF para o respectivo trecho de EMG. 
O Somador Retificador calcula inicialmente o módulo do sinal de EMG, obtendo assim o vetor de EMG retificado. A média dos valores deste vetor identificará o índice ARV.

O Comparador Digital, baseado nos valores de MNF e ARV (se injured estiver em nível lógico alto), será o sub-módulo responsável pelas decisões que informarão o usuário a respeito do progresso do esgotamento de seu grupo muscular via sinais "fad" e "maxfad". 


\section{CAPÍtulo 5}

No Capítulo 4, foi proposto o diagrama interno do Bloco de Processamento Digital (BPD). Neste capítulo será apresentada a descrição comportamental em VHDL do BPD, e o resultado das simulações comparado ao processamento do software Matlab. Logo, o funcionamento do Bloco de Processamento Digital será testado através de comparações com o mesmo processamento realizado por software matemático conhecido no meio acadêmico, cuja precisão é assumida como referência.

$\mathrm{O}$ código VHDL que será apresentado foi desenvolvido com o objetivo de reproduzir o processamento obtido com os scripts Matlab. Para atingir esse objetivo foram utilizadas as funções disponíveis nas bibliotecas matemáticas pré-declaradas pela Mentor Graphics, incluindo a capacidade do compilador e do simulador VHDL de manipular números reais e complexos. Com isso obtivemos o código VHDL funcional do Bloco de Processamento Digital.

A comparação quantitativa entre as curvas obtidas com Matlab e as obtidas com as simulações do código VHDL será feita nos três estágios apresentados na Figura 5.1, extraídos do diagrama da Figura 4.4.

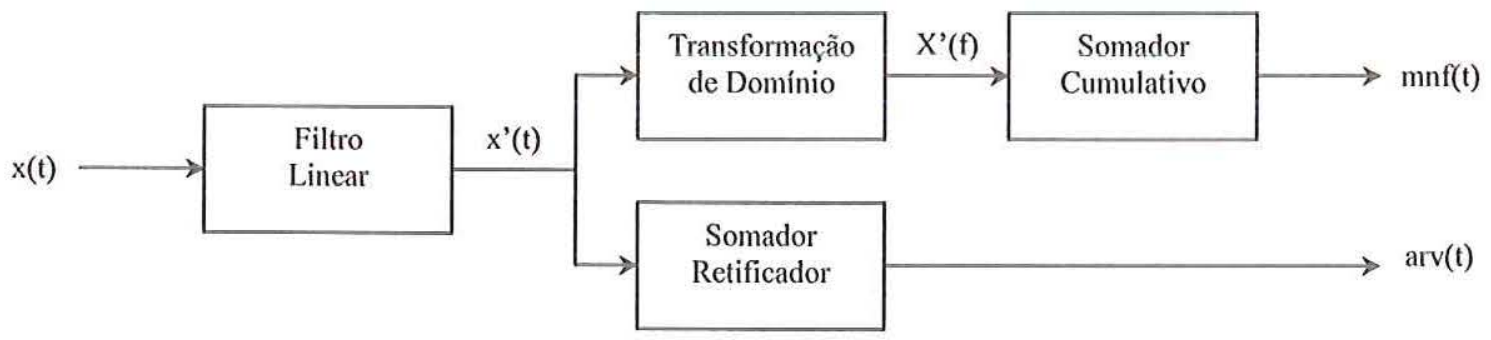

Figure 5.1: Diagrama extraído da Figura 4.4 com sinais para comparação entre VHDL. e Matlab 
No gráfico da Figura 5.1, o sinal de EMG é transmitido para o Filtro Linear, resultando em $x^{\prime}(t)$. Em seguida o sinal filtrado $x^{\prime}(t)$ é submetido a dois processamentos paralelos: o cálculo do espectro de potências X'(f) e do índice ARV. O sinal de X'(f) é então transmitido para o Somador Cumulativo que vai calcular a respectiva freqüência mediana e média.

As simulações com o código VHDL terão como amostra de EMG o sinal de um músculo clinicamente normal. Porém o resultado obtido no Capitulo $3 \mathrm{com}$ a análise do sinal de EMG do músculo paralisado, será utilizado neste capítulo para comparação.

\subsection{Captura do Sinal de EMG Voluntário sem lesão medular}

A amostra do sinal de EMG de superfície do músculo normal foi coletada do quadríceps direito de um voluntário do sexo masculino, 25 anos, $72 \mathrm{Kg}, 1.74 \mathrm{~m}$, clinicamente normal, não sedentário. A configuração do exercício procura reproduzir o cenário criado no Capítulo 3 de forma a induzir a musculatura ao esgotamento para amostragem do EMG do músculo normal em resposta natural (sem o estímulo elétrico artificial). Neste experimento foi utilizado dinamômetro isocinético eletrônico Biodex Multi-Joint System 2 (Biodex-Medical Systems Inc), software Biodex Advantage Software v.4.5, alocado no ambulatório de Fisioterapia da Universidade Federal de São Carlos (UFSCar).

A amostragem do EMG foi realizada utilizando eletromiógrafo computadorizado de 16 canais LINX (Lynx Tecnologia Eletrônica Ltda), software AqDados5, composto por um conversor analógico digital (CAD 12/32), um amplificador, interfaceados a um microcomputador, com uma freqüência de amostragem de $1000 \mathrm{~Hz}$, filtro digital passaalta de $20 \mathrm{~Hz}$ e passa-baixa de $500 \mathrm{~Hz}$ e sensibilidade de amplitude de $5000 \mu \mathrm{V}$ para os músculos bíceps femoral e reto da coxa. Foram utilizados eletrodos ativos de superfície de prata, os quais foram fixados após tricotomia e limpeza da pele, sobre o ventre muscular e longitudinalmente em relação às fibras musculares. 
O voluntário foi então submetido a uma força constante (carga para contração máxima disponibilizada pelo sistema Biodex), e instruído a realizar contração voluntária máxima e a manter respiração normal durante o exercício.

O gráfico da Figura 5.2 apresenta o sinal EMG anotado para o músculo normal. A marcação em vermelho representa a parte do EMG efetivamente utilizada para análise.

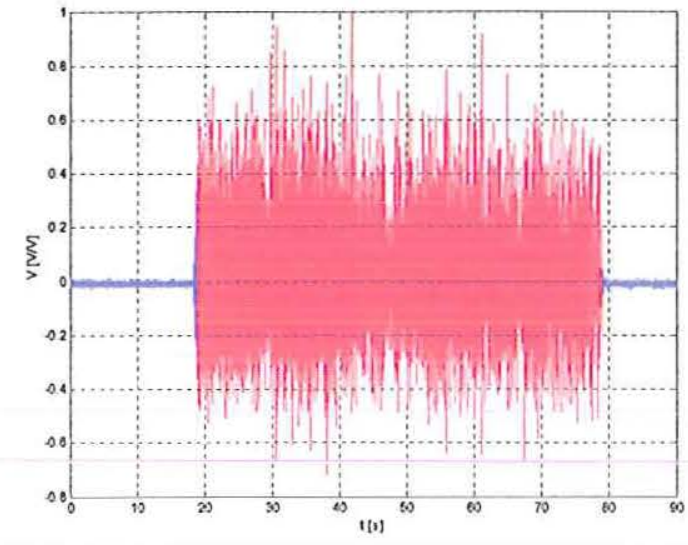

(a) EMG normal

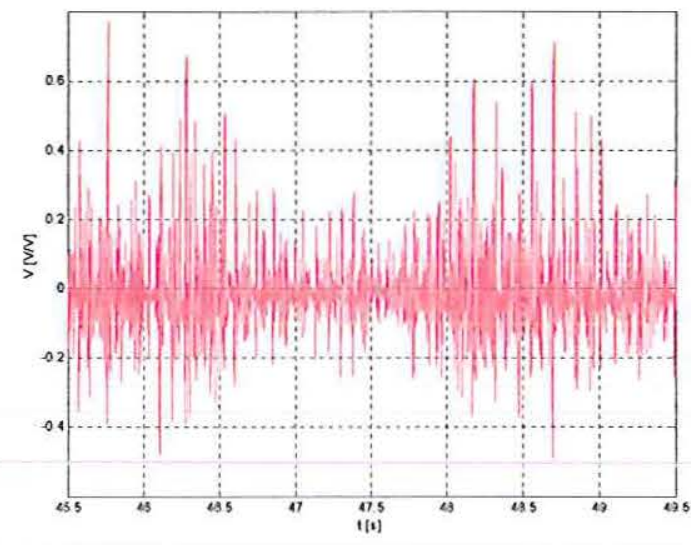

(b) detalhe do EMG em (a)

Figura 5.2: Sinal de EMG de músculo normal - amplitude normallzada

O sinal de EMG será dividido em trechos de mínimo comprimento tal que ainda mantenha suas características quasi-estacionárias. Considerando trechos de $500 \mathrm{~ms}$, temos que para a freqüência de amostragem de $3200 \mathrm{~Hz}$, o sinal será dividido em trechos de:

$$
N=\frac{500 E-3}{\frac{1}{3200}}=1600 \cong 2^{11} \text { pontos }
$$

Dessa forma, para um trecho de $2^{11}$ pontos temos então que a análise estará sendo feita a intervalos de $640 \mathrm{~ms}$.

Aplicando o mesmo cálculo para a frequêencia de $1000 \mathrm{~Hz}$ (caso específico do sinal de EMG do músculo normal em questão), temos que os trechos para análise serão de $2^{9}$ pontos (512ms). 


\subsection{Análise do EMG normal}

Realizando o processamento idêntico ao descrito no Capítulo 3 para um sinal EMG de músculo paralisado, mas agora para o EMG de músculo normal, obtemos os gráficos de índices de esgotamento muscular da Figura 5.3.

Diferentemente do sinal obtido com o músculo eletroestimulado da Figura 5.3.c, o sinal do músculo normal não apresentou o patamar que delimita a região crítica de fadiga no gráfico de MDF. Muito provavelmente o sinal teria atingido tal patamar, se o exercício tivesse perdurado por mais tempo, o que foi impraticável devido ao aumento da sensibilidade causado pelo grande esforço.

Mais uma vez verificado, agora para este caso de análise do sinal de EMG de músculos normais, temos que o índice MNF novamente mostrou ser o ICM mais conveniente para acompanhar a manifestação mioelétrica do esgotamento muscular. Com característica monotônica decrescente em função do tempo e morfologia mais estável que os demais, é mais um indicativo da ocorrência de compressão espectral como uma função da queda de energia do grupo muscular. 


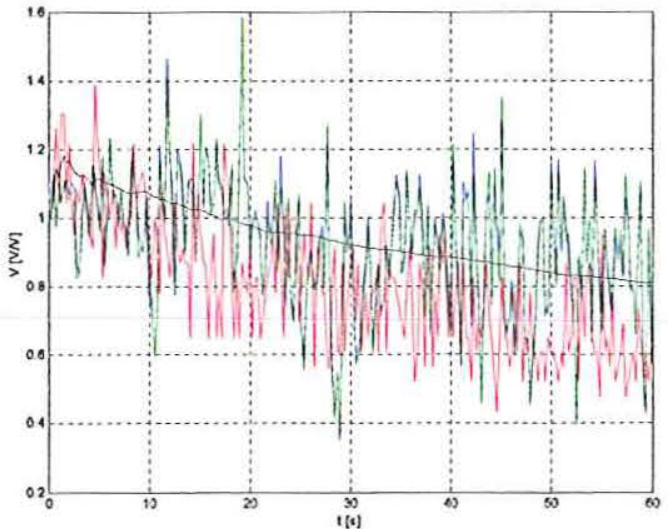

(a) Normal: todos índices

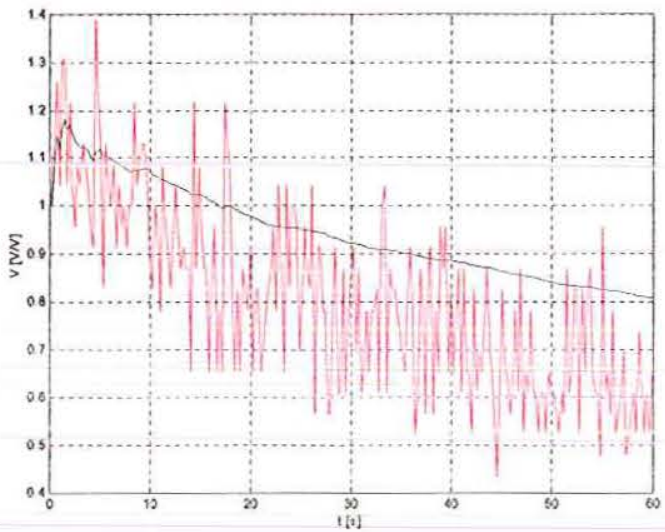

(b) Normal: MDF e MNF

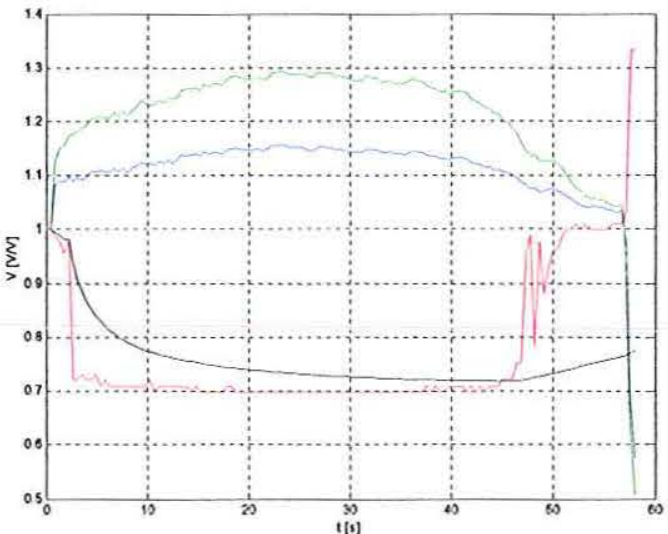

(c) Paralisado: todos índices

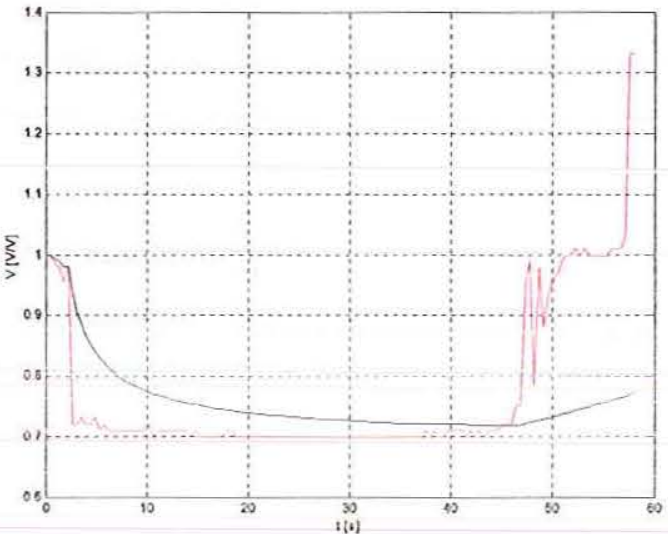

(d) Paralisado: MDF e MNF

Figura 5.3: Comparação entre Índices do Esgotamento Muscular (a)(b) Músculo Normal - (c)(d) Músculo Paralisado

$$
\begin{aligned}
& \diamond: \text { MNF (Mean Frequency) } \\
& \text { : MDF (Median Frequency) } \\
& \diamond: \text { RMS (Root Mean Square) } \\
& \diamond: \text { ARV (Average Rectified Value) }
\end{aligned}
$$




\subsection{Os Ambientes de Simulação:}

Os itens a seguir mostrarão como carregar as rotinas utilizadas para realizar o processamento desenvolvido desta pesquisa.

\subsubsection{Rotinas Matlab}

A rotina principal do processamento em Matlab é aqui chamada de tee.m. Esta rotina deve ser executada utilizando a linha de comando Matlab:

$\%$ cd $<$ rundir $>$

$\%$ tee

É necessário editar o arquivo config.m para que o Matlab leia o arquivo onde está armazenado o sinal de EMG. Este arquivo pode ter o formato de duas colunas (separadas por espaços ou tabulações) contendo as variáveis reais: tempo e amplitude. Veja a descrição das rotinas no Apêndie B.

\subsubsection{Simulação Digital Mentor Graphics ModelSim}

A versão do simulador digital utilizada neste experimento está descrita abaixo. Qualquer outra versão poderá exigir que os códigos VHDL sejam recompilados.

Mentor Graphics Model Technology ModelSim SE/EE vsim 5.4a Simulator 2000.04 Apr 212000

O simulador digital ModelSim da Mentor Graphics possui uma interface gráfica de fácil utilização. Seguem alguns comandos básicos para rápida inicialização. Maiores informações podem ser encontradas nos manuais de usuário da ferramenta.

Para compilar os códigos VHDL é necessário criar a biblioteca que vai armazenar os arquivos binários resultantes da compilação. Utilize os comandos Unix abaixo para criar a biblioteca de códigos compilados "work" e compilar o programa VHDL do arquivo "source.vhd". 
$\%$ cd <rundir >

$\%$ qhlib work

$\%$ quhcom source.vhd

Verifique no item "Siglas e Símbolos" no final deste trabalho para reconhecer a simbologia utilizada a seguir. Para utilizar a interface gráfica digite:

$\%$ qhsim \&

[ModelSim]\% cd /home/fabio/docs/personal/masters/vhdl

[ModelSim]\% view *

[ModelSim SE/EE]: Design > Load New Design...

Selecione a entidade do projeto que deseja simular.

[ModelSim Signals]: View > Wave > Signals in Region...

[ModelSim SE/EE]\% force start 1

[ModelSim SE/EE]\% run $200 \mathrm{~ms}$

Podemos utilizar os recursos do Unix para inicializar rapidamente o simulador vsim sem a interface gráfica, através da declaração de alias, apenas para gerar o arquivo de saída contendo o resultado do processamento do EMG. O comando abaixo realiza a simulação sobre a entidade exec do código VHDL recém compilado. Todos os comandos, resultados de execução e mensagens do simulador serão armazenados no arquivo output.log.

$\%$ alias vss "vsim work.exec -do sim.do -c -keepstdout -I output.log"

$\%$ vss

Onde "sim.do" é um arquivo texto que contém os comandos para o simulador. Exemplo de arquivo "sim.do":

\# Simulation commands
add wave sim:/exec/*
force start 1
run $200 \mathrm{~ms}$
quit
yes


Observação: o alias acima é aceito tanto pelo Unix quanto pelo simulador ModelSim. Ao declarar o alias acima na linha de comandos do simulador, o comando "vss" irá reinicializar a simulação com a última versão compilada da entidade encontrada na biblioteca work.

Todos os códigos VHDL do Anexo B devem ser compilados para efetuar a simulação da entidade exec descrita no arquivo source.vhd. Este é o arquivo que controla todo o processamento em VHDL.

\subsection{O Filtro Recursivo}

Alguns autores defendem o uso de filtros preditivos adaptativos para eliminar as Ondas-M do sinal de EMG considerando a não-estacionariedade do sinal de EMG ([Sen97]). Para o presente, adotamos um período de $500 \mathrm{~ms}$ no qual o sinal pode ser considerado quasi-estacionário e dessa forma o filtro utilizado tem ordem e coeficientes constantes.

Como descrito no Capítulo 3 (item 3.2.1), iremos utilizar no processamento dois tipos de filtros: um rejeita-faixa e um filtro passa-faixa. Os filtros serão do tipo IIR (Infinite Impulse Response) que possue equacionamento no plano $\mathrm{Z}$ apresentado pela Equação 5.1.

$$
G(z)=\frac{P(z)}{D(z)}=\frac{p_{0}+p_{1} z^{-1}+p_{2} z^{-2}+\ldots+p_{N} z^{-N}}{1+d_{1} z^{-1}+d_{2} z^{-2}+\ldots+d_{N} z^{-N}}
$$

Desenvolvendo a Equação 5.1, encontramos sua representação no domínio do tempo [Ham89]:

$$
y_{n}=\sum_{k=0}^{\text {ord }}\left(b_{k} x_{n-k}\right)-\sum_{k=1}^{\text {ord }}\left(a_{k} y_{n-k}\right)
$$


A Equação 5.3, desenvolvida a partir do somatório da Equação 5.2, representa o algoritmo que será utilizado para implementar a rotina VHDL e que também é identicamente utilizado pelo Matlab (função filter).

$$
\begin{aligned}
y_{n}= & b_{1} x_{n}+b_{2} x_{n-1}+\ldots+b_{\text {ord }} x_{n-\text { ord }-1}+b_{\text {ord }+1} x_{n-\text { ord }} \\
& -a_{2} y_{n-1}-a_{3} y_{n-2}-\ldots-a_{\text {ord }} y_{n-\text { ord }-1}-a_{\text {ord }+1} y_{n-\text { ord }}
\end{aligned}
$$

Esse será então o equacionamento utilizado para implementar o código VHDL de cada estágio do filtro, variando-se apenas os coeficientes de acordo com o tipo de rejeição (passa-faixa ou rejeita-faixa).

Como os filtros terão característica comum para qualquer sinal, então seus coeficientes serão fixos. Dessa forma, podemos utilizar Matlab para obter os melhores coeficientes.

\subsubsection{Cálculo dos Coeficientes do Filtro IIR}

Vários fatores podem contribuir para a não estabilidade de filtros recursivos. Dentre eles podemos citar:

$>$ pólos externos ao círculo unitário;

$>$ baixa precisão dos coeficientes do polinômio;

$>$ especificação de parâmetros muito agudos (fs, fp, As, Ap)

$>$ inconsistência no algoritmo do filtro.

Dessa forma, a análise da estabilidade do filtro é fundamental para evitar inconsistências no resultado das simulações. O cálculo da posição dos pólos em relação ao círculo unitário deve ser feito com auxílio da função zplane do Matlab.

Para os filtros calculados nesse trabalho foi utilizado o máximo de precisão do Matlab 6 R12 que é de 16 dígitos decimais. Trabalhos futuros podem identificar a precisão necessária e suficiente para o correto funcionamento de cada estágio dos filtros, que traria maiores ganhos para a velocidade de processamento. 
Verifique o código VHDL descrito nas rotinas do Apêndice B para obter uma referência do algoritmo do filtro.

Os coeficientes dos filtros foram projetados utilizando o método de Chebyshev, considerando atenuação máxima na banda passante (Ap) de $0.5 \mathrm{~dB}$ e atenuação mínima na banda de corte (As) de $30 \mathrm{~dB}$, conforme descrito a seguir.

\subsubsection{Filtro Rejeita-Faixa}

O filtro Rejeita-Faixa foi calculado utilizando os comandos Matlab descritos nas rotinas do Apêndice A. Considerando coeficientes de Chebyshev tipo 1 par a banda de corte entre 59 a $61 \mathrm{~Hz}$ com atenuação mínima de $30 \mathrm{~dB}$, e banda passante abaixo de $55 \mathrm{~Hz}$ e acima de $65 \mathrm{~Hz}$ com atenução máxima de $0.5 \mathrm{~dB}$, obtemos os coeficientes da Tabela 5.1 para o filtro rejeita-faixa de ordem 6.

\begin{tabular}{|c|c|}
\hline B & A \\
\hline 0.9376148565044788 & 1.0 \\
\hline-5.2308697088465860 & -5.4599673048504150 \\
\hline 12.5403631844726100 & 12.8100178270047400 \\
\hline-16.4916237818137000 & -16.4860340936865400 \\
\hline 12.5403631844726100 & 12.2677027466081900 \\
\hline-5.2308697088465860 & -5.0073618010141240 \\
\hline 0.9376148565044788 & 0.8782355083854569 \\
\hline
\end{tabular}

Tabela 5.1: Coeficientes do Filtro Rejeita-Faixa

A Figura 5.4 apresenta o Diagrama de Bode e a posição dos pólos e zeros em relação ao círculo unitário para o filtro Passa-Faixa. 


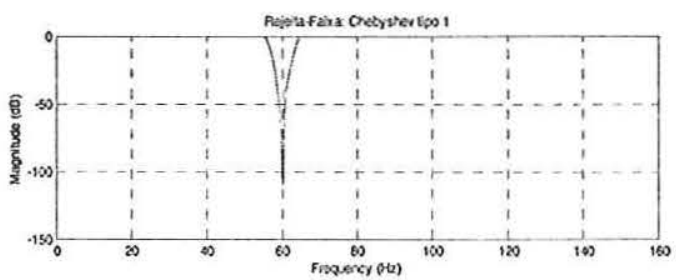

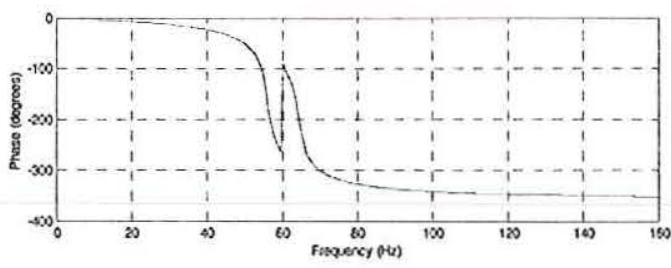

(a) Diagrama de Bode

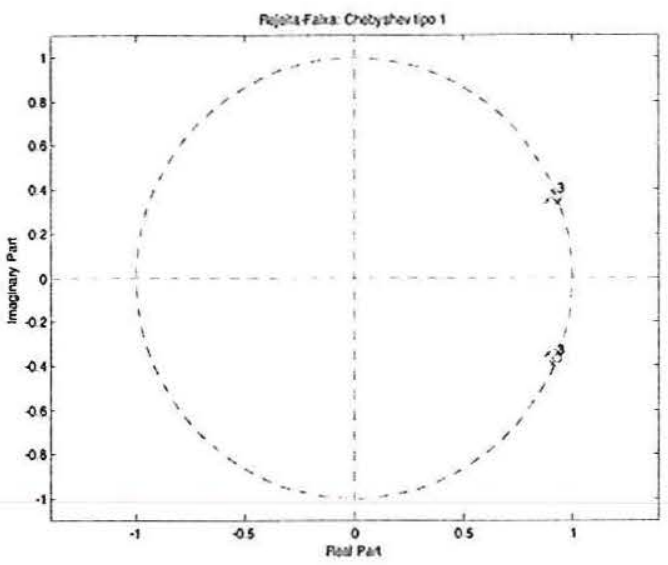

(b) Pólos e Zeros

Figura 5.4: Resposta em Freqüência, Pólos e Zeros do Filtro Rejeita-Faixa $\left(f_{\mathrm{a}}=1 \mathrm{KHz}\right)$

A Figura 5.4(a) apresenta do gráfico original Matlab apenas o trecho nas redondezas da frequência de rejeição de $60 \mathrm{~Hz}$, uma vez que este se extende igualmente até a frequência de $500 \mathrm{~Hz}$.

Observando os diagramas da Figura 5.4, conclui-se que os coeficientes do filtro rejeita-faixa irão implementar um filtro estável (pólos dentro do círculo unitário no plano Z) para eliminar a interferência de rede de $60 \mathrm{~Hz}$ do sinal de EMG.

\subsubsection{Filtro Passa-Faixa}

O filtro passa-faixa foi obtido através da convolução dos coeficientes de um filtro passa-alta e outro passa-baixa. O filtro passa-alta tem banda de corte de $20 \mathrm{~Hz}$ e banda passante de $30 \mathrm{~Hz}$. O filtro passa-baixa tem banda de corte de $500 \mathrm{~Hz}$ e banda passante de $480 \mathrm{~Hz}$. O projeto do filtro passa-faixa pode ser conferido no script Matlab nas rotinas do Apêndice A. Seguem os valores dos coeficientes obtidos para o filtro passa-faixa de $8^{\mathrm{a}}$ ordem. 


\begin{tabular}{|c|c|}
\hline B & A \\
\hline 0.4908646931386786 & 1.0 \\
\hline-1.9634587725547141 & -3.4103169982787134 \\
\hline 1.9634587725547137 & 3.0543925493490747 \\
\hline 1.9634587725547128 & 2.0645189284942429 \\
\hline-4.9086469313867882 & -4.8711897016621126 \\
\hline 1.9634587725547124 & 1.6043699499238038 \\
\hline 1.9634587725547141 & 1.6650856692295397 \\
\hline-1.9634587725547141 & -1.4244197428294512 \\
\hline 0.4908646931386786 & 0.3186208522803104 \\
\hline
\end{tabular}

Tabela 5.2: Coeficientes do Filtro Passa-Banda

A Figura 5.5 apresenta o diagrama de Bode do filtro Passa-Faixa.
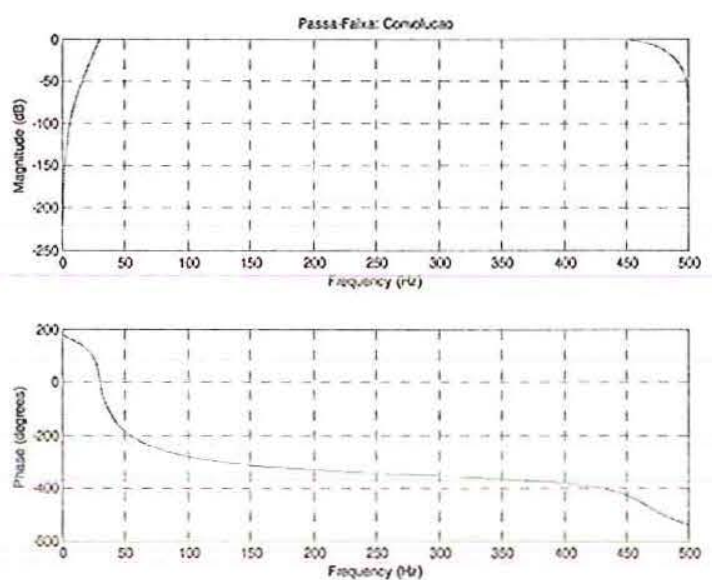

(a) Diagrama de Bode

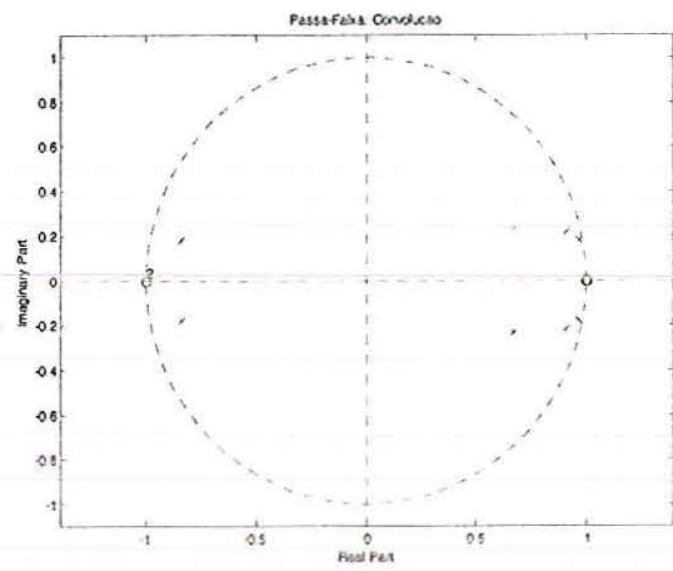

(b) Pólos e Zeros

Figura 5.5 Resposta em Freqüência, Pólos e Zeros do Filtro Passa-Faixa $\left(f_{a}=1 \mathrm{KHz}\right)$

Tendo os pólos internos ao círculo unitário no plano $\mathrm{Z}$, temos garantida a estabilidade para o filtro rejeita-faixa apresentado na Figura 5.5.a.

Seguindo o diagrama da Figure 5.1, após submeter o sinal de EMG à filtragem linear, podemos passar ao cálculo dos parâmetros no domínio da frequência. 


\subsection{Transformação de Domínio (FFT)}

A melhor aproximação para o processamento de sinais não estacionários consiste na segmentação da seqüência em subseqüências na qual estacionariedade pode ser assumida ou estatisticamente testada. O algoritmo da FFT implementa esta estratégia.

Infelizmente existe a correlação (incerteza) entre a resolução do espectro e o comprimento da janela de observação. Assim, janelas curtas de observação implicam em baixa resolução da distribuição espectral.

Merletti [Mer89] verificou que o janelamento retangular é aceitável e mesmo preferido para utilização na estimação da Freqüência Mediana. Para o sinal dividido em trechos de 1 a 2 s, o coeficiente de variação é de 4-6\%; já para trechos de $0.25 \mathrm{~s}$, o coeficiente dobra de tamanho e para trechos de dados menores, o coeficiente assume valores não aceitáveis.

Como assumimos que o sinal seria considerado quasi-estacionário para trechos de 0.5 a $1 \mathrm{~s}$, temos que a janela retangular é mais conveniente para o presente.

Para transferir o sinal do domínio do tempo para o domínio da freqüência, podemos utilizar a Transformada Discreta de Fourier dada pela Equação 5.4.

$$
X_{n}=\sum_{k=0}^{N-1} x_{0}(k) e^{-j 2 m k / N} \quad n=0,1,2, \ldots, N-1
$$

O cálculo da transformada utilizando o equacionamento convencional tem alto custo computacional. Vários autores propuseram algoritmos otimizados para o cálculo da transformada de Fourier. Para este trabalho, utilizou-se o algoritmo descrito por Brigham [Bri40] para o cálculo da Transformada Rápida de Fourier (FFT). A implementação do algoritmo da FFT em VHDL pode ser conferida nas rotinas do Apêndice B. 
Para a implementação do algoritmo de cálculo da Transformada Rápida de Fourier (FFT) apresentado por Brigham [Bri40], deve-se atentar para:

correta operação de divisão entre números inteiros e reais;

precisão das variáveis.

$>$ trabalhar com vetores sempre com número de componentes expressos por $2^{\mathrm{N}}$, sendo $\mathrm{N}$ um número inteiro positivo.

\subsubsection{Comparação entre processamentos VHDL e Matlab para o FFI}

Cada trecho de 500ms do sinal de EMG será agora submetido ao cálculo da FFT. Aplicando-se o filtro rejeita-faixa e o filtro passa-faixa no sinal de EMG da Figura 3.3, e em seguida calculando o seu FFT, obtemos o gráfico da Figura 5.6.

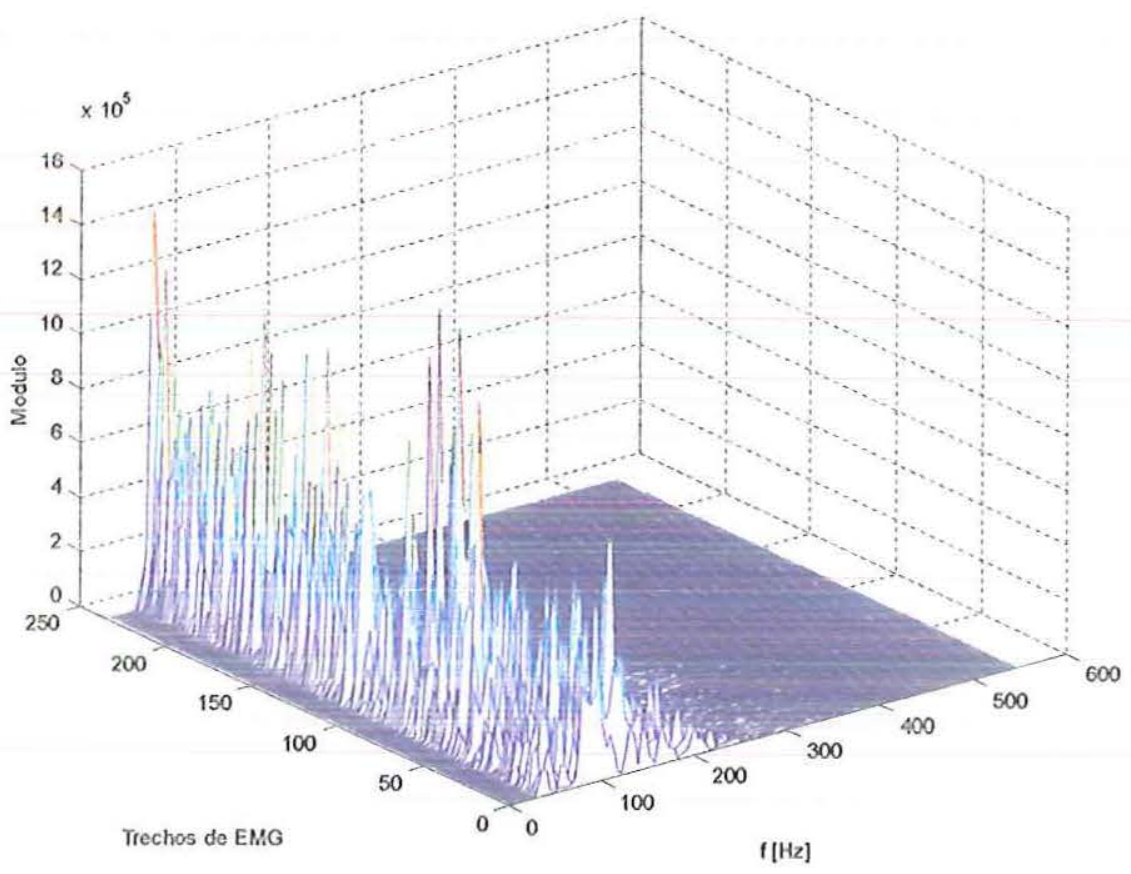

Figura 5.6.a: Espectro de Potências de cada trecho de 500ms do sinal de EMG 


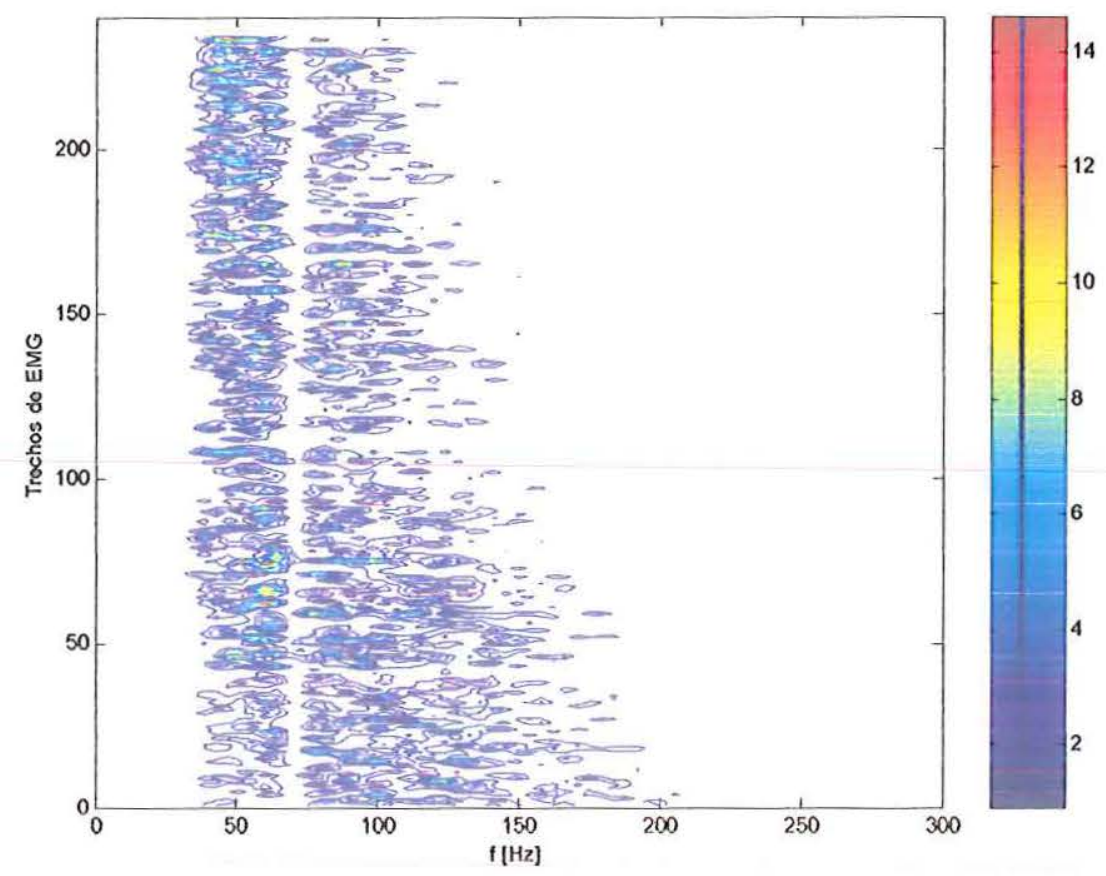

(b) Curvass de nível para o Espectro de Potências de todos os trecho de $500 \mathrm{~ms}$ do sinal de EMG

Figura 5.6: Espectro de Potências e Curvas de Nivel para sinal de EMG Normal

O gráfico da Figura 5.6.a, que apresenta o Espectro de Potências de todos os trechos de $500 \mathrm{~ms}$ do sinal de EMG, vem reforçar a compreensão sobre o processamento de obtenção do MDF e respectivo MNF. Este contém a representação gráfica do fenômeno da compressão espectral que pode ser meihor visualizado na Figura 5.6.b.

Os resultados do processamento em VHDL foram sobrepostos aos do Matlab para comparação. O erro relativo médio entre as duas amostras foi calculado de acordo com a Equação 5.5, e está na ordem de 1E-6.

$$
e_{R M}=\frac{1}{N-1} \sum_{i=0}^{N-1} \frac{x_{R E F}(i)-x(i)}{x_{R E F}(i)}
$$




\subsection{Somador Cumulativo}

O Somador Cumulativo é o sistema responsável pelo cálculo da Freqüência Mediana e da Freqüência Média. Sua operação segue o descrito pela Equação 3.2 (Soma Cumulativa) e 2.3 (Frequência Mediana e Média). Veja as rotinas do somador no Apêndice B.

\subsubsection{Comparação entre processamentos VHDL e Matlab para o Somador Cumulativo}

Os trechos do sinal de EMG que foram submetidos ao cálculo do FFT, agora serão repassados ao somador cumulativo. O erro relativo médio é da ordem de $1 \mathrm{E}-5$ entre os dois modelos de somador cumulativo (VHDL e Matlab). A freqüência mediana então será identificada como sendo a freqüência que leva ao ponto 0.5 da curva de soma cumulativa de cada trecho de $500 \mathrm{~ms}$ do sinal de EMG.

A partir do vetor de Soma Cumulativa, o próprio somador calcula os vetores de freqüências mediana e média do espectro de potências de todos os trechos do sinal de EMG. Em seguida armazena o vetor num arquivo e transmite os respectivos valores de frequêencia média para o Comparador Digital. Os gráficos de MNF obtidos pelo somador cumulativo estão apresentados na Figura 5.7.

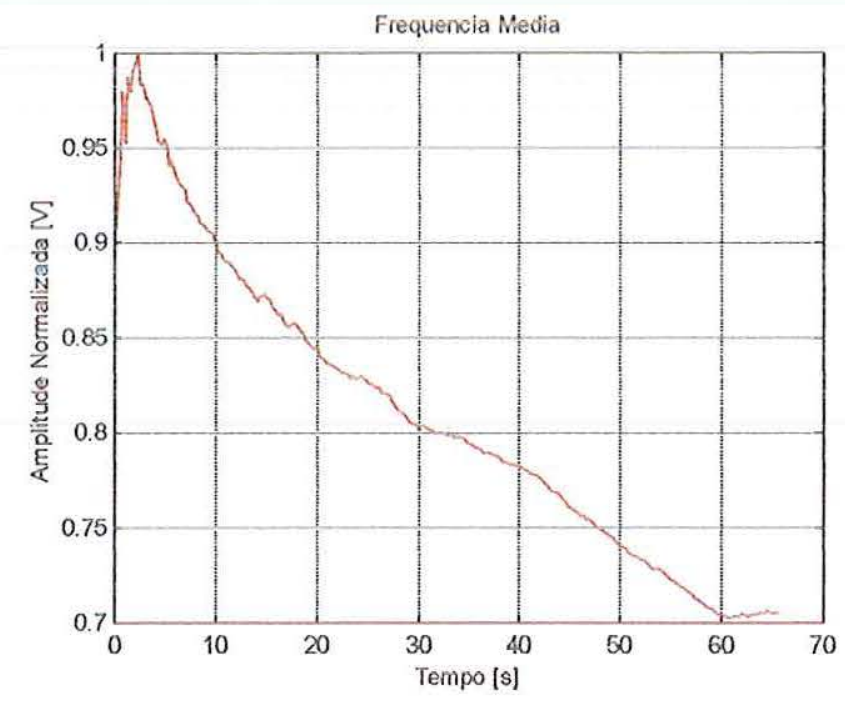

Figure 5.7: Comparação entre Freqüências Média Matlab e VHDL 


\subsection{Somador Retificador}

O Somador Retificador somente será utilizado para monitorar o avanço do esgotamento muscular em eletromiogramas extraídos de músculo paralisado. Como descrito no item 4.3.1, seu funcionamento está condicionado ao nível lógico do sinal injured.

O Somador Retificador tem o comportamento descrito pela Equação 2.2. Veja as rotinas no Apêndice B. Comparando os resultados do processamento em VHDL com o processamento do Matlab, temos que o erro relativo médio está na ordem de 1E-5.

Tendo os módulos apresentados no diagrama da Figura 5.1 devidamente comparados, e assumindo que o erro entre as amostras, tendo como referência os dados produzidos pelo Matlab, possa ser desconsiderado, podemos passar para circuito que irá utilizar os gráícos de MNF e ARV para avaliar o decaimento da energia muscular ao longo do tempo.

\subsection{Comparador Digital}

Voltando ao diagrama da Figura 4.4, temos no comparador digital o circuito que vai anotar o valor da MNF e do ARV (em se tratando de músculo paralisado - injured em nível lógico alto) no início da contração e compará-la com os valores ao longo do exercício em intervalos de $500 \mathrm{~ms}$.

Nesse processamento o Comparador irá avaliar ambos ICMs e anotar os seus respectivos valores máximo e mínimo, respectivamente Valor Máximo de Referência (VRMAX) e Valor Mínimo de Referência (VRMIN) - este último somente para MNF.

À cada $1 \%$ de decaimento do no valor do ICM em relação ao seu VRMAX, o sinal de saída "fad" receberá um pulso. Quando o sinal de EMG apresentar uma MNF superior a $1 \%$ de seu VRMIN, então o sinal de "maxfad" é acionado para alertar o usuário da baixa energia muscular detectada. 
Os gráficos das Figura 5.8 e 5.9 apresentam a janela "wave" do simulador digital Modelsim, com as formas de onda resultantes do processamento.

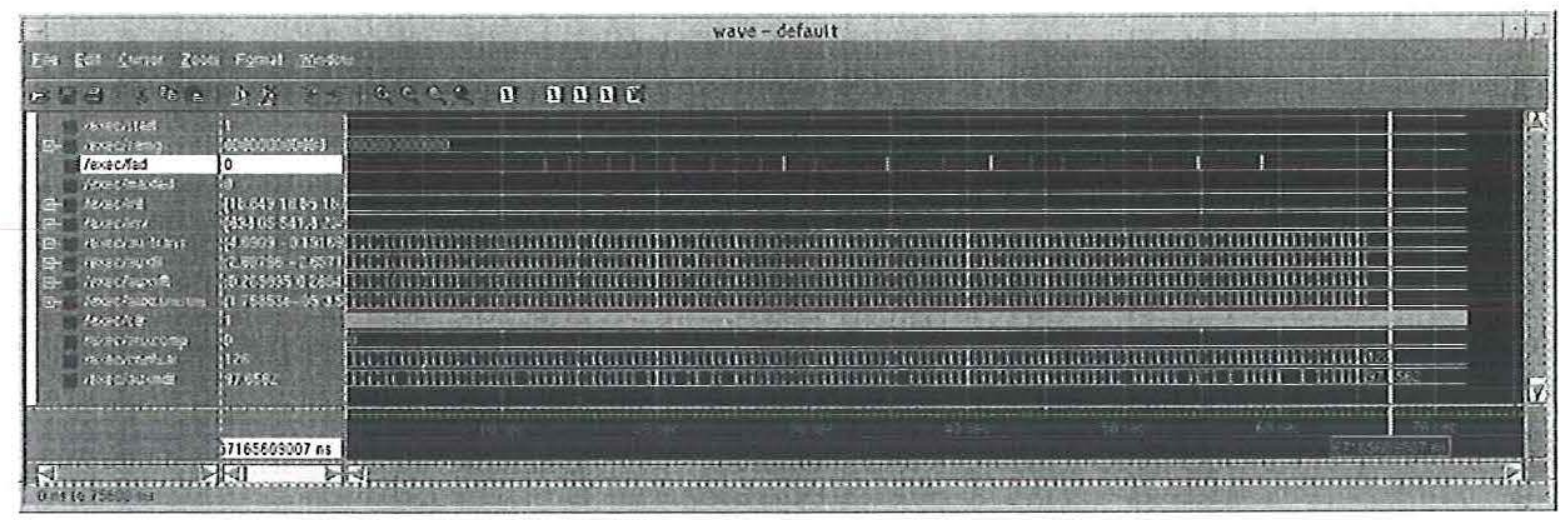

Figure 5.8: Formas do onda obtida da simulação com sinal de EMG de músculo normal

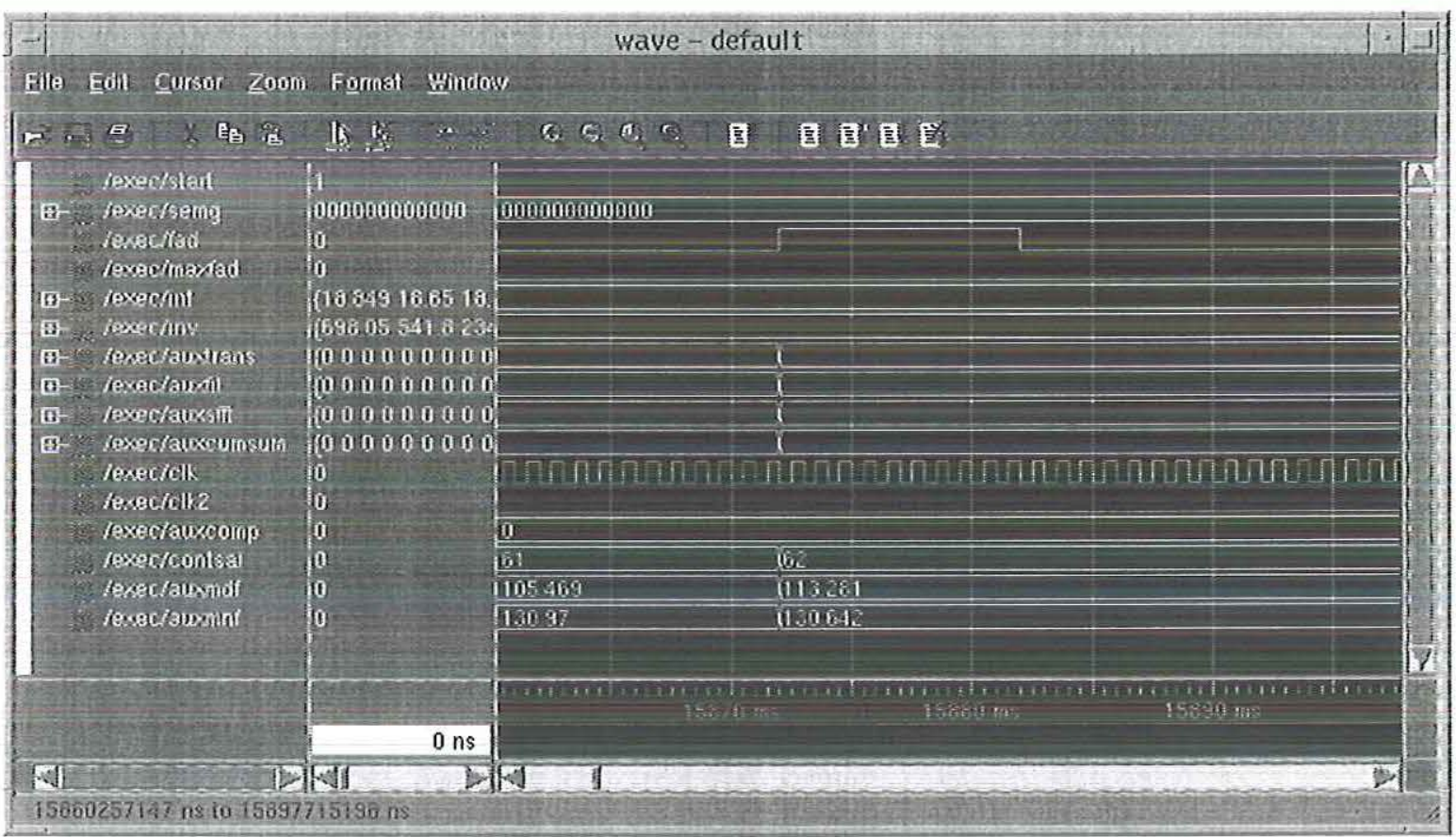

Figure 5.9: Detalhe do gráfico da Figura 5.8

Observando o sinal "fad" temos uma seqüência de pulsos que permitirão implementar um circuito para informar o usuário sobre o progresso de seu esgotamento muscular, ou seja, implementar um circuito que transforme o pulso elétrico "fad" em outro tipo de energia: luminosa, sonora, etc. 
Nesse caso, o sinal do voluntário não chega a atingir o nível considerado de esgotamento máximo, logo "maxfad" permanece em nível lógico zero. Se o exercício tivesse perdurado por mais alguns instantes, talvez teríamos na Figura 5.7, o nível necessário para que o comparador digital avaliasse a musculatura com maximamente fatigada.

\subsection{Simulação Digital utilizando EMG de músculo paralisado}

Podemos realizar agora a simulação utilizando o sinal de EMG do músculo paralisado. O gráfico de saída do simulador MNF está apresentado na Figura 5.10.

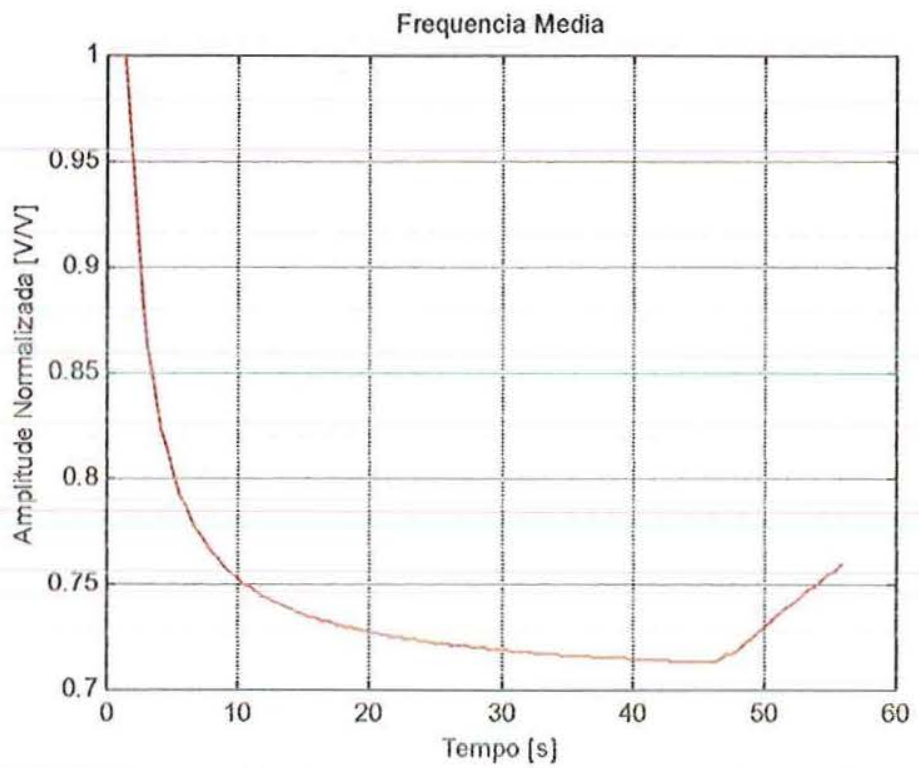

Figura 5.10: Comparaçäo entre Freqüências Média Mallab e VHDL.

$$
\text { - VHDL Matlab }
$$

No caso do músculo paralisado, devido à falta de sensibilidade na região eletroestimulada e por conseqüência maiores níveis de esgotamento foram atingidos, é esperado que o Comparador Digital identifique o Máximo Esgotamento da estrutura. 


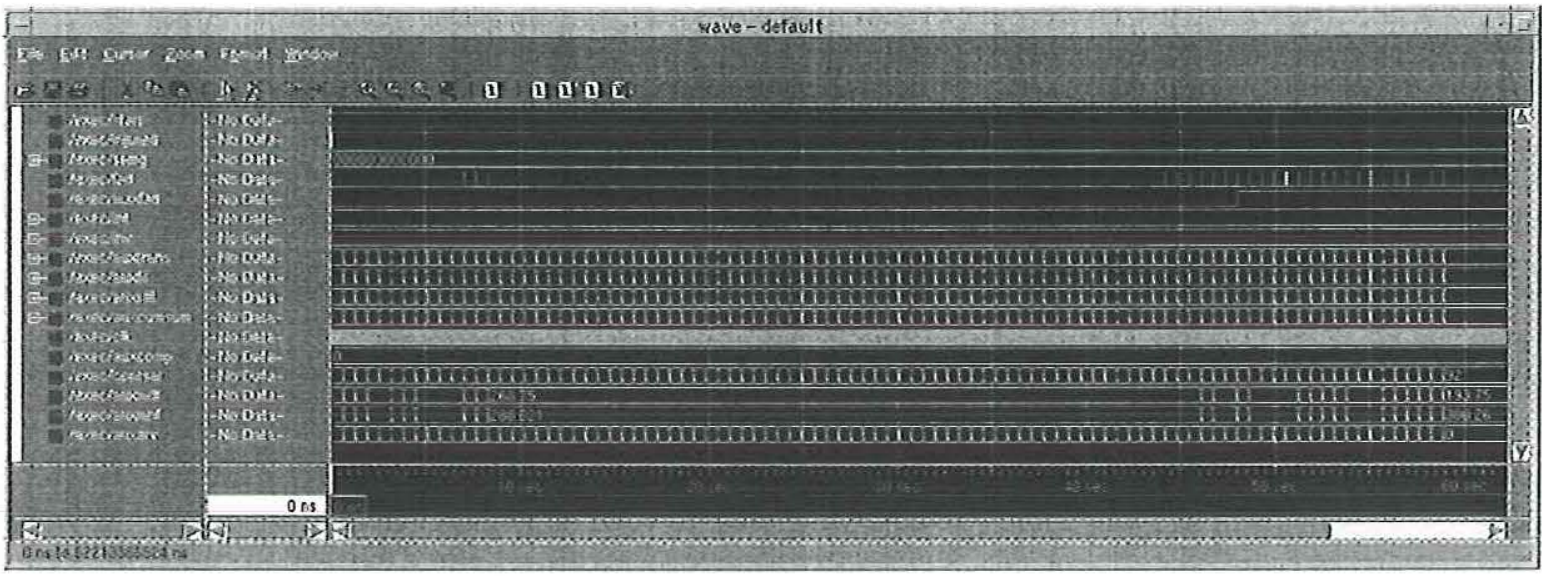

Figure 5.11: Formas de onda obtida da simulação com sinal de EMG de músculo paralisado

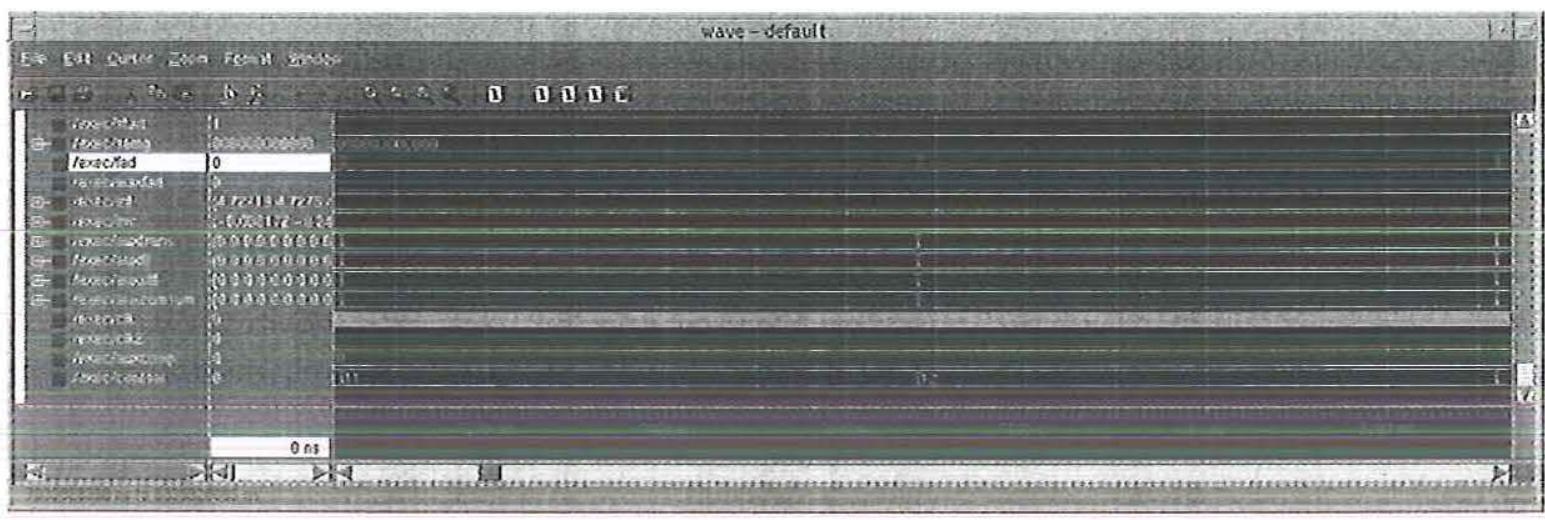

Figure 5.12: Detalhe da Figura 5.11 - sinal "fad"

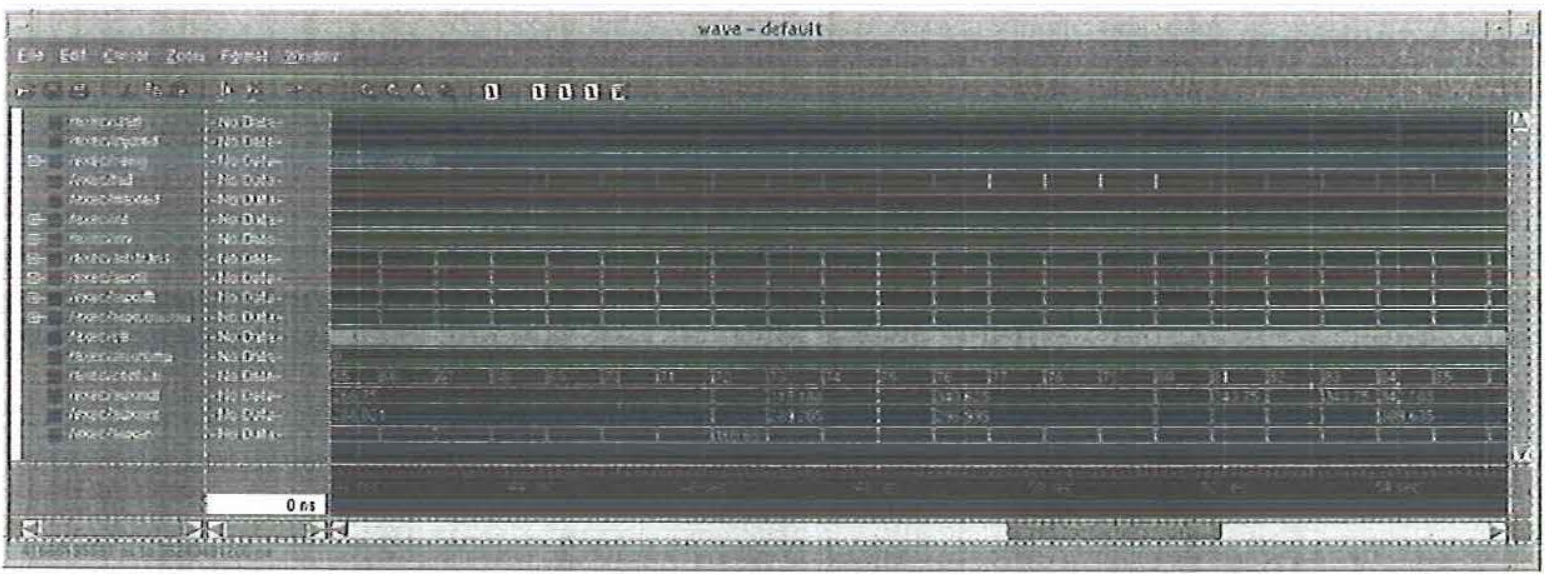

Figure 5.13: Detalhe da Figura 5.11 - sinal "fad" e "maxfad" (sinal injured em nível lógico alto)

Como resultado esperado, o usuário atinge o nível de esgotamento máximo, e o sinal de "maxfad" é levado a nível lógico "1". Nos instantes que precedem o Máximo Esgotamento, podemos perceber a influência do índice ARV no sinal de "fad". 
Tanto "fad" quanto "maxfad" podem ser utilizados pelo Atuador de forma a controlar a aplicação de estímulos elétricos, no caso de pacientes lesados medulares. Para usuários clinicamente normais, ambos sinais podem ser utilizados para monitorar a performance física do grupo muscular em exercício de força constante. 


\section{CAPítulo 6}

\subsection{Conclusões}

Dos resultados obtidos, podemos verificar a real aplicabilidade do eletromiograma de superfície para acompanhar a manifestação mioelétrica da fadiga muscular. Esta técnica possui a característica principal de ser não-invasiva, o que reduz problemas de rejeição ao material em contato com o usuário.

Os dois Índices de Contração Muscular selecionados para a implementação do Bloco de Processamento Digital, Freqüência Média do Espectro de Potência (MNF) e Valor Retificado Médio (ARV) do sinal de EMG, apresentaram características mais convenientes que os demais índices aqui analisados.

O procedimento de monitorar a MNF apresenta uma vantagem mecânica, ou seja, a possibilidade de utilizar apenas quatro eletrodos, dois de estimulação e dois de realimentação, para realizar o controle da Estimulação Elétrica Neuro-Muscular.

Em resumo, quando técnicas clássicas de estimação espectral são utilizadas, existe a necessidade de sinais estacionários, o que limita a utilização do EMG para avaliação e monitoramento da fadiga. No entanto, verificamos que assumindo condições de quasiestacionariedade, a análise da atividade elétrica muscular através de eletromiografia de superfície mantém uma precisão razoável e muito conveniente para monitorar o progresso do esgotamento muscular. 
Esta aproximação esta longe de ser um modelo realístico das atividades musculares típicas da vida diária. De maneira que, para estender a aplicabilidade clínica dos estudos sobre fadiga a novos e importantes campos tais como esportes, ergonomia, medicina de reabilitação, será necessário adotar técnicas de estimação capazes de tratar sinais nãoestacionários. Por exemplo, os parâmetros espectrais MDF e MNF aqui investigados não prevêem variações na forma do EMG em função do grupo muscular de origem, ou seja, não realiza o reconhecimento de padrões.

As considerações acima sugerem a necessidade de novas investigações da aplicabilidade da análise de EMG de superfície sobre condições estáticas para comprovar a repetibilidade do comportamento dos ICM apresentados, e dinâmica para identificar a relação com o estudo ora apresentado. 


\section{BIBLIOGRAFIA}

[Air94] Airiau, R.; Bergé, J.M.; Olive, V.; Circuit Synthesis with VHDL; 1994;

[Arm89] Armstrong, J.R.; Chip-Level Modeling with VHDL; Englewood Cliffs: PrenticeHall, Prentice Hall Series in Computer Engineering; 1989;

[Bas85] Basmajian JV, De Luca CJ; Muscles Alive; Williams \& Wilkins, Baltimore MD, 1985.

[Bha95] Bhasker, Jayaram; A VHDL Primer; Prentice Hall, Upper Saddle River, 1995.

[Bri40] Brigham, E.O.; The Fast Fourier Transform and Its Applications; Englewood Cliffs: Prentice-Hall; 1940;

[Che97] Chen, Jia-Jin J; Yu, Nan-Ying; The Validity of Stimulus-Evoked EMG for Studying Muscle Fatigue Characteristics of Paraplegic Subjects During Dynamic Cycling Movement; IEEE Transactions on Rehabilitation Enginnering; Vol.5, N 2, 1997;

[Chi92] Chizeck, HJ; Kobetic, R; Marsolais, EB; Abbas, J]; Donner,HH; Simon,E; Control of Functional Neuromuscular Stimulation System for Standing and Locomotion in Paraplegics; Proc. IEEE, vol. 76, 1988.

[Chu60] Churchill, R.V.; Complex variables and aplications; Mcgraw-Hill Book; 1960;

[Coe89] Coelho, D.R.; The VHDL Handbook; Boston: Kluwer Academic; 1989;

[Cur79] Currier, D.P.; Lehman, J.; Lightfoot, P.; Electrical Stimulation in Exercise of the Quadriceps Femoris Muscle; Physical Therapy; v.59, n.12, p.1508-1512, 1979;

[Cur83] Currier, D.P; Mann, R.; Muscular Strengh Developmente by electrical Stimulation in Health Individual; Physical Therapy; v.63, p.915-921, 1983; 
[Erf96] Erfanian, A; Chizeck, HJ; Hashemi, RM; Excitation-Contraction Fatigue During Sustained Electrical Stimulation of Paralyzed Muscle; $18^{\text {th }}$ Annual International Conference of the IEEE Engineering In Medicine and Biology Society; 1996.

[Far00] Farina, Dario; Fortunato, Elena; Merletti, Roberto; Noninvasive Estimation of Motor Unit Conduction Velocity Distribution Using Linear Elecrode Arrays; IEEE Transactions on Biomedical Engineering, vol.47, no.3, 2000;

[Fer99] Ferreira, F.A.; Pereira, J.C., Sistemas Digitais em VHDL para Tecnologias FPGA e ASIC: Relatório FAPESP; LIM/SEL/EESC/USP; 1999;

[Fra95] Franken, HM; Veltink, PH; Tijsmans, R; Nijmeijer H; Boom, HBK; Identification of Quadríceps-shank Dynamics using randomized interpulse interval stimulation; IEEE Trans. Rehab. Eng; vol. 3, 1995.

[Hal80] Halback, J.W.; Straus, D.; Comparison of Electro-myo Stimulation to Isokinetic Training in Increasing Power of the Knee Extensor Mechanism; Journal of Orthopaedic and Sports Physical Therapy; v.2, p.20-24, 1980;

[Kha89-1] Khang, G; Zajac, FE; Paraplegic Standing Controlled by Functional Electrical Stimulation, part I: Computer Model and Control-System Design; IEEE Trans. Biomed. Eng; vol. 36, 1989.

[Kha89-2] Khang, G; Zajac, FE; Paraplegic Standing Controlled by Functional Electrical Stimulation, part II: Computer Simulation Studies; IEEE Trans. Biomed. Eng; vol. 36, 1989.

[Kob94] Kobetic, R; Marsolais, B; Synthesis of Paraplegic Gait with Multichannel Functional Neuromuscular Stimulation; IEEE Trans. Rehab. Eng., vol 2, 1994.

[Kub87] Kubiak,R..J.; Whitman, B.S.; Johnston, R.M.; Changes in Quadriceps Femoris Muscle Strength using Iisometric Exercise Vrsus Electrical Stimulation; Journal of Orthopaedic and Sports Physical Therapy; v.8, n.11, p.537-541, 1987; 
[Lip89] Lipsett, R.; Schaefer, C.F.; Ussery, C.; VHDL: Hardware Description and Design; Boston: Kluwer Academic; 1989;

[Men98] Manuais Internos Mentor Graphics (Bold Browser):

[Mer89] Merletti, R; Balestra, G; Knaflitz, M; Effect of FFT Based Algorithms on Estimation of Myoelectric Signal Spectral Parameters; IEEE eng. In Medicine \& Biology Society $11^{\text {th }}$ Annual Intern. Conference; 1989.

[Mer99-1] Merletti, Roberto; Lo Conte, Loredana; Avignone Elena; Guglielminotti Piero; Modeling the Surface Myoelectric Signals, Part I: Model Implementation;

[Mer99-2] Merletti, Roberto; Lo Conte, Loredana; Avignone Elena; Guglielminotti Piero; Modeling the Surface Myoelectric Signals, Part II: Model-Based Signal Interpretation;

[Nat85] Nathan, A.; Andor, L.; Baltes, H.P.; Schmidt-Weinmar, H.G.; Modeling of a Dual-Drain NMOS Magnetic-Field Sensor; IEEE Journal of Solid-State Circuits; v.20, n.3, Junho, 1985;

[Opp37] Oppenheim, A.V., Schafer, R.W.; Digital Signal Processing; Englewood Cliffs: Prentice-Hall; 1937;

[Pei96] Peixoto, B.O.; Cliquet Jr, A.; Redução da Fadiga Muscular através da Estimulação Elétrica Neuromuscular em Paciente Portadores de Lesão Medular; Revista Brasileira de Engenharia, Caderno de Engenharia Biomédica; v.12, n.2, Jul/Dez, p.21-46, 1996;

[Pop99] Popovic, Dejan; Stein, Richard B; Oguztoreli, M Namik; Lebiedowska, Maria; Jonic, Slavica; Optimal Control of Walking with Funcional Electrical Stimulation: A Computer Simulation Study; IEEE Trans. Rehab. Eng, Vol. 7, № 1, March 1999

[Sel85] Selkowitz, D.M.; Improvement in Isometric Strength of Quadriceps Femoris Muscle after Training with Electrical Stimulation; Physical Therapy; v.65, n.2, p.186-196, 1985; 
[Sen97] Sennels, Soren; Biering-Sorensen, Fin; Andersen, Ole Trien; Hansen, Steffen Duus; Functional Neuromuscular Stimulation Controlled by Surface Electromyographic Signals Produced by Volitional Activation of the Muscle Response from the Recorded EMG Signal; IEEE Trans. Reh. Engineering, vol.5, no.2, 1997;

[Spi98] Spinelli, E; Felice, CJ; Mayosky, M; Politti, JC; Valentinuzzi, ME; A Correlation Technique for Muscle Fibre Action Potential Conduction Velocity Measurement Using a Single Acquisition Channel; 20th Annual Intern. Confer. IEEE Eng. In Medicine and Biology Society; vol. 20, $\mathrm{n}^{\circ}$ 5, 1998.

[Stu81] Stulen F, De Luca CJ: Frequency Parameters of the Myoelectric Signal as a Measure of the Muscle Conductions Velocity; IEEE Trans. on Biomed. Eng. BME-28:512-523,1981.

[Yam90] Yamaguchi, GT; Zajac, FE; Restoring Unassisted Natural Gait to Paraplegics via Funciotnal Neuromuscular Stimulation: A Computer Simulation Study; IEEE Trans. Biomed. Eng.; Vol. 37, 1990.

[Win90] Winter, D.A.; Biomechanics and Motor Control of Human Movement; WileyInterscience; 277p, 1990;

Nota: Figura da folha Dedicatória extraida do artigo [Yam90], gentilmente cedida pelo autor. 


\section{ANEXO A: ROTINAS MLATLABB}

As rotinas abaixo foram testadas com o software matemático MathWorks Matlab 6.0.0.88 (R12)

A forma de execução está descrita no item 5.3.1.

\section{A.1. Matlab: tee.m}

\author{
\%\%\%\%\%\%\%\%\%\%\%\%\%\%\%\%\%\%\%\%\%\%\%\%\%\%\% \\ $\% \% \%$ \\ $\% \% \%$ Autor: Fabio Alves Ferreira \\ $\% \% \%$ Criado em 10/Jan/1999 \\ $\% \% \%$ Ultima Edicao 13/Nov/2003 \\ $\% \% \%$ \\ $\% \% \%$ Matlab 6.0.0.88 (Release 12) - \\ $\% \% \%$ September 22th, 2000 \\ $\% \% \%$ \\ $\% \% \% \% \% \% \% \% \% \% \% \% \% \% \% \% \% \% \% \% \% \% \% \% \% \% \%$
}

$\% \%$ Leitura do Sinal de sEMG

clear, graficos, config
iir_pb,B3,A3,iir_pbanda,Aconv,Bconv);

emgvec $(:, i+1)=$ emg;

emgorig $(:, i+1)=\operatorname{emgv}(i * \operatorname{len}+1:(i+1) * \operatorname{len})$;

[fimedx(i+1),

medfreq(emg,fs,med,len);

$\operatorname{tmedx}(\mathrm{i}+1)=(\mathrm{i}+1)^{*} \operatorname{tmedx}(1)$;

frms $(i+1)=r m s(e m g)$;

$\operatorname{farv}(\mathrm{i}+1)=\operatorname{arv}(\mathrm{emg})$;

disp('Iteração No. '),disp(i)

end

\%\% Cálculo da Frequência Média

for $\mathrm{j}=1$ :epoch

fmean $x(j)=\operatorname{sum}(\operatorname{fmed} x(1: j)) / j$;

end

emg=

iir(emgv(1:len), iir_rf,B,A,iir_pa,B2,A2,iir_pb,B3,A3,

iir_pbanda, Aconv, Bconv):

figure(2), elf, $[\mathrm{fmedx}(1)$, myarea $(:, 1), \operatorname{Pxx\times }(:, 1)]=$ medfreq(emg,fs, med,len); tmedx(1)=len $/ \mathrm{fs}$;

$\operatorname{frms}(1)=\operatorname{rms}(\operatorname{emg}(1: \operatorname{len}))$

$\operatorname{farv}(1)=\operatorname{arv}(\operatorname{emg}(1:$ len $))$;

disp('Iteração No. '), disp(1)

emgvec $(:, 1)=\mathrm{emg}$

emgorig $(:, i+1)=\operatorname{emgv}(1:$ len $)$

$\% \% \%$ Ciclo Completo de Contração

for $\mathrm{i}=1$ :epoch -1 ,

emg=

iir(emgv(i*len+1:(i+1)*len), iir_rf,B,A,iir_pa,B2,A2,

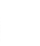

$\% \%$ Normalização em relação ao valor no inicio da contração

$\mathrm{ref}=\mathrm{fims}(1)$;

fimsplot $=$ frms/ref;

$\mathrm{ref}=\operatorname{farv}(1)$

farvplot $=$ farv/ref;

[refmed,irefmed] $=\max (f \operatorname{med} x)$

[refmean,irefmean $]=\max ($ fmean $x)$

for $m=1$ :epoch,

fmedx $(\mathrm{m})=\operatorname{fmedx}(\mathrm{m}) /$ refmed;

fmeanx $(m)=$ fmeanx $(m) / r e f m e a n ;$

end 
$\% \%$ Gráficos

figure(1), clf

plot(emgt,emgv)

ylabel('Amplitude Normalizada')

xlabel('Tempo [s]')

title('Sinal sEMG')

grid

figure(3), clf

plot(tmedx,frmsplot, 'b'), hold on

plot(tmedx,farvplot,'g')

plot(tmedx,fmedx, 'r')

plot(tmedx,fmeanx, $\left.\mathrm{k}^{\prime}\right)$

ylabel('V $[\mathrm{V} / \mathrm{V}]$ ')

xlabel('t [s]')

grid

figure(2), clf

plot(tmedx,fmedx, 'r'), hold on

plot(tmedx,fmeanx, $\left.\mathrm{k}^{\prime}\right)$

ylabel('V [V/V]')

xlabel('t [s]')

grid

pause

figure(2), clf

$[\mathrm{a}, \mathrm{b}]=\operatorname{size}(\mathrm{Pxxx})$;

$\mathrm{x}=[1: \mathrm{b}]$;

$\mathrm{y}=[1: \mathrm{a}]$;

waterfall $\left(y, x, P_{x x x}\right) ; \%$ or $\operatorname{mesh}\left(y, x, P_{x x x}\right)^{\prime}$;

xlabel('f $\left.[\mathrm{Hz}]^{\prime}\right)$

ylabel(Trechos de EMG')

zlabel('Modulo')

figure(3), clf

contour $(\mathrm{y}, \mathrm{x}, \mathrm{Pxxx}, 16)$, colorbar;

xlabel(' $\left.f(\mathrm{~Hz}]^{\prime}\right)$

ylabel('Trechos de EMG')

\section{A.2. Matlab: config.m}

$\% \% \% \% \% \% \% \% \% \% \% \% \% \% \% \% \% \% \% \% \% \% \% \% \% \% \% \% \% \%$

$\% \% \%$ EMG Normal

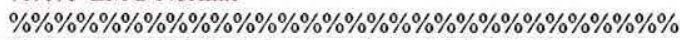

$\%$ A variavel 'fullsize' eh o tamanho total do $\mathrm{sEMG}$

$\%$ A variavel 'len' eh o tamanho de cada trecho do sEMG

load('.. Isignallemg_normal.dat','r'); emgin = emg_normal; $\mathrm{fs}=1000 ;$ fullsize $=2^{\wedge} 16$;

len $=2^{\wedge} 9 ;$ temg $=(1.885 \mathrm{E} 4: 1.885 \mathrm{E} 4+$ fullsize -1$)$;

$\% \% \% \% \% \% \% \% \% \% \% \% \% \% \% \% \% \% \% \% \% \% \% \% \% \% \% \% \% \%$ $\% \%$ EMG de Voluntario Lesado Medular

$\% \% \% \% \% \% \% \% \% \% \% \% \% \% \% \% \% \% \% \% \% \% \% \% \% \% \% \%$

$\%$ load('..lsignallemg_lesado.dat','r'); emgin = emg_lesado; fs $=3200$; fullsize $=2^{\wedge} 18$; len $=2^{\wedge} 11$; temg $=(132: 132+$ fullsize -

1);
$\% \% \% \% \% \% \% \% \% \% \% \% \%$

$\%$ Leitura $\%$

$\% \% \% \% \% \% \% \% \% \% \% \%$

$\% \% \%$ Vetor de sEMG: tempo

emgt = emgin(:,1);

$\% \% \%$ Vetor de sEMG: Amplitude

emgv = emgin $(: 2)$;

emgvn = emgin(:,2)/max (abs(emgin(:,2)));

figure(1), clf

plot(emgt,emgvn):

xlabel('t [s]')

ylabel('V [V/V]')

grid

hold on

$\%$ Selecao de parte do sinal para analise: variavel temg do arquivo config.m

emgv = emgv(temg);

emgvn = emgvn(temg); \% somente para plot

emgt = emgt(temg);

plot(emgt,emgvn,'r')

hold off

pause
\%\%\%\%\%\%\%\%\%\%\%\%\%\%\%\%\%\%\%\%\%\%\%\%\%\%\%\%\%\%\%

$\% \% \% \%$ Dados comuns para qualquer sinal de entrada $\% \% \% \% \% \% \% \% \% \% \% \% \% \% \% \% \% \% \% \% \% \% \% \% \% \% \% \% \% \%$

$\%$ pontos para calculo da funcal fo freqz: default $=1024$ pontos

ptos $=1024$;

$\%$ Quantidade de pontos para ajustar o Power Spectrum Density

$\%$ O PSD sera aproximado para uma m\%sedia calculada a cada 'med' pontos

$\operatorname{med}=1$;

$\% \% \% \% \% \% \% \% \% \% \% \% \% \% \% \% \% \% \% \% \% \% \% \% \% \% \% \% \% \%$

$\%$ O sinal sera dividido em partes de 'len' pontos $\% \% \% \% \% \% \% \% \% \% \% \% \% \% \% \% \% \% \% \% \% \% \% \% \% \% \% \% \% \%$ epoch $=$ length $($ emgt $) /$ len

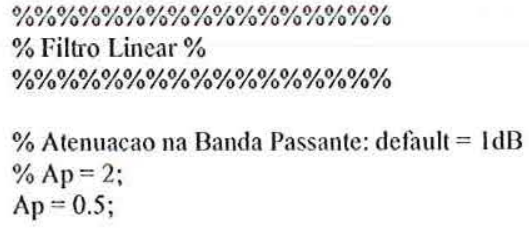

$\%$ Atenuacao na Banda Passante: default $=I \mathrm{~dB}$

$\% \mathrm{Ap}=2$;

$\mathrm{Ap}=0.5$;

$\%$ Atenuacao na Banda de Corte: default $=20 \mathrm{~dB}$ As $=30$; 
$\% \% \% \% \% \% \% \% \% \% \% \% \% \% \% \% \% \% \% \% \% \% \% \% \% \% \% \% \% \%$

$\%$ Arquivo para salvar dados dos filtros $\%$

\%\%\%\%\%\%\%\%\%\%\%\%\%\%\%\%\%\%\%\%\%\%\%\%\%\%\%\%\%\%

per $=$ fopen('./iir.dat','w');

fprintf(per, ${ }^{\circ} \% \operatorname{sln} \% 1.16$ fln $\backslash n$ ','PI:',pi);

$\% \% \% \% \% \% \% \% \% \% \% \% \% \% \% \% \% \% \% \% \% \% \% \% \% \% \% \% \% \%$

$\%$ Filtro RF: Chebyshev tipo $1 \%$

\%\%\%\%\%\%\%\%\%\%\%\%\%\%\%\%\%\%\%\%\%\%\%\%\%\%\%\%\%\%

$\%$ Banda de Corte

frfs $=\left[\begin{array}{ll}59 & 61\end{array}\right]$

$\%$ Banda de Atenuacao Maxima

frfp $=\left[\begin{array}{ll}55 & 65\end{array}\right]$;

$\%$ iir_rf $=0:$ filtro desativado

$\%$ iir_rf $=1$ : filtro ativado

iir_ $\mathrm{r} f=1$;

if (iir_ff==1),

$\mathrm{Wp}=2 * \mathrm{frfp} / \mathrm{fs}$;

$\mathrm{Ws}=2 * \mathrm{fr} \mathrm{fs} / \mathrm{fs}$ :

$\%[\mathrm{~N}, \mathrm{Wn}]=$ buttord $(\mathrm{Wp}, \mathrm{Ws}, \mathrm{Ap}, \mathrm{As})$

$\%[\mathrm{~B}, \mathrm{~A}]=\operatorname{butter}\left(\mathrm{N}, \mathrm{Wn}\right.$, 'stop' $\left.^{\prime}\right)$;

$[\mathrm{N}, \mathrm{Wn}]=$ cheblord $(\mathrm{Wp}, \mathrm{Ws}, \mathrm{Ap}, \mathrm{As})$

$[\mathrm{B}, \mathrm{A}]=\operatorname{cheby} 1\left(\mathrm{~N}, \mathrm{Ap}, \mathrm{Wn}, \mathrm{stop}^{\prime}\right)$;

figure(2), cif

fregz (B, A,ptos, fs);

$\% \operatorname{axis}\left(\left[\begin{array}{lllll}0 & 120 & -120 & 10\end{array}\right]\right)$

$\% \operatorname{axis}\left(\left[\begin{array}{lllll}0 & 120 & -400 & 10\end{array}\right]\right)$

title('Rejeita-Faixa: Chebyshev tipo 1')

figure(3), clf

zplane $(\mathrm{B}, \mathrm{A})$;

fprintf(per, $\%$ sin','Filtro Rejeita Faixa');

fprintf(per, \%1.16f, ',B)

fprintf(per,' $\left.1 n^{\prime}\right)$;

fprintf(per, $\left.\% 1.16 f,{ }^{\prime, A}\right)$;

pause

end

$\% \% \% \% \% \% \% \% \% \% \% \% \% \% \% \% \% \% \% \% \% \% \% \% \% \% \% \% \%$

$\%$ Filtro PBANDA (Convolucao): ordem $7 \%$

$\% \% \% \% \% \% \% \% \% \% \% \% \% \% \% \% \% \% \% \% \% \% \% \% \% \% \% \% \% \%$

$\%$ iir pbanda $=0:$ filtro desativado

$\%$ iir_pbanda $=1:$ filtro ativado

iir pbanda $=1$;

if (iir_pbanda $==1$ ),

$\mathrm{Wp}_{\mathrm{p}}=2 * \mathrm{fpap} / \mathrm{fs}$;

$\mathrm{Ws}=2 * \mathrm{fpas} / \mathrm{fs}$;

$[\mathrm{N}, \mathrm{Wn}]=$ cheblord $(\mathrm{Wp}, \mathrm{Ws}, \mathrm{Ap}, \mathrm{As})$;

$[\mathrm{B} 2, \mathrm{~A} 2]=\operatorname{chebyl}\left(\mathrm{N}, \mathrm{Ap}, \mathrm{Wn}, \mathrm{high}^{\prime}\right)$

$\mathrm{Wp}=2 * \mathrm{fpbp} / \mathrm{fs}$;

$\mathrm{Ws}=2 * \mathrm{fpbs} / \mathrm{fs}$;
$[\mathrm{N}, \mathrm{Wn}]=$ cheblord $(\mathrm{Wp}, \mathrm{Ws}, \mathrm{Ap}, \mathrm{As})$;

$[\mathrm{B} 3, \mathrm{~A} 3]=\operatorname{chebyl}(\mathrm{N}, \mathrm{Ap}, \mathrm{Wn})$;

Bconv $=\operatorname{conv}(\mathrm{B} 2, \mathrm{~B} 3)$;

Aconv $=\operatorname{conv}(\mathrm{A} 2, \mathrm{~A} 3)$;

figure(2), clf

freqz(Bconv,Aconv,ptos,fs)

title('Passa-Faixa: Convolucao');

figure(3), clf

zplane(Bconv,Aconv);

title('Passa-Faixa: Convolucao')

fprintf(per,' 'nln\%sln','Filtro Passa Banda');

fprintf(per, $\% 1.16 f$, ',Bconv);

fprintf(per,' $(n ')$;

fprintf(per, '\%1.16f, ',Aconv);

pause

end;

$\% \% \% \% \% \% \% \% \% \% \% \% \% \% \% \% \% \% \% \% \% \% \% \% \% \% \% \% \% \%$

$\% \% \%$ Fechando o arquivo com dados dos filtros $\% \% \%$

\%\%\%\%\%\%\%\%\%\%\%\%\%\%\%\%\%\%\%\%\%\%\%\%\%\%\%\%\%\%\%

fclose(per);

\section{A.3. Matlab: iir.m}

function $y=\operatorname{iir}(x$, iir If, $\mathrm{B}, \mathrm{A}$, iir_pbanda,Aconv,Bconv)

yaux $=x$

$\% \% \% \% \% \% \% \% \% \% \% \% \% \% \% \% \% \% \% \% \% \% \% \% \% \% \% \% \% \%$

$\%$ Filtro Rejeita-Faixa: Chebyshev tipo I

$\% \% \% \% \% \% \% \% \% \% \% \% \% \% \% \% \% \% \% \% \% \% \% \% \% \% \% \% \% \%$

if (iir $\mathrm{rf}=1$ ),

yaux $=$ filter $(B, A$, yaux $)$;

end

$\% \% \% \% \% \% \% \% \% \% \% \% \% \% \% \% \% \% \% \% \% \% \% \% \% \% \% \% \% \%$

$\%$ Teste FILTRO PASSA BANDA - convoluca

$\% \% \% \% \% \% \% \% \% \% \% \% \% \% \% \% \% \% \% \% \% \% \% \% \% \% \% \% \% \%$

if (iir_pbanda $==1$ ),

yaux $=$ filter $($ Bconv, Aconv,yaux $)$;

end;

$y=$ yaux; 


\section{A.4. Matlab: rms.m}

function $y=\operatorname{rms}(x)$;

$\mathrm{y}=\mathrm{x} \cdot{ }^{\wedge} 2$;

$\mathrm{y}=\operatorname{mean}(\mathrm{y})$;

$y=\operatorname{sqrt}(y)$;
$\%$ calculada a cada 'med' pontos

\% 'med': parâmetro fornecido no arquivo config.m

medi $=1$;

meds $=$ med;

aux $=0$;

while meds<length(Pxx),

for $\mathrm{i}=$ medi:meds

aux = aux + Pxx(i);

end

aux = aux/med;

for $\mathrm{i}=$ medi:meds

$\operatorname{Pxx}(\mathrm{i})=\mathrm{aux}$;

end

aux $=0$;

meds $=$ meds + med;

medi $=$ medi + med

end

function $y=\operatorname{arv}(x)$

$\mathrm{y}=\operatorname{abs}(\mathrm{x})$;

$\mathrm{y}=\operatorname{mean}(\mathrm{y})$

$\%$ PLOT

figure(2), clf

$\operatorname{plot}\left(\mathrm{fx}, \mathrm{Pxx}, \mathrm{r}^{\prime}\right)$

grid on

area $=$ cumsum $(\operatorname{Pxx}, 1)$;

$\%$ length(area);disp('my area'); break

\section{A.6. Matlab: medfreq.m}

\% normalização

area $=\operatorname{are} / \max (\operatorname{abs}($ area $))$

function [fmed, area,Pxx, $\mathrm{fx}]=$ medfreq( $\mathrm{A}, \mathrm{fs}$, med,len $)$;

$\%$ Zero padding for FFT

Apow2 $=2^{\wedge}($ nextpow $2(A))$

$A=\{A ; z e r o s(A p o w 2-\operatorname{lenghih}(A), i)\}$

$\%$ npt: número de pontos da janela de Hanning (default) para o

$\%$ cálculo do PSD

$\mathrm{npt}=$ length $(\mathrm{A})$;

$\%$ Amostragem

$\mathrm{ts}=1 / \mathrm{fs}$;

$t=[0: t s:($ length $(A)-1) / f s]$;

$\%$ Numero de pontos da FFT

$\mathrm{N}=$ length $(t)$

$\mathrm{Nfft}=2^{\wedge}($ nextpow $2(\mathrm{~N}))$;

$\%$ Power Spectrum

$\mathrm{A}=\mathrm{A} .{ }^{*}$ hanning(npt)

Afn_cplx $=\mathrm{ff}(\mathrm{A}, \mathrm{NfI})$;

$\mathrm{Aff}=\operatorname{abs}($ Aft_cplx $) \wedge^{\wedge} 2 ;$

$\mathrm{Px}=2 * \mathrm{Afft} /$ length $(\mathrm{A})$;

$\mathrm{f}=\mathrm{fs} *(0: \mathrm{Nfft}-1) / \mathrm{Nfft}$

sup $=$ round(length(Afft $) / 2) ;$

$\operatorname{Pxx}=\operatorname{Px}(1$ :sup $)$

$\mathrm{fx}=\mathrm{f}(\mathrm{I}$ :sup)

figure(2),clf, plot(fx,Pxx),xlabel('Modulus'), hold on

\% O Espectro de Potências foi aproximado para uma média
$\%$ retirando o 5th e 95th percentil de 'area'

for $\mathrm{k}=1$ :length(area),

if area $(k)>=0.05$, inf $=k$; break;

end

end

for $\mathrm{k}=1$ :length(area),

if $\operatorname{area}(k)>=0.95$, sup $=k$; break; end

end

areamed $=$ area(inf:sup);

\% O último elemento da Soma Cumulativa identifica a área

$\%$ total sob a curva de PSD

areatot $=$ areamed(length(areamed));

$\%$ buscamos o 50 th percentil

for $\mathrm{fm}=1$ :length(areamed),

if areamed $(\mathrm{fm})>=0.5^{*}$ areatot, break

end

end

$\%$ nesse ponto temos o ponto $(\mathrm{fm})$ que identifica 050 th

$\%$ percentil de areamed

$\%$ O 50 th percentil de 'area' é fm+inf

$\%$ A frequência que procuramos é fmed

$\%$ fmed $=0.5^{*} \mathrm{fs}^{*}(\mathrm{fm}+\mathrm{inf}) /$ length $(\mathrm{fx})$

fmed $=\mathrm{fx}(\mathrm{fm}+\mathrm{inf})$ 
As rotinas abaixo foram testadas com simulador digital Mentor Graphics ModelSim 5.4a (Model Technology ModelSim SE/EE vsim 5.4a Simulator 2000.04 Apr 21 2000). A forma de execução está descrita no item 5.3.2.

\section{B.1. VHDL: source.vhd}

$$
\cdots
$$

-- Autor: Fabio Alves Ferreira

-- Revisao 1.0 - 03/Jan/2003/Jan/03

-. Revisao 1.1 - 13/Nov/2003

-- Mentor Graphics Modeltech 5.4

-- Model Technology ModelSim SE/EE vsim 5.4a Simulator 2000.04 Apr 212000

-- Model Technology ModelSim SE/EE vcom 5.4a Compiler 2000.04 Apr 192000

library ieee;

use ieee.math_complex.all;

use work.intpack.all;

use std.textio.all;

- Declaracao dos sinais de entrada e saida

- o sinal de sEMG sera lido de arquivo extemo.

entity exec is

port( start, injured: in bit := '0',

--sEMG: in bit_vector(0 to 11);

fad: inout bit := '0';

end exec; maxfad: out bit : $=0^{\circ}$ )

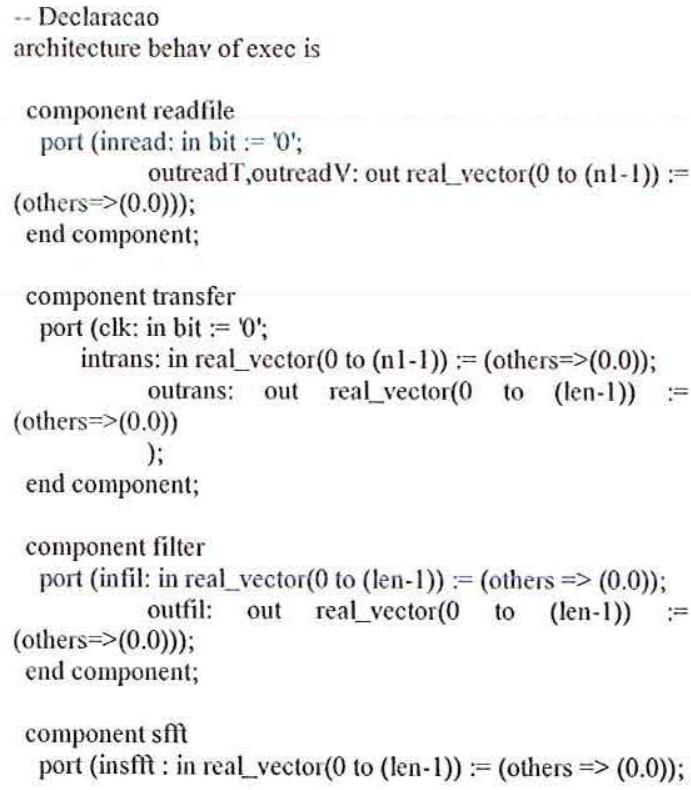


WALK: block(start='1')

begin

-- Leitura dos dados de arquivo

-. Para simulacao, substitui os terminais de entrada sEMG reading: readfile port map (start,inT,inV);

-. Particionando o sinal em trechos de $500 \mathrm{~ms}$ transfering: transfer port map (clk,inV,auxTrans);

.. BPD: Inicio

-. Filtragem Linear

filtering: filter port map (auxTrans,auxfil);

-. Tranformacao de Dominio

fastfourier: sfft port map (auxfil,auxsfft);

-. Somador Cumulativo

cumulative: cumsum port map (auxsfft,auxcumsum);

-. Frequencia Mediana

medianfrequency: medianfreq port map

(auxcumsum,contsai,auxmdf)

.. Frequencia Media

meanfrequency: meanfreq port map (auxmdf,auxmnf);

-. Valor Retificado Medio

rectifier: retsum port map (injured, auxil,auxarv);

-. Comparador Digital

comparison: compdig port map (auxmnf,auxarv,fad,maxfad);

.. BPD: Fin

- Arquivo de Saida

- writing: writefile port map (auxTrans);

-. writing: writefile port map (auxsfft)

- writing: writefile port map (auxcumsum)

writing: writefile_real port map (contsai,auxmnf);

end block WALK:

end behav; library ieee:

use ieee.math_complex.all;

use std.textio.all;

package intpack is

-. Tipos/Variaveis Genericos ..

.. Constante PI (Matlab for Windows)

constant pi: real $:=3.1415926535897931$;

constant pi2: real $:=2 * 3.1415926535897931$;

-. constant clkper: time $:=1 \mathrm{~ms} ; \quad$-- para o sinal amostrado com fa $=1000 \mathrm{~Hz}$

constant clkper: time := 312.5 us ;. para o sinal amostrado com fa $=3200 \mathrm{~Hz}$

type real_vector is array(integer range $\diamond$ ) of real;

type complex_vector is array(integer range $>$ ) of complex;

type polar_vector is array(integer range $\diamond$ ) of complex_polar; type coef_vector is array (integer range $\diamond$ ) of real;

type ord_vector is array (integer range $>$ ) of integer;

--type real matrix is array(integer range $\diamond$,integer range $\diamond$ ) of real;

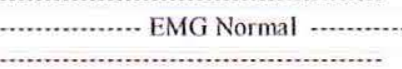

- file inpfileT: text is in "../signal/fabriciot dat";

-. file inpfileV: text is in ".Jsignal/fabricioV.dat"; .. esse arquivo eh produzido pelo Matlab

- constant fa: real $:=1000.0 ; \quad$.. Frequencia de Amostragem

- constant expn 1 : integer $:=16$;

- constant $n \mathrm{l}$ : integer $:=2 * * \operatorname{cxpnl}$

-. constant explen: integer $:=9 ; \quad \cdots 8 \mathrm{OK}$;

- constant len: integer $:=2 * *$ explen;

.. numero de

\section{GFMG de Lesado Medular}

file inpfileT: text is in "../signal/gazetaT.dat";

file inpfileV: text is in "../signal/gazetaV.dat",

constant fa: real $:=3200.0 ; \quad \ldots \quad$ Frequencia de

Amostragem

constant expn $1:$ integer $:=18$;

constant $n 1$ : integer $:=2 * *$ expnl; $\quad$.. número de

pontos escolhido

constant explen: integer $:=11 ; \quad-.9 \mathrm{OK}$

constant len: integer $:=2^{* *}$ explen;.. numero de pontos de cada trecho a ser analisado

\section{B.2. VHDL: intern.vhd}


constant ordrf: integer $:=6 ; \quad$.. ordem do filtro

signal brf: coef_vector $(0$ to ordrf $):=($-. coeficientes de numerador

0.9376148565044788

12.5403631844726100

12.5403631844726100 ,

$-5.2308697088465860$ $-16.4916237818137000$

-5.2308697088465860 , 0.9376148565044788

);

signal arf: coef_vector $(0$ to ordrf $):=(--$ coeficientes de denominador

1.0000000000000000

12.8100178270047400

12.2677027466081900 ,

0.8782355083854569

);

Filtro Passa-Banda

constant ordpbanda: integer $:=7 ;-.-$ ordem do filtro

signal bpbanda: coef_vector $(0$ to ordpbanda) $:=($-. coeficientes de numerador

$0.5929539263756156, \quad-2.9647696318780780$

$5.3365853373805390, \quad-2.9647696318780790$,

$2.9647696318780790, \quad 5.3365853373805390$,

$2.9647696318780780,0.5929539263756156$

);

signal apbanda: coef_vector $(0$ to ordpbanda $):=($.. coeficientes de denominador

1.0000000000000000 ,

$-4.1409827845592680$

$3.8194823823990180, \quad 4.9627967073054470$,

$2.3316647426243710,0.4095922153849348$

);

function norm (vecin: in real vector(l to $\mathrm{nl})$ ) return real_vector;

function nomlen (vecin: in real_vector(1 to len)) return real_vector;

function normlen2 (vecin: in real_vector(1 to len/2)) return real_vector;

end intpack;

\section{B.3. VHDL: readfile.vhd}

use std.textio.all;

use work.intpack.all;

entity readfile is

port (inread: in bit : $=0$ ';

(others $=>(0.0))$ ); outreadT,outreadV: out real_vector $(0$ to $(\mathrm{nl}-1))$ := end readfile;

architecture behav of readfile is

procedure reads (variable vetX,vetY: out real vector( 0 to $(\mathrm{nl}-1)))$ is

variable auxV,auxT: line;

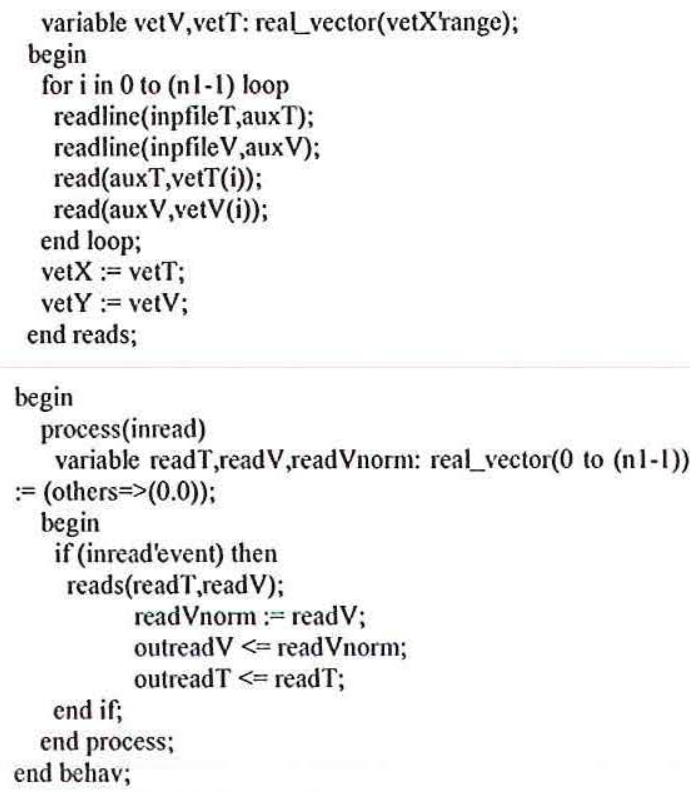

\section{B.4. VHDL: transfer.vhd}

use work.intpack.all;

entity transfer is

port (clk: in bit : $=0$ ', intrans: in real vector $(0$ to $(n 1-1)):=($ others $\Rightarrow(0.0))$; (others $=>(0.0)$ ) outrans: out real_vector(0 to (len-1)) )

end transfer:

architecture behav of transfer is

begin

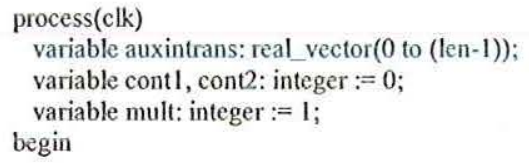

\section{B.5. VHDL: filter.vhd}

use work.intpack.all 
entity filter is

port (infil: in real_vector $(0$ to $($ len- 1$)):=($ others $=>(0.0))$

outfil: out real_vector $(0$ to $($ len- 1$)):=($ others $=>(0.0))$

end filter;

architecture behav of filter is

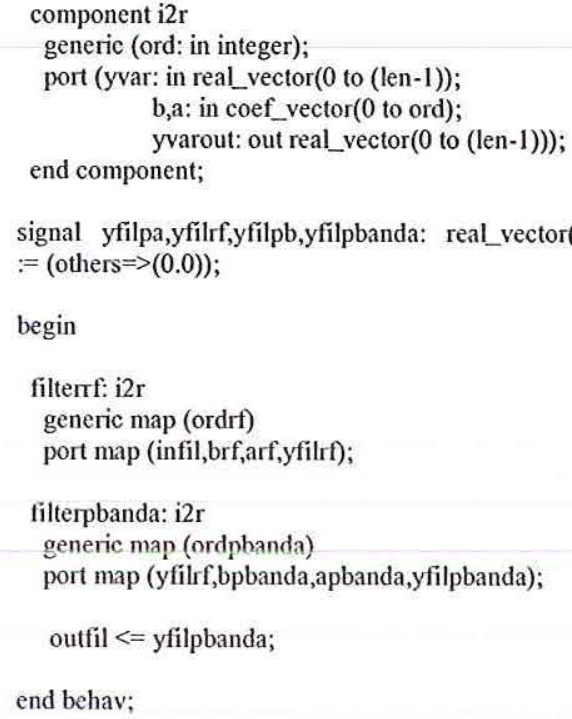

\section{B.6. VHDL: i2r.vhd}

use work.intpack.all;

\section{entity $i 2 r$ is}

generic (ord: in integer);

port (yvar: in real_vector $(0$ to (len- 1$))$; $\mathrm{b}, \mathrm{a}$ : in coef vector( 0 to ord $)$;

end $i 2 r$; yvarout: out real_vector $(0$ to (len-1)));

architecture behav of $i 2 r$ is

begin

process(yvar)

variable $\mathrm{x}, \mathrm{y}$ : real_vector(yvar'range) $:=($ others $=>0.0)$

variable $\mathrm{j}$ : integer $:=0$;

begin

$y:=($ others $=>0.0$ );

$\mathrm{x}:=\mathrm{yvar}$;

sweepl: for $\mathrm{n}$ in yvar'range loop

$$
y(n):=b(0) * x(n) ;
$$

sweep2: for $\mathrm{j}$ in 1 to ord loop

$$
\begin{aligned}
& \text { if }((n-j)>=0) \text { then } \\
& \qquad \begin{array}{l}
y(n):=y(n)+b(j)^{*} x(n-j) ; \\
y(n):=y(n)-a(j)^{*} y(n-j) ;
\end{array} \\
& \text { end if; }
\end{aligned}
$$

end loop sweep2;

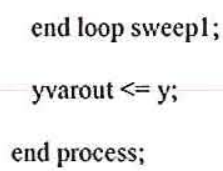

\section{B.7. VHDL: sfft.vhd}

library ieee;

use ieee.math_complex.all;

use icee.math_real.all;

use work.intpack.all;

entity sftt is

port (insfft : in real vector $(0$ to len- 1$):=($ others $=>(0.0))$;

outsff : out real_vector $(0$ to len/2-1) $=($ others $\Rightarrow(0.0))$

end sfft;

architecture behav of sfft is

procedure $\mathrm{ft}(\mathrm{x}$ : inout complex_vector(insflt'range); $\mathrm{n}, \mathrm{nu}$ : integer) is

variable $\mathrm{n} 2, \mathrm{nu} 1, \mathrm{i}, \mathrm{l}, \mathrm{k}, \mathrm{m}$ : integer;

variable treal,timag,p,arg,c,s: real;

function ibitr (constant $\mathrm{j}, \mathrm{nu}$ : in integer) return integer is variable $i, j 1, j 2, k$ : integer;

begin

ji : = j;

$\mathrm{k}:=0$;

for $\mathrm{i}$ in 1 to nu loop

$\mathrm{j} 2:=\mathrm{j} 1 / 2$;

$k:=k * 2+(j 1-2 * j 2)$

j1 := j2;

end loop;

return $k$;

end ibitr;

begin

$\mathrm{n} 2:=\mathrm{n} / 2$;

$\mathrm{nul}:=\mathrm{nu}-\mathrm{l}$

$\mathrm{k}:=0$;

chave: for 1 in 1 to nu loop

lbll: while $\mathrm{k}<\mathrm{n}$ loop

IbL: for $\mathrm{i}$ in 1 to $\mathrm{n} 2$ loop

$:=$

...> integer division

integer(round( integer division

$\begin{aligned} & p:=\operatorname{real}(i b i t r(m, n u)) ; \\ & \text { point } \\ & \arg :=p i 2^{*}(p / r e a l(n)) ; \\ & c:=\cos (\arg ) ; \\ & s:=\sin (\arg ) ;\end{aligned}$

if $((k+n 2)>$ len- 1$)$ then 


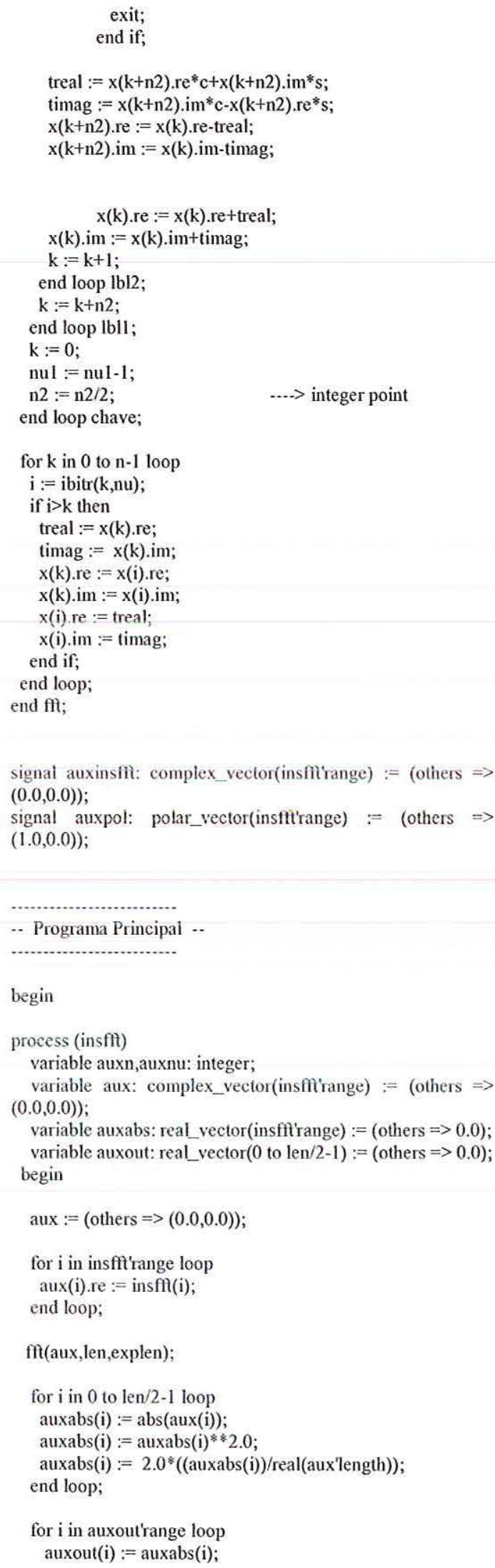

\section{B.8. VHDL: cumsum.vhd}

library ieee:

use ieee.math_complex.all;

use ieee.math_real.all;

use work.intpack.all;

entity cumsum is

port( insum : in real_vector $(0$ to $($ len/2-1) $):=($ others $=>0.0)$; outsum : out real_vector $(0$ to $($ len $/ 2-1)):=($ others $=>0.0)$ );

end cumsum;

architecture behavior of cumsum is

begin -- programa principal

process (insum)

variable areamod,areatot: real;

variable area: real_vector(insum'range) $:=($ others $\Rightarrow 0.0)$;

begin

$\operatorname{area}(0):=$ insum $(0)$;

for $\mathrm{m}$ in 1 to (insum'right) loop

$\operatorname{area}(\mathrm{m}):=\operatorname{insum}(\mathrm{m})+\operatorname{area}(\mathrm{m}-1)$; end loop;

area $:=$ normlen2(area);

outsum $<=$ area;

end process; end behavior;

\section{B.9. VHDL: medianfreq.vhd}

library ieee;

use ieee.math_complex.all;

use ieee.math_real.all;

use work.intpack.all;

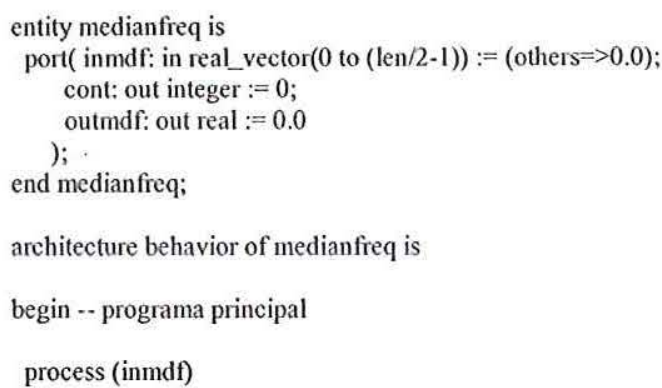




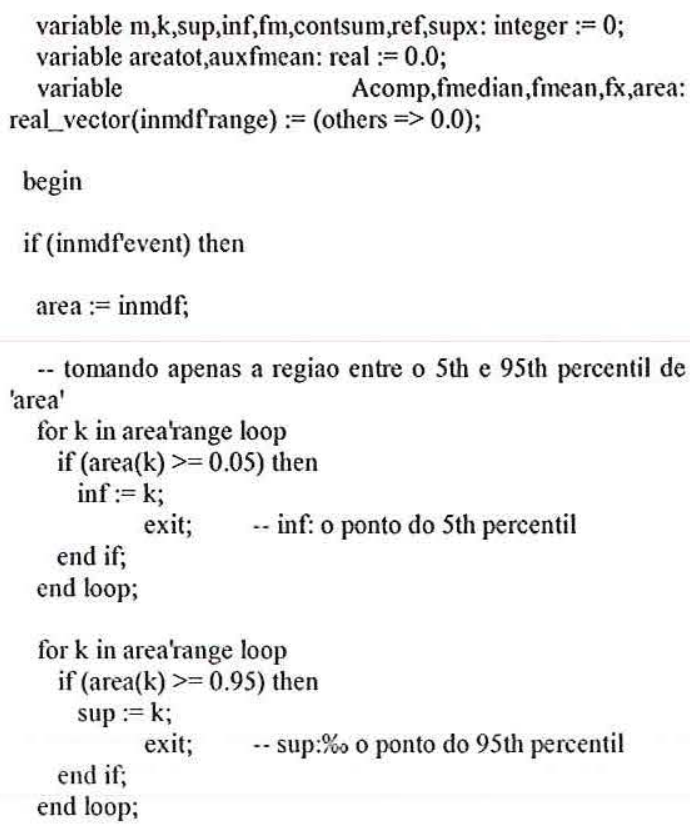

-- O ultimo elemento da Soma Cumulativa identifica a area total sob a curva de PSD

\section{B.10. VHDL: meanfreq.vhd}

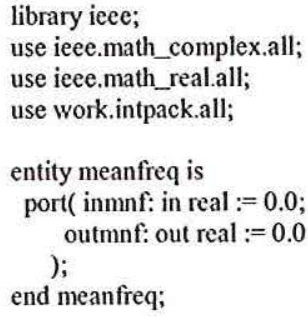

\section{B.11. VHDL: arv.vhd}

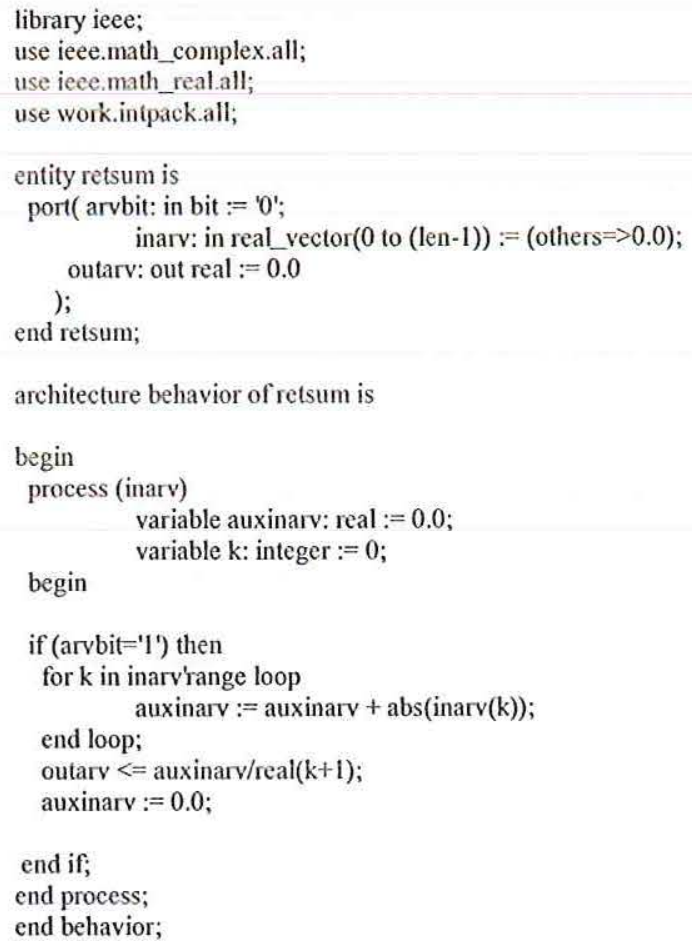

end if;

end process;

end behavior; 


\section{B.12. VHDL: digcomp.vhd}

\section{library ieee;}

use ieee.math_complex.all;

use ieee.math_real.all;

use work.intpack.all;

entity compdig is

port (incmp_mnf,incmp_arv: in real : $=0.0$;

fatigue: inout bit := '0';

maxfatigue: out bit : $=0^{\prime}$ )

end compdig;

architecture behavior of compdig is

begin

fadiga: process (incmp_mnf,incmp_arv)

variable step_mnf,step_arv: real $:=0.9$;

variable cmpref_mnf,comp_mnf,cmpref_arv,comp_arv :real

$:=-3.0 \mathrm{e} 30$;

begin
-. Analise para detecao de Maxima Fadiga ..

maxfadiga: process (fatigue,incmp_mnf)

variable ref: integer $:=0$;

variable maxfadref : real $:=3.0 \mathrm{e} 30$;

begin

-- verifica se ocorreu o primeiro "fad"

if (fatigue'event and ref $=0$ ) then

ref $:=1$

else

if (incmp_mnfevent and ref $=1$ and

maxfadref>incmp_mnf) then maxfadref := incmp_mnf;

else

if (incmp_mnf $>1.01 *$ maxfadref) then maxfatigue $<=$ '1';

end if

end if;

end if;

end process maxfadiga;

end behavior;

.. Analise baseado no MNF .-

if (incmp_mnfevent) then

if (cmpref_mnf $<$ incmp_mnf) then

cmpref_mnf:=incmp_mnf;

else

comp_mnf:=cmpref_mnf*step_mnf;

.- verificando por incmp_mnf vezes $0.1,0.2,0.3 \ldots$

if (incmp_mnf $<=$ comp_mnf) then

step_mnf :=step_mnf -0.01

fatigue $<=$ ' 1 ';

fatigue $<=$ transport $0^{\prime}$ after $10^{*}$ clkper;

end if;

end if;

end if;

. Analise baseado no ARV ..

if (incmp_arv'event) then

if (cmpref_arv<incmp_arv) then

cmpref_arv := incmp_arv;

else

comp_arv := cmpref_arv*step_arv;

.- verificando por incmp arv vezes $0.1,0.2,0.3$.

if (incmp_arv $<=$ comp_arv) then

step_ary :=step_arv -0.01 ;

fatigue $<=$ '1';

fatigue $<=$ transport $0^{\prime}$ after $10^{*}$ clkper;

end if;

end if;

end if;

end process fadiga;

\section{B.13. VHDL: writefile.vhd}

use std textio all

use work.intpack.all;

entity writefile is

port (inwriteV: in real_vector $(0$ to (len/2-1)));

end writefile;

architecture bchav of writefile is

file outfileV: text is out "../signal/vhdlV_out.dat";

procedure writes (variable vetY: in real_vector $(0$ to (len/2-

1))) is

variable auxV: line;

begin

for $\mathrm{i}$ in vetY'range loop

write(auxV,vetY(i)):

writeline(outfileV,auxV);

end loop;

end writes;

begin

process(inwriteV)

variable writeV: real_vector(inwriteV'range) $:=$ (others $\Rightarrow$ $0.0)$;

begin

if (inwriteV'event) then

writeV:= inwriteV;

writes(writeV);

end if;

end process;

end behav; 


\section{ANEXO C: SIGLAS E SÍMBOLOS}

\section{Símbolos:}

$<$ texto $>$ : texto obrigatório

[texto]: texto opcional

$\%$ : Unix prompt

[Matlab]\% : prompt do Matlab

[ModelSim]\% : prompt do simulador digital Mentor Graphics ModelSim

[ModelSim SE/EE]: menus da janela "SE/EE" do simulador digital Mentor Graphics ModelSim

[MóodelSim Signals]: menus da janela "Signals"do simulador digital Mentor Graphics ModelSim.

\section{Siglas:}

ASIC: Application Specific Integrated Circuit

BPD: Bloco de Processamento Digital

CAD: Computer-Aided Design

CPLD: Complex PLD

EDA: Electronic Design Automation

EDIF: Electronic Design Interchange Format

EENM: Estimulação Elétrica Neuromuscular (Estímulo Elétrico Neuromuscular)

EMG: Eletromiograma (Eletromiografia) de Superfície

FFT: Fast Fourier Transform

FIR: Finite Impulse Response

FPGA: Field Programmable Gate Array

HC: Hospital das Clínicas

ICM: Índice de Contração Muscular

IEEE: Institute of Electrical and Electronic Engineers

IF: Índice de Contração Muscular

IIR: Infinite Impulse Response

PLD: Programmable Logic Device

$\mathrm{SB} \mu$ : Sociedade Brasileira de Microeletrônica

VHDL: VHSIC Hardware Description Language

VHSIC: Very High Speed Integrated Circuit 